Ann. Abeille, I961, 4 (3), I65-270.

\title{
LE COMPORTEMENT AGRESSIF DES OUVRIÈRES D'APIS MELLIFICA L.
}

J. LECOMTE

Station de Recherches sur l'Abeille et les Insectes sociaux. Bures sur Yvette (Seine et Oise).

\section{PLAN DU MÉMOIRE}

INTRODUCTION.

I. - COMPORTEMENT VIS-A-VIS DES LEURRES.

II. - LE ROLE DES FACTEURS EXTERNES.

III. -- LE ROLE DES FACTEUURS INTERNES.

IV. - ANALYSE DES GRANDES CARACTÉRISTIQUES DU COMPORTEMENT AGRESSIF.

V. - LA RECONNAISSANCE DU PARTENAIRE SOCIAL, ET LE ROLE DE L'ABEILIE GARDIENNE.

CONCluUions GÉNÉRALES.

\section{INTRODUCTION}

Les manifestations agressives des ouvrières d'Apis mellifica vis-à-vis des " ennemis de la ruche " sont connues depuis les commencements de l'apiculture.

Cependant, si l'on peut trouver de nombreuses observations, dans les écrits des praticiens et si la manipulation des abeilles est en fait fondée en partie sur une connaissance implicite des comportements agressifs, il faut remarquer que les travaux expérimentaux en ce domaine sont très rares. Aucun travail portant sur l'agressivité des abeilles n'avait été publié avant I95I, date de parution de ma première note sur cette question. Pour cette raisotı, il m'a paru particulièrement intéressant de tenter une analyse causale de ce comportement. Une première remarque s'impose ; on ne peut assimiler l'agressivité aux grandes pulsions qui forment la charpente du psychisme animal, par exemple la faim, la soif, la pulsion sexuelle ou le sommeil.

En effet, un animal peut présenter un comportement agressif, aussi bien pour acquérir de la nourriture que pour défendre ses petits ou chasser un rival sexuel. 
Dans le cas de l'abeille ouvrière, il s'agit de la défense contre un certain nombre d'ennemis. Dans la nature, ceux-ci sont très nombreux, soit qu'il s'agisse de concurrents de la même espèce, c'est-à-dire d'abeilles pillardes appartenant à une autre ruche, soit qu'il s'agisse de prédateurs appartenant à d'autres espèces. J'ai donc voulu rechercher, en premier lieu, quels sont les facteurs qui donnent à un objet ce caractère d'ennemi. Ensuite, j'ai essayé de mettre en évidence la nature de ce que défend l'abeille. Il était évidemment intéressant de voir si les stimuli significatifs étaient les mêmes à l'intérieur et en dehors de la ruche et si une distinction pouvait être faite entre différents comportements agressifs en fonction du lieû où ils apparaissent.

Ėnfin, j'ai cherché à savoir quels sont les facteurs indépendants de l'objet de l'attaque, susceptibles d'avoir une influence sur ces comportements.

Postérieurement à I95I, un certain nombre d'auteurs ont publié d'intéressants travaux se rapportant à l'agressivité et je me propose de les discuter. Ainsi Bu'rleir et Freie (I952), Free (I954) et RibBands (I954), ont particulièrement étudié le comportement des ouvrières à l'entrée de la ruche. L'on peut rencontrer quatre catégories d'abeilles sur la "planche de vol " située devant l'entrée d'une ruche. Ce sont des gardiennes, des butineuses sur le point de s'envoler ou venant d'atterrir, des butineuses en provenance d'une autre colonie et égarées, enfin des abeilles pillardes cherchant à s'emparer du nectar ou du miel contenu dans les rayons. C'est en fait le processus de reconnaissance des pillardes par les gardiennes qui est l'objet des études des auteurs cités. Étant donné l'ampleur de la controverse entre ces auteurs et étant donné que mes premières publications sont antérieures aux leurs, il m'a paru plus intéressant d'exposer d'abord mes propres travaux et de donner une analyse détaillée de ces publications quand j'aurais à évoquer les problèmes qu'elles traitent.

Ceci ne constitue d'ailleurs qu'un cas particulier de la question de l'agressivité que nous cherchons à étudier dans son ensemble.

\section{MATÉRIEL ET MÉTHODES GÉNÉRALES. PREMIERES OBSERVATIONS}

J'ai expérimenté dans un grand nombre de cas avec des petites populations d'abeilles ouvrières : 20 à 30 . Ces ouvrières étaient maintenues dans des cagettes de bois de $25 \times \mathrm{I} 2 \times 3$ centimètres. Ces cagettes, vitrées sur les deux faces, ne contiennent pas de cires dans le but de faciliter l'observation des abeilles. Elles renferment un nourrisseur garni d'un mélange de miel et de sucre glace, connu sous le nom de "candi à reine ") et aussi un abreuvoir d'eau pure (fig. I-2). Ces cagettes sont placées 
dans une étuve obscure à une température variant entre 25 et $30^{\circ}$. Dans ces conditions, l'on ne constate aucune mortalité et aucune variation notable du comportement durant les sept premiers jours. D'autres observations ont été effectuées sur des Ruchettes de $42 \times 25 \times 3$ centimètres. Ces ruchettes contiennent un rayon de cire bâti par les abeilles sur une

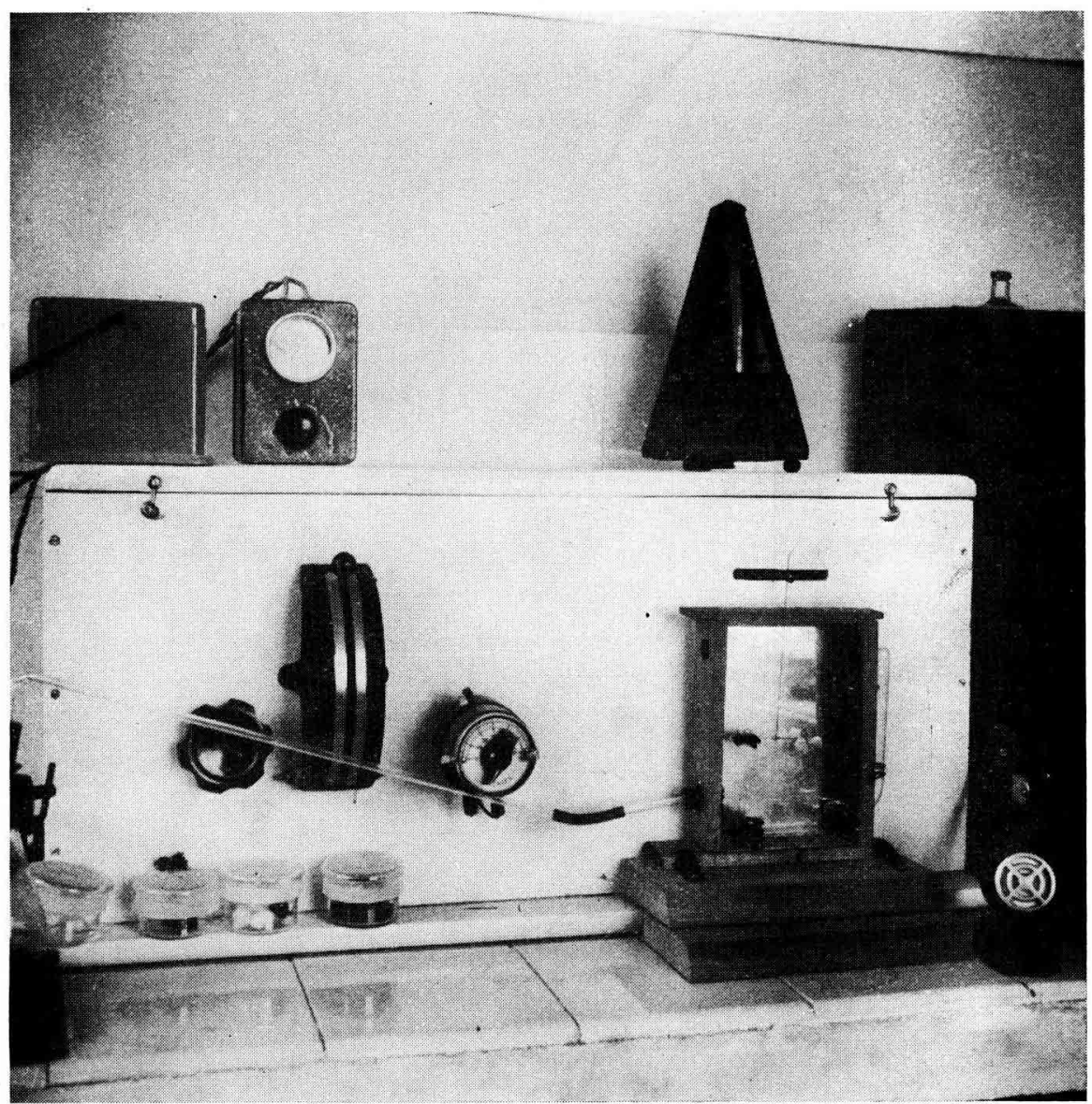

FIG. I. - Vue d'ensemble du dispositif expérimental.

De gauche à droite: Soufflerie permettant de modifier l'atmosphère de la cagette, les rhéostats permettant de faire varier la vitesse d'agitation du leurre, le chronorupteur, la cagette expérimentale, le microphone permettant la notation des résultats.

plaque de verre à partir d'une feuille de cire gaufrée sur une seule face et collée sur la plaque. Cette disposition permet de ne jamais perdre de vue une ouvrière marquée dont on veut suivre le comportement. Dans ces ruchettes, peuvent vivre I 000 à 2000 abeilles avec leur reine. Rappelons que la population d'une ruche moyenne se situe aux environs de 40000 individus. Les ouvrières de ces ruchettes peuvent sortir librement et rapportent des provisions, cependant un supplément important de nourri- 
ture doit leur être fourni. Les diverses observations effectuées à l'aide de cagettes ou de ruchettes ont de plus été répétées, dans tous les cas où la chose était possible, sur des ruches normales des types les plus fréquemment utilisés par les apiculteurs. Enfin dans tous les cas où le contraire ne sera pas précisé, le matériel utilisé est constitué par des ouvrières de la race noire commune.

Les abeilles sont généralement capturées par brossage des rayons ou en tapotant près de l'orifice du couvre-cadre situé sous le toit de la ruche. Ce dernier procédé provoque presque toujours une sortie en masse, il est particulièrement employé en hiver, car il évite l'ouverture, toujours nuisible de la ruche.

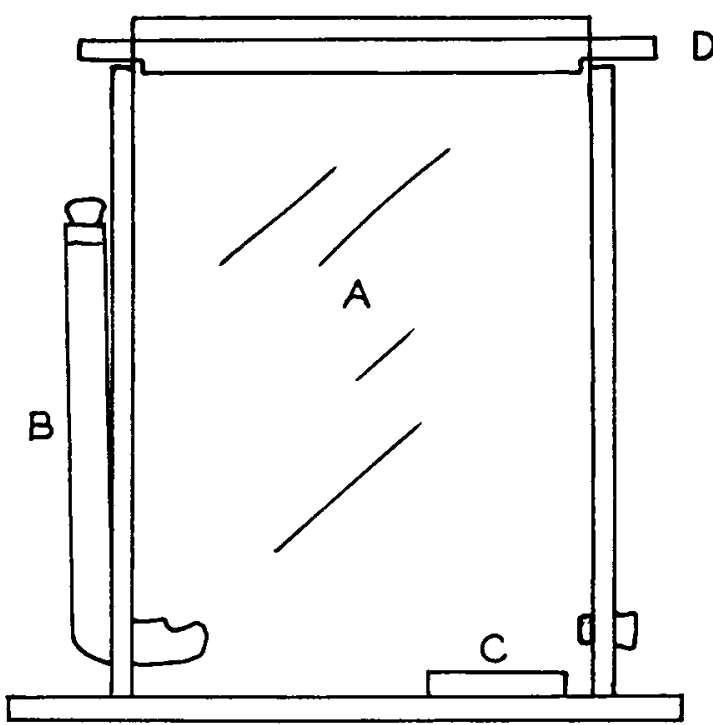

Fis. 2. - Cagette d'élevage : A, paroi transparente en plexiglas, I3 nourrisseur à eau, C nourrisseur is candi, D couvercle mobile.

Ces techniques fournissent évidemment des ouvrières d'âge inconnu. Pourtant, il est indispensable dans bien des cas de connaître l'âge des abeilles étudiées. Dans ce but, j'ai fait éclore des rayons de couvain operculé en les maintenant dans une étuve à $35^{\circ}$. Les ouvrières sont prélevées et marquées dès leur naissance et maintenues en cagettes dans les conditions précitées, ou confiées à une ruchette contenant déjà une population importante.

Les différents marquages nécessités par mes recherches ont été effectués, soit au moyen de petits disques de papier coloré fixés sur le thorax au moyen de colle cellulosique, soit au moyen de points de peinture cellulosique disposés sur le thorax èt l'abdomen, selon un code très simple. De tels marquages permettent de reconnaître rapidement et sûrement 
l'ouvrière, même quand elle est en mouvement rapide. Les abeilles capturées dans les ruches furent le plus souvent endormies à l'anhydride carbonique avant d'être comptées et distribuées dans les cagettes. Mais étant donné l'effet connu de ce gaz sur certains comportements de l'abeille, (RibBands, I950), j'ai effectué de nombreuses expériences de contrôle sans narcose préalable. De toute manière, je laisse toujours s'écouler vingt quatre heures entre la récolte des abeilles et les premiers essais. Les autres détails techniques seront donnés au fur et à mesure qu'ils se présenteront.

\section{AGRESSIVITÉ A L'ÉGARD D'OUVRIERES ÉTRANGËES}

Dans une première série d'expériences, $j$ 'ai observé les résultats de l'introduction dans une cagette de cinq ouvrières en provenance d'une autre ruche. Le premier phénomène observable est 1'Agitation des abeilles habitantes. Cette agitation, qui est la règle générale, est suivie selon les cas par différents comportements. L'on observe, en fait, très rarement l'indifférence absolue vis-à-vis des étrangères, parfois cependant l'agitation cesse rapidement et un retour au calme antérieur est alors observable. Plus souvent (le pourcentage varie en fonction de nombreux facteurs, mais est toujours supérieur à $90 \mathrm{p}$. IOO), l'on voit apparaitre un véritable comportement agressif. Tout d'abord, une ou plusieurs habitantes se dirigent vers l'étrangère, cette Approche peut être très courte ou devenir une véritable poursuite. Puis l'on assiste à ce que j'ai appelé le Houspillage. Ce comportement consiste en une bousculade de l'étrangère par les habitantes. Ces dernières ne cessent de promener leurs antennes sur le corps des intruses. Elles tournent autour, sans jamais cesser de leur faire face. L'on peut remarquer que la région postérieure de l'abdomen et la tête sont toujours l'objet des palpations antennaires les plus prolongées. Souvent, ce houspillage est particulièrement violent, l'habitante harcelle 1'étrangère et cherche à la mordre. Elle réussit dans un grand nombre de cas à saisir ainsi l'aile de son adversaire, et la tord plusieurs fois sur elle-même. Il n'est pas rare de voir ainsi une étrangère trainée dans toute la cagette, l'aile étant solidement tenue par les pièces buccales d'une habitante. Si l'ouvrière étrangère reste parfaitement calme et passive, les choses ne vont généralement pas plus loin. Au bout de peu de temps, l'agitation elle-même cesse et la population contenue dans la cagette revient à 1'état antérieur à l'introduction. Il est d'ailleurs remarquable de constater que ce retour au calme constitue un phénomène à peu près irréversible. Après ce que 1'on peut considérer comme l'acceptation d'une ouvrière, il n'y a jamais retour en arrière et celle-ci n'est jamais plus l'objet de comportements agressifs sérieux. Des examens à l'aide des antennes, des débuts de houspillage, peuvent être observés après l'intro- 
duction (7I heures est le maximum observé) mais jamais de graves houspillages. Notons que chez un Apide relativement voisin : Meliponula bocande $\ddot{i} \mathrm{Cock}$ dont j'ai pu comparer le comportement sur certains points, il en est tout autrement. Une ouvrière qui apparemment n'avait déclenché aucune réaction spéciale au moment de son introduction fut cependant mise à mort dans les heures suivantes. Cette observation a d'ailleurs pu être répétée plusieurs fois. Cependant, les abeilles étrangères ont souvent un comportement actif, le comportement passif étant assez rare dans les conditions de ces expériences. Elles essaient alors de se dégager ou de se défendre. L'inspection ou le houspillage se transforme très vite en un véritable combat. Les deux adversaires luttent corps à corps en cherchant à se piquer mutuellement.

Les combats, en apparence les plus achainés, ne comportent qu'assez rarement une issue fatale. Les deux adversaires placés abdomen contre abdomen, tournent sur eux-mêmes, et dans cette position, il semble que 1'approche de 1'aiguillon fasse reculer l'abeille qui va être piquée. Les coups mortels sont donnés surtout dans d'autres positions de combat. Enfin, il faut noter que si les habitantes sont particulièrement agressives ou les étrangères particulièrement agitées et à fortiori quand ces deux conditions sont remplies, la mise à mort a lieu sans aucun préambule.

Je donne ci-dessous les fréquences d'apparition des différents comportements. Les observations ont porté sur 35 cagettes en provenance de 7 ruches différentes. Les chiffres se réfèrent au comportement maximum observé lors de l'introduction de 5 ouvrières étrangères dans une cagette. J'ai ainsi observé 7 fois l'agitation suivie d'un retour au calme, I6 fois 1'approche et le houspillage avec 6 cas de morsure de l'aile, et enfin I 2 combats dont ro eurent des suites mortelles.

Si l'on prend soin de marquer les abeilles ou d'employer deux races différentes facilement reconnaissables par leurs différences de coloration, l'on s'aperçoit que les victimes de ces combats sont presque toujours les étrangères. Lors d'un essai portant sur 4 cagettes il y eut 60 morts qui tous appartenaient aux abeilles étrangères. L'on peut noter aussi que les ouvrières qui ont été endormies au $\mathrm{CO}_{2}$ sont en état d'infériorité pendant plusieurs heures, par rapport à celles qui ne l'ont pas été.

A la suite de ces observations, nous distinguerons donc dans le comportement agressif vis-à-vis d'une ouvrière étrangère introduite dans une cagette, quatre séquences.

Ces séquences sont :

1'agitation

l'approche

le houspillage

le combat. 
CHAPITRE PREMIER

\section{COMPORTEMENT VIS-A-VIS DES LEURRES}

Les variations du comportement des étrangères, influençant celui des habitantes, j'ai mis au point une technique basée sur l'emploi de leurres plus facilement contrôlables.

\section{Nature des leurres, leur présentation.}

I,es leurres sont des volumes ou des silhouettes de différentes substances, dont la taille est, sauf mention du contraire, sensiblement comparable à celle d'une ouvrière. Dans tous les cas, où il n'est pas mentionné une forme particulière, le leurre ressemble grossièrement à une abeille privée de ses membres. Les couleurs indiquées le sont par comparaison avec le code universel des couleurs de SEGUY (I936). Le numéro indiqué entre parenthèses après chaque nom de couleur se rapporte à ce code. Les essais sont effectués à la lumière du jour. Le leurre est suspendu à un fil d'acier de 5/Io mm et introduit dans une cagette d'élevage du type précédemment décrit. Un dispositif mécanique permet de l'animer d'un mouvement de va et vient selon un plan horizontal pendant un temps donné et à une vitesse donnée. Ce dispositif mécanique est constitué par un moteur électrique dont on fait varier la vitesse au moyen d'un rhéostat. Le mouvement de rotation de ce moteur est transformé en mouvement de va et vient par un excentrique. La cagette et le dispositif mécanique sont suffisamment isolés l'un de l'autre pour que les vibrations produites par le moteur ne soient pas transmises (fig. I).

\section{Notation des résultats.}

Le leurre étant mis en mouvement, je note le nombre de secondes pendant lesquelles une ou plusieurs abeilles se posent sur le leurre et cherchent à le mordre ou à le piquer, au cours d'une présentation d'une durée totale de soixante secondes. Cette technique de notation des résultats sera désignée par la suite sous le nom de "Technique A ".

Une autre technique, assez différente, a été aussi utilisée : au lieu de noter le nombre de secondes d'attaques, je note à chaque top d'un métronome battant la seconde, le nombre d'ouvrières en train d'attaquer 
le leurre. Je continue cette notation pendant une minute ; cette technique sera désignée sous le nom de "Technique $B$ ".

Enfin, il est possible de noter le nombre de secondes écoulées entre la présentation du leurre et la première attaque, ce sera la "Technique $\mathrm{C}$ ".

Ces trois techniques présentent des avantages et des inconvénients : la « $B$ » ne peut pratiquement être utilisée qu'à l'aide d'un appareil enregistreur magnétique, la " $\mathrm{C}$ " est la plus facile à utiliser dans les tests sur le terrain ou quand il s'agit d'une ruchette où le nombre élevé des ouvrières rend l'observation malaisée.

\section{Comportement des ouvrières.}

Les ouvrières ont à peu près la même gamme de réactions vis-à-vis des leurres et vis-à-vis des ouvrières étrangères avec cependant quelques légères différences que nous allons passer en revue.

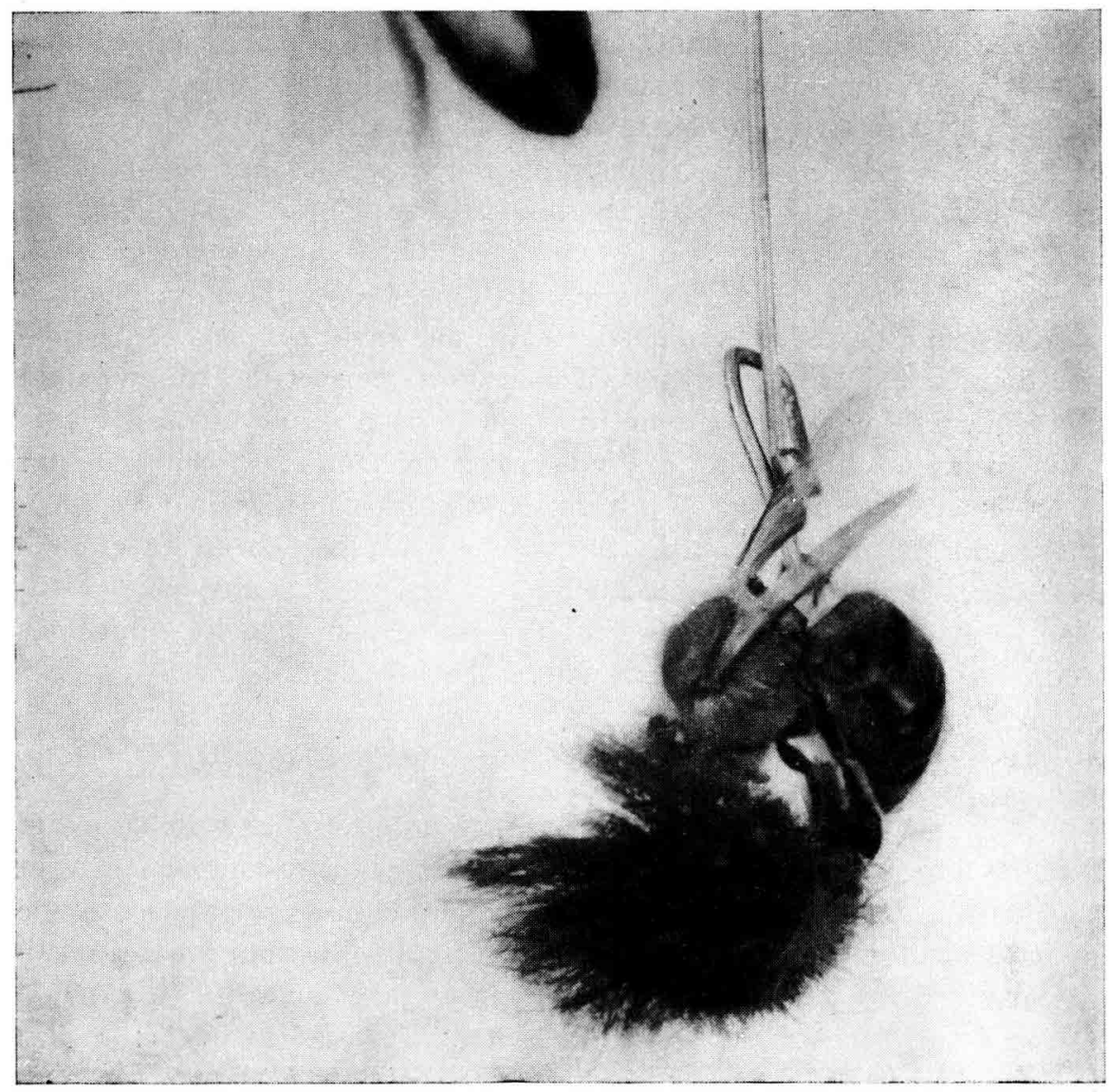

FIG. 3. - Attaque du leurre par une ouvrière. 
L'A gitation, cette phase est très comparable dans l'une ou l'autre situation.

L'Approche, étant donné le comportement particulier du leurre qui se déplace sans arrêt, à la hauteur du premier tiers inférieur de la cagette; le comportement d'approche est assez différent de celui que l'on peut observer dans le cas de l'introduction d'une abeille étrangère.

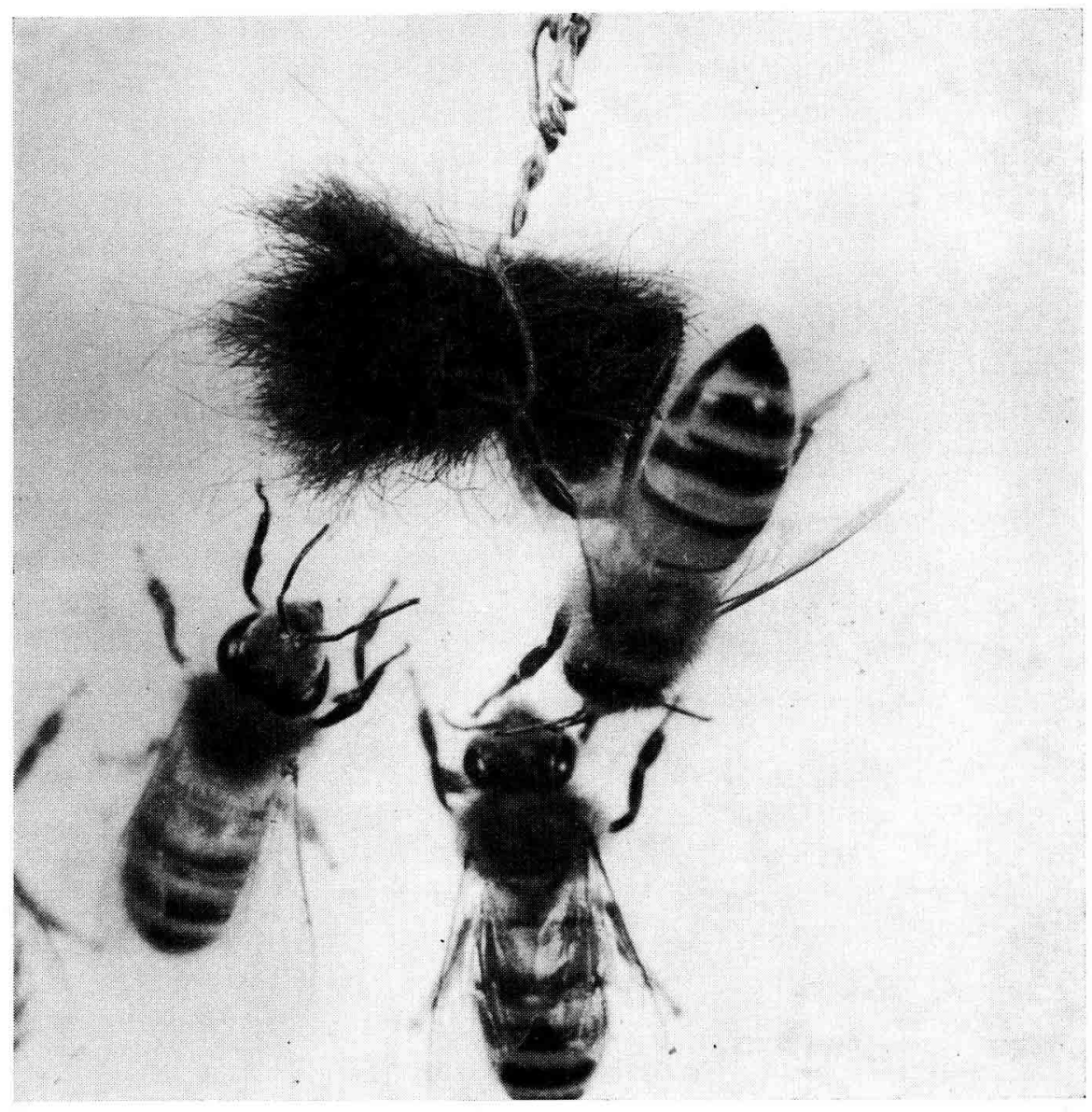

FIG. 4. - Une ouvrière cesse son attaque, une autre la commence. Les positions prises par les antennes sont très différentes.

Cette dernière est, en effet, le plus souvent peu mobile et se déplace le long des parois en marchant. Dans le cas d'un leurre, il est très souvent possible d'observer une montée vers celui-ci et une position bien particulière de l'abeille. Agrippée par les pattes à la paroi de la cagette, elle suit des yeux le leurre en effectuant un mouvement pendulaire synchronisé avec les déplacements de ce dernier. Elle se dresse sur ses deux paires de pattes postérieures, tend les antennes dans la direction du leurre et 
finalement saute dans sa direction. Dans d'autres cas, le mouvement pendulaire est absent et l'abeille saute directement sur le leurre, ou bien s'en approche rapidement et rompt le contact aussitôt.

Le Houspillage est une phase très réduite dans les manifestations d'agressivité vis-à-vis des leurres. I1 y a attaque réelle ou abandon mais l'examen est toujours bref. Les échanges de titillations antennaires ne sont évidemment pas possibles et des essais effectués avec des leurres munis d'appendices de diamètre et d'aspect voisins des antennes d'ouvrières n'ont donné aucun résultat. Les abeilles mortes présentées comme des leurres, ne sont pas non plus l'objet d'un houspillage prononcé. Le rôle du mouvement est sans doute, dans ce cas, déterminant.

L'attaque proprement dite, correspondant au Combat entre deux ouvrières, est une phase particulièrement spectaculaire lorsqu'il s'agit de l'agressivité vis-à-vis d'un leurre. Les abeilles mordent et piquent, dans les cas oì l'objet présenté est significatif, avec une intensité au moins égale à celle observée dans les combats avec des congénères.

\section{Recherche des stimuli significatifs.}

Dans une première série d'expériences, j'ai cherché à caractériser les principaux facteurs susceptibles de déclencher l'agressivité des abeilles en faisant varier la nature du leurre. Le tableau ci-dessous donne les résultats d'une série d'expériences effectuées en cagette. Les chiffres correspondent à la moyenne de 25 essais, technique de notation A.

\section{TABLEAU I}

\begin{tabular}{|c|c|c|}
\hline Nature du leurre & Immobile & $\begin{array}{c}\text { Mobile } \\
\text { Nombre d'attaques }\end{array}$ \\
\hline Abeille morte fraîche ... & I & 25 \\
\hline Abeille morte desséchée .......... & o & I4 \\
\hline Pelote de laine marron (1 12$) \ldots \ldots$ & o & 23 \\
\hline Pelote de laine blanche $\ldots \ldots \ldots \ldots \ldots \ldots \ldots \ldots$ & o & I 2 \\
\hline Silhouette de carton marron (1 12$) \ldots \ldots \ldots \ldots \ldots$ & o & 16 \\
\hline Silhouette de carton blanc $\ldots \ldots \ldots \ldots \ldots \ldots \ldots$ & o & 0,4 \\
\hline
\end{tabular}

Dans les chapitres suivants, nous nous proposons de faire l'analyse de ce tableau et de répondre aux différentes questions que sa lecture permet de se poser.

\section{A. - LE RôLE, DU MOUVEMENT.}

Le rôle essentiel du mouvement ressort clairement du simple aspect des résultats exposés dans le tableau I. I1 est d'ailleurs confirmé par l'observation, relatée plus haut, des abeilles étrangères vivant impuné- 
ment, dans une cagette d'élevage, lorsqu'elles restent immobiles dans les premières minutes suivant leur introduction. La vitesse d'agitation du leurre a une grande importance, une augmentation de cette vitesse entraîne une augmentation du nombre et de la vivacité des attaques. Ainsi, quand le leurre effectue I34 allers et retours de $5 \mathrm{~cm}$, soit $6,70 \mathrm{~m}$ à la minute, le nombre d'attaques comptées selon la technique B est de 38,8 , moyenne de vingt essais. Quand ce leurre effectue 184 allers et retours de $6 \mathrm{~cm}(6 \mathrm{~cm}$ au lieu de 5 , par suite de l'élasticité de la tige métallique soutenant le leurre) soit II,04 $\mathrm{m}$ à la minute, le nombre moyen des attaques passe à 53. I1 faut temarquer que les vitesses calculées ne tiennent pas compte du très court temps mort qui existe à chaque extrémité du mouvement de va et vient.

La figure 6 donne un aperçu des variations de l'agressivité en fonction de l'augmentation de la vitesse d'agitation du leurre. Cette augmentation ne se montre d'ailleurs stimulante que dans une certaine limite. Au-dessus d'une vitesse située aux environs de 15 mètres à la minute, le leurre devient nettement répulsif, du moins dans les conditions de 'expérimentation en cagette. Les raisons de ce dernier phénomène sont sans doute purement mécaniques : choc violent lors de la rencontre du leurre, difficulté de la poursuite dans la cagette, etc.

Le rôle de la vitesse de déplacement du leurre est également très important en ce qui concerne la vivacité des attaques. Il apparait nettement, sans que des résultats numériques soient possibles à donner, que les abeilles en attaquant le leurre cherchent surtout à le mordre aux vitesses basses; des tentatives de piqûres ne se rencontrent qu'aux vitesses élevées. Une vitesse très basse, I $\mathrm{m}$ par minute, n'a pas été suffisante pour induire une seule attaque vraie, mais plusieurs approches et l'agitation correspondant aux premières séquences d'un comportement agressif furent cependant nettement observées.

La nature du mouvement demande aussi à être étudiée. Dans mes expériences, le type de mouvement (agitation dans tun plan horizontal) est sensiblement le même que celui exécuté par les abeilles pillardes volant devant l'entrée des ruches étrangères. BUTLER et FREE (I952) ont émis 1 'hypothèse que ce type de mouvement pourrait être le plus significatif et provoquer plus sûrement l'apparition des comportements agressifs qu'une agitation dans le plan vertical.

Un certain nombre d'essais de présentation du même leurre, soit devant une ruche, soit à l'intérieur d'une cagette, en l'animant des deux types de mouvement n'a pas révélé de différences appréciables. Il semble donc que le stimulus significatif soit le mouvement, la signification augmentant seulement avec la vitesse et non selon le type de mouvement. 


\section{B. - LA COULEUR E'T LA I,EUCIE.}

Un deuxième stimulus significatif serait la couleur du leurre. La différence entre le nombre moyen d'attaques du leurre de laine blanche et du leurre de laine marron (tableau I) est très significative, l'une étant double de 1'autre. Plus que la longueur d'onde, à laquelle est attachée la notion de couleur, il semble que ce soit la leucie qui soit ici l'élément important. En effet, à leucies égales, un leurre gris est attaqué aussi bien qu'un leurre marron. Rappelons que la LEUCIE est " la variable selon laquelle un objet semble réfléchir ou transmettre une partie plus ou moins grande de la lumière incidente. Elle peut s'exprimer par des réponses telles que : foncé, clair; pour les couleurs neutres : noir, gris foncé... blanc. Elle dépend essentiellement de la clarté de l'objet" (Durup, I95I).

J'ai réalisé une série de leurres de leucies croissantes au moyen de fragments d'éponges artificielles en polyuréthane, imbibés de solutions de plus en plus diluées d'encre de Chine. Les essais ont été, dans ce cas, conduits en lumière artificielle, de valeur constante. J'ai obtenu les résultats suivants :

TABIEAU II

\begin{tabular}{c|c}
\hline \hline $\begin{array}{c}\text { Valeur relative } \\
\text { de la leucie du leurre }\end{array}$ & $\begin{array}{c}\text { Nombre moyen d'attaques, } \\
\text { Notation B, } \\
\text { moyenne de vingt essais }\end{array}$ \\
\hline Noir & 44 \\
Gris foncé & 30 \\
Gris clair & I5 \\
Blanc & I0 \\
\hline \hline
\end{tabular}

Le rôle important de la leucie peut être également mis en évidence, non plus par des présentations successives mais par une présentation simultanée. Dans tous les cas, où j'ai présenté en même temps dans une cagette deux leurres de leucies très différentes, il m'a été possible d'observer que le plus foncé était aussi le plus attaqué. Il faut cependant faire remarquer que la perception visuelle du leurre n'est pas du tout indispensable pour qu'il y ait attaque. Les apiculteurs savent bien que les attaques de nuit sont très fréquentes, par exemple au cours des opérations de transports de ruches en vue de la transhumance.

J'ai effectué quelques essais en comparant le comportement des abeilles vis-à-vis d'un leurre en lumière blanche et en lumière rouge monochromatique très faible.

Les résultats suivants ont été obtenus :

L,umière blanche, moyennẹ de 20 essais, Notation A : 27

Lumière rouge 
Les essais effectués en lumière rouge, ont été conduits avec une intensité lumineuse aussi faible que possible mais permettant cependant à l'observateur d'effectuer les comptages.

L'on sait depuis longtemps (HERTZ, I938), que les abeilles sont aveugles aux radiations lumineuses de longueur d'onde supérieure à $650 \mu$ ce qui permet de considérer que les essais effectués en lumière rouge n'ont pas permis aux abeilles d'avoir une perception visuelle du leurre.

\section{C. - Strud'ture physigue. Forme eit tailite DU LEURRE.}

La consistance d'un leurre joue également un rôle très important, toutes choses étant égales, par ailleurs, il est constant qu'un leurre lisse soit moins attaqué qu'un leurre pileux. J'ai également observé que de nombreuses abeilles sont intéressées par le leurre composé d'une silhouette de carton marron (voir tableau I). Mais seules les premières séquences du comportement agressif prennent de l'importance et les ouvrières abandonnent tout de suite leurs attaques après un bref temps de contact. Dans le cas où le leurre est constitué par une silhouette de carton blanc, toutes les séquences semblent également réduites. Peu d'abeilles semblent intéressées par le leurre et celles qui le sont, abandonnent très rapidement leurs attaques. Enfin, le leurre de laine blanche se révèle peu efficace pour déclencher les premières séquences du comportement. Peu d'abeilles sont intéressées par ce type de leurre, mais celles qui le sont restent longtemps en contact avec lui. Il ne m'a pas paru qu'il s'agissait simplement du fait que la laine agrippe les pattes de l'abeille. Celle-ci tourne en effet sans difficulté autour du leurre sans le quitter cependant.

J'ai déjà signalé plus haut que dans le cas général, les leurres utilisés sont de taille et de force sensiblement égales à celles d'une abeille ouvrière : soit approximativement $\mathrm{I} 2 \times 5 \times 5 \mathrm{~mm}$.

Un certain nombre d'essais effectués avec des leurres de taille différente, dans les limites compatibles avec les dimensions de la cagette ont donné les résultats suivants :

TABLEAU III

\begin{tabular}{c|c}
\hline $\begin{array}{c}\text { Dimensions du leurre } \\
\text { en millimètres. } \\
\text { Leurre de drap Sépia-68r. }\end{array}$ & $\begin{array}{c}\text { Nombre moyen d'attaques. } \\
\text { Moyenne de 20 essais. } \\
\text { Notation A }\end{array}$ \\
\cline { 2 - 2 } & \\
5200 & $\mathbf{1 2 , 8}$ \\
$10 \times 12$ & 23,7 \\
$5 \times 12$ & 21,8 \\
$5 \times 6$ & 46,5 \\
\hline
\end{tabular}


Les abeilles ont d'autant plus tendanceà attaquer un leurreque celui-ci est plus petit. A la limite, il n'est pas rare d'observer plus d'attaques dirigées vers le fil d'acier de $5 /$ Io de millimètre de diamètre qui supporte le leurre que vers celui-ci.

La forme du leurre n'est pas non plus un facteur négligeable. Un certain nombre d'essais ont été effectués avec des silhouettes de carton noir. Les silhouettes utilisées s'inscrivent dans un cercle de $8 \mathrm{~mm}$; elles se montrent d'autant plus efficaces qu'elles sont plus découpées.

TABLEAU IV

\begin{tabular}{c|c|c}
\hline Leurre I & Nombre moyen d'attaques & $\begin{array}{c}\text { Moyenne de zo essais. } \\
\text { Notation A }\end{array}$ \\
\hline No I & I8 & \\
No 2 & I4 & \\
No 3 & 6 & \\
\hline
\end{tabular}

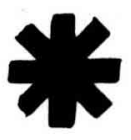

I

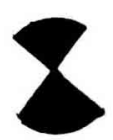

2

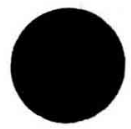

3

L'on retrouve ici, l'effet stimulant des formes découpées que ZERRHAN en I934 et HERTZ en I937 ont mis en évidence en étudiant des phénomènes très différents. En particulier ZERRHAN a montré que les butineuses étaient fortement attirées par des figures divisées et qu'un dressage prolongé ne pouvait leur faire surmonter cette préférence.

\section{D. - Composante olfactive.}

La différence constatée entre le pouvoir stimulant de l'abeille morte desséchée et celui de l'abeille morte fraîche (tableau I) a attiré mon attention sur l'existence d'une composante olfactive.

Il est bien connu des apiculteurs que nombre de substances provoquent chez l'abeille un comportement agressif. Parmi ces substances, se trouverait en particulier le venin des ouvrières elles-mêmes. Il est fréquent de constater qu'un apiculteur venant de recevoir une piqûre est victime d'autres attaques dues à d'autres abeilles, sur une région du corps très voisine. De même l'augmentation progressive de l'agressivité, souvent observée lors de la visite d'un rucher de la première à la dernière ruche a été très souvent attribuée à l'action de l'odeur du venin.

Voulant mettre en évidence la réalité de ce phénomène, j'ai testé différents leurres, les uns supposés avoir l'odeur du venin, les autres pas. 
Le tableau ci-dessous donne les résultats des principaux essais effectués avec des leurres contenant des glandes à venin très fraîches. Les leurres étaient constitués d'un sac, de la taille approximative d'une ouvrière, contenant les glandes et un peu de coton.

TABLEAUU V

\begin{tabular}{|c|c|}
\hline Nature du leurre & $\begin{array}{l}\text { Moyenne du nombre des attaques } \\
\text { Moyenne des Io essais-Notation B }\end{array}$ \\
\hline 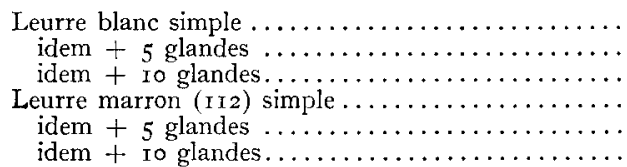 & $\begin{array}{l}1 \\
2,3 \\
12 \\
39 \\
70 \\
90\end{array}$ \\
\hline
\end{tabular}

Ce tableau montre très clairement l'augmentation sensible de l'agressivité en présence de leurres contenant des glandes à venin.

En outre, ces résultats ont l'intérêt de nous éclairer sur la manière dont des stimuli d'origine différente peuvent contribuer à déclencher une réaction. Ce phénomène a été décrit par GRASsÉ (I942) lors d'une étude du comportement d'essaimage des termites, sous le nom de règle de la pluralité des stimuli.

Il a été également mis en évidence chez certains poissons par SEITZ (I940) et cet auteur a créé le terme de Reizsummenregel. I1 semble bien que ce dernier terme, que l'on peut traduire par : loi de la sommation hétérogène est inadéquat. En effet, dans le cas qui nous intéresse, il s'agit non pas d'une sommation mais bien d'une multiplication. Dans l'exemple choisi le multiplicateur est voisin de 2 . Dans le tableau V, il est en effet visible que le fait d'ajouter au leurre blanc une odeur de venin fait passer l'indice d'agressivité de I à 2, 3. Dans les mêmes conditions en employant le leurre marron, l'on peut voir cet indice passer de 39 à 70 . Ce multiplicateur peut d'ailleurs être très variable, mais les différents stimuli semblent toujours multiplier leurs effets et non les ajouter. Ies résultats ne sont pas moins nets, si au lieu de glandes entières le leurre en contient un broyat frais ou s'il a reçu des piqûres.

\section{TABLEAU VI}

\begin{tabular}{|c|c|}
\hline Nature du leurre & $\begin{array}{c}\text { Nombre moyen d'attaques moyenne de } \\
\text { Io essais-Notation B }\end{array}$ \\
\hline 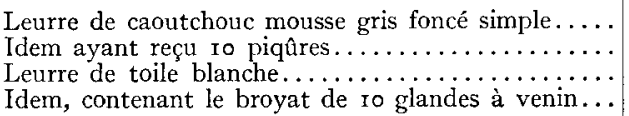 & $\begin{array}{l}9 \\
7 \mathrm{I} \\
2,5 \\
\mathrm{I} 2\end{array}$ \\
\hline
\end{tabular}

Cette action semble propre au set1l venin d'Apis mellifica. J'ai testé sans Iésultat le venin de Bombus terrestris, B. lapidarius et B. agrorum. 
La fraction efficace doit être très labile; des glandes déshydratées à $0^{\circ}$ puis réhydratées quarante-huit heures ensuite, dans le sérum physiologique ne sont plus efficaces.

\section{L'effet de l'odeur du venin.}

L'on peut se demander si l'effet de l'odeur du venin est comparable à celui des autres stimuli.

Si 1'on agite dans une cagette simultanément deux leurres, l'un marron, l'autre blanc, l'on retrouve, nous l'avons vu précédemment, les mêmes différences que celles mises en évidence lors d'expériences de présentations successives. Mais, si l'on présente deux leurres de même taille, de même couleur, à la même vitesse, 1'un contenant des glandes à venin, 1'autre n'en contenant pas, l'on constate que ces deux leurres sont également attaqués :

TABLEAU VII

\begin{tabular}{|c|c|}
\hline Nature du leurre & $\begin{array}{l}\text { Nombre moyen d'attaques - moyenne de io essais } \\
\quad \text { - présentation simultanée-Notation } B\end{array}$ \\
\hline $\begin{array}{l}\text { Leurre marron (I I } 2) \text { simple } \ldots \ldots \ldots \ldots \ldots \ldots \ldots \\
\text { idem }+5 \text { glandes } \ldots \ldots \ldots \ldots \ldots \ldots \ldots \ldots \ldots\end{array}$ & $\begin{array}{l}29 \\
34\end{array}$ \\
\hline
\end{tabular}

Il est possible de supposer que, du moins dans un espace restreint, l'odeur du venin a un effet global et élève l'agressivité de 1'ouvrière sans la diriger vers un point précis.

L'expérience suivante me semble concluante; je fais déboucher dans une cagette un léger courant d'air qui se charge d'odeur de venin en barbotant dans un sérum physiologique contenant dix glandes à venin fraîches. J'ai pu constater, lors de plusieurs essais que l'arrivée de ce courant d'air élevait considérablement le niveau d'agressivité des abeilles par rapport à un courant d'air témoin.

De plus, en l'absence de tout leurre, l'arrivée de ce courant d'air à odeur de venin augmente l'activité locomotrice des abeilles dans la cagette, de manière très sensible. Le venin semble donc abaisser le seuil de réponse aux divers stimuli qui induisent les différentes séquences de l'attaque et provoquer à lui seul un état d'alerte caractérisé par l'agitation des ouvrières. Les ouvrières, en état d'excitation, font ressortir leur aiguillon au bout duquel perle souvent une gouttelette de venin. Ce venin est littéralement vaporisé par les mouvements des ailes et répand une odeur très sensible pour l'homme en certaines circonstances.

Le fait que le venin joue par son odeur un rôle de mise en garde, permet sans doute de le rapprocher d'un groupe de substances dites " sub- 
stances terrifiantes" (Schreckstoffen). Ces substances ont en commun avec le venin la propriété de provenir du corps même de l'animal et de jouer un rôle protecteur vis-à-vis des congénères. Ce rôle protecteur est réalisé en provoquant la fuite dans le cas des substances effrayantes, en créant un état d'alerte dans le cas du venin. Cette notion a été introduite par vON FrISCH (I94I) qui découvrit qu'une substance répulsive était contenue dans la peau du Vairon Phoxinus loevis, A. G. Cette substance libérée par une blessure met en fuite les Vairons proches de l'animal blessé. Pareils phénomènes ont été signalés à plusieurs reprises, notamment par Eirb-Eibesfelitit (I949) et HRBACEK (I950) chez les têtards de divers batraciens, par KEMPENDORFT (I942) chez un mollusque Heliosoma nigricans et enfin par HEINTZ (I955) chez A pis mellifica et différents insectes. En ce qui concerne l'Abeille la substance active serait contenue dans les muscles et non dans les téguments.

\section{Odeurs diverses.}

En dehors du venin, un certain nombre d'odeurs ont la propriété d'abaisser le seuil des réactions agressives. De ces odeurs, le plus grand nombre n'a probablement aucune signification biologique, elles sont signalées dẻ temps à autre par des apiculteurs. En particulier, on a souvent pensé que les prédateurs naturels des ruches étaient reconnus comme tels par l'abeille grâce à leur odeur. Je n'ai rien trouvé de tel en étudiant l'effet d'un cadavre frais d'Acherontia atropos. On peut cependant signaler l'observation de WEGNER (I949) qui a constaté une forte agressivité des ouvrières d'Apis indica en dehors de la ruche vis-à-vis de la dépouille d'un Mustelidé de Java connu comme un destructeur actif des colonies.

Plus intéressant est le cas des sueurs. Il est bien connu qu'un homme ou un mammifère en état de transpiration déclenche plus facilement des réactions agressives. En cagette. l'on peut constater qu'un leurre imprégné de sueur est toujours plus attaqué que le même leurre n'ayant pas subi d'imprégnation. Néanmoins, cette augmentation du niveau d'agressivité est très faible par rapport avec celle obtenue par l'odeur du venin et en particulier l'odeur seule ne semble pas jouer un rôle marquant.

Un courant d'air chargé d'odeur de sueur humaine ne provoque absolumeut pas un état d'alerte parmi les habitantes d'une cagette.

Il semble qu'il en soit différemment avec certaines sueurs animales. En particulier les essais que j'ai effectués avec des leurres imprégnés de sueur de cheval ont donné des résultats assez comparables, en ce qui concerne le déclenchement des réactions agressives, avec ceux obtenus par des leurres contenant des glandes à venin.

Cependant dans le cas de l'odeur de sueur de cheval comme dans 
celui de l'odeur de sueur humaine, l'odeur seule n'a pas l'effet spectaculaire que provoque le venin.

Bien que je n'aie pas effectué une série suffisante d'essais systématiques, j'ai cependant pu constater l'existence de différences interindividuelles à cet égard, très importantes, aussi bien entre êtres humains qu'entre Chevaux.

\section{Comportement vis-à-vis des leurres à l'extérieur de la ruche.}

L'abeille peut présenter des comportements agressifs en dehors de la ruche. En particulier, elle attaque une certaine catégorie d'objets dans une zone d'étendue variable. Elle attaque également certains objets

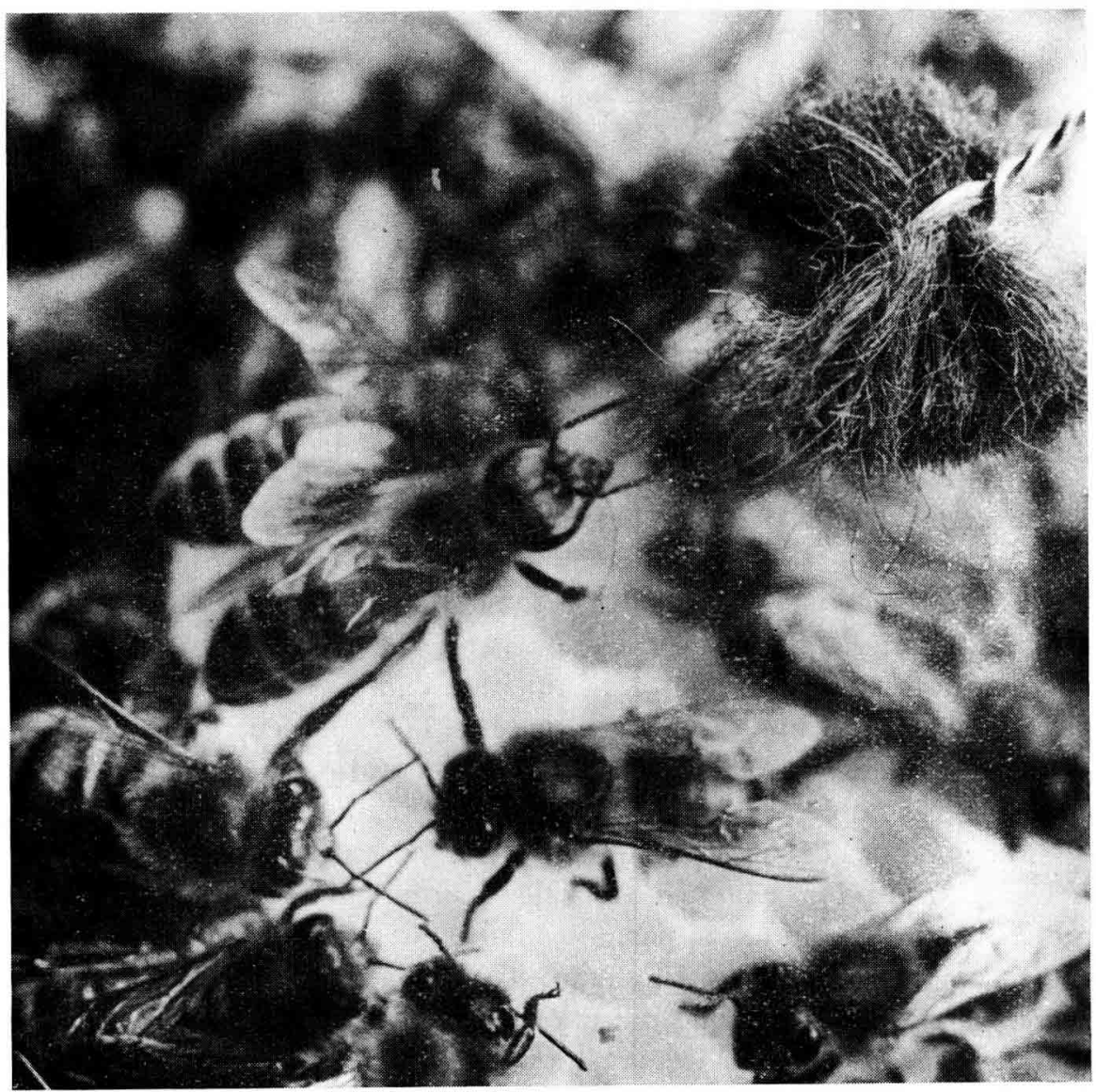

Fic. 5. -- Présentation d'un leurre revant un essaim arant constrnit à l'air libre. Not:" l'attiturle " Iressee "rle l'onvricere et la position des antemucs. 
le long des chemins qu'elle suit pour se rendre sur les lieux de récolte. C'est d'ailleurs par l'observation des phénomènes d'agressivité que j'ai pu mettre en évidence l'existence de ces chemins de butinage (LECOMTE I956). Avant d'étudier ce qui confère la qualité de "ruche "à un lieu pour l'abeille, et de voir comment sont répartis les zones et les chemins dont nous venons de parler, il peut être intéressant de se pencher sur le comportement des abeilles vis-à-vis de leurres situés à l'extérieur. L L mouvement, la leucie, la structure physique jouent exactement le même

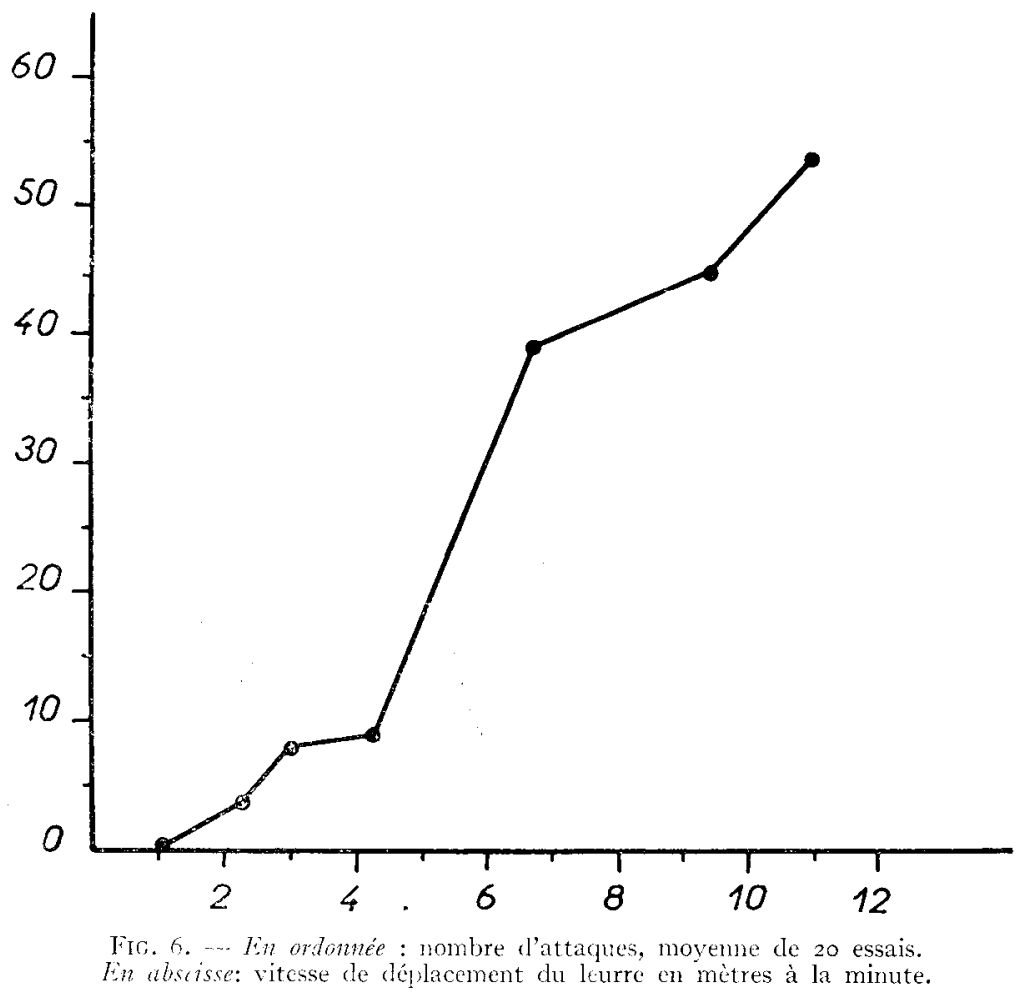

rôle à l'extérieur de la ruche qu'à l'intérieur. Toutes les expériences effectuées confirment que le leurre le plus efficace est un leurre mobile, foncé et pileux. En ce qui concerne la forme, l'on retrouve comme en cagette, tune plus forte efficacité des leurres de forme découpée.

De même, si dans une figure de grande taille, il existe un détail bien individualisé, le plus grand nombre des attaques sera dirigé vers ce détail. Si l'on agite devant l'entrée d'une ruche, un leurre formé d'un disque de ouate de cellulose gris clair de $5 \mathrm{~cm}$ de diamètre, portant en son centre un point noir de $2 \mathrm{~cm}$ de diamètre, la plupart des attaques et des piqûres seront dirigées vers ce dernier point. Ceci est sans doute l'explication d'un fait, bien souvent remarqué lors des travaux apicoles : les abeilles 
attaquent très fréquemment les environs immédiats du bracelet-montre qui forme un anneau sombre sur le poignet.

Le rôle de l'odeur du venin semble également très important à l'extérieur de la ruche, une simple expérience permet de s'en rendre compte. En agitant devant le trou de vol, un fragment d'étoffe de quelques centimètres carrés, il est possible de déclencher de vives réactions d'agressivité. Cependant, dans un rucher donné, il existe comme nous le verrons en détail par la suite, des différences considérables d'agressivité entre des colonies. Si, au lieu de présenter aux ruches qui se sont révélées non agressives de simples leurres, on leur présente des leurres ayant reçu des piqûres lors de présentation à d'autres colonies, l'on peut toujours observer une élévation très nette de l'agressivité. Il est très rare que les colonies ne réagissent pas à de tels leurres. Ici, encore, l'odeur du venin a joué un rôle important en abaissant le seuil de la réaction.

La présentation à l'extérieur de la ruche permettant d'employer des leurres de plus grande taille, j'ai pu explorer plus en détail qu'à l'aide des cagettes, cet aspect du problème. Nous nous trouvons ici en face d'une différence essentielle entre l'agressivité, telle qu'elle existe à l'intérieur de la ruche et celle observable à l'extérieur.

Dans le premier cas, $j$ 'ai mis en évidence (tableau III), que plus le leurre est petit, plus il déclenche des attaques vives et nombreuses. En dehors de la ruche, cette règle n'existe pas; bien au contraire, en dessous d'une certaine taille un objet ne peut être attaqué. Ainsi, la présentation de leurres constitués de fragments de draps sepia (68I) à l'entrée d'une ruche dont l'agressivité était particulièrement élevée a donné les résultats suivants.

\section{TABLEAU VIII}

\begin{tabular}{|c|c|c|}
\hline Taille du leurre & Indice d'agressivité & Moyenne de ro essais \\
\hline $\begin{array}{r}200 \times 25 \mathrm{~mm} \ldots \ldots \ldots \ldots \ldots \ldots \ldots \ldots \\
30 \times 25 \mathrm{~mm} \ldots \ldots \ldots \ldots \ldots \ldots \ldots \ldots \\
25 \times 15 \mathrm{~mm} \ldots \ldots \ldots \ldots \ldots \ldots\end{array}$ & $\begin{array}{c}\text { Très nombreuses attaques } \\
\text { Une attaque } \\
\text { Aucune attaque }\end{array}$ & \\
\hline
\end{tabular}

Les leurres étaient présentés successivement à environ $20 \mathrm{~cm}$ du trou de vol, suspendus à un fil d'acier de $5 /$ ro de $40 \mathrm{~cm}$ de longueur, au bout d'une perche de $3 \mathrm{~m}$ permettant un éloignement suffisant de l'observateur. Pour le plus grand nombre des leurres, il n'est pas possible de donner des résultats chiffrés, plusieurs dizaines d'abeilles l'ayant attaqué à la fois.

En présentation simultanée, l'on retrouve des résultats très comparables. 
COMPORTEMENT AGRESSIF DES OUVRIÈRES D'Apis mellifica L. $\quad$ I85

\section{TABLEAU IX}

\begin{tabular}{|c|c|c|}
\hline Taille du leurre Sépia 68I & Nombre d'attaques & Moyenne de ro essais \\
\hline $20 \times 10 \mathrm{~mm} \ldots \ldots \ldots \ldots \ldots \ldots$ & $\mathrm{I}$ & \\
\hline $\mathrm{t} 80 \times 25 \mathrm{~mm} \ldots \ldots \ldots \ldots \ldots$ & 30 & \\
\hline $25 \times 15 \mathrm{~mm} \ldots \ldots \ldots \ldots \ldots$ & O,I & \\
\hline $208 \times 35 \mathrm{~mm} \ldots \ldots \ldots \ldots \ldots \ldots$ & Très nombreuses attaques & \\
\hline
\end{tabular}

Diverses expériences effectuées avec des leurres de la taille d'une abeille montrent que ceux-ci ne sont jamais attaqués en dehors de la ruche, alors que, nous nous en souvenons, ils sont fortement attaqués à l'intérieur. Il est d'ailleurs intéressant de remarquer qu'à cet égard, les habitantes de cagettes peuplées de 25 ouvrières, de ruchettes peuplées de I 000 à $\mathrm{I} 500$ et de ruches pouvant en contenir 40000 se comportent de la même manière vis-à-vis des leurres. 


\section{CHAPITRE II}

\section{LES FACTEURS EXTERNES}

\section{La nature du gîte.}

$\mathrm{I}_{\text {L }}$ différence entre agressivité d'intérieur et d'extérieur m'a amené à me demander sur quoi reposait la notion de "gîte " pour l'abeille. J'emploie le terme de " gîte " car, comme nous le verrons par la suite, la ruche peut difficilement être assimilée au territoire tel qu'il a été défini chez les vertébrés. Une première observation m'a montré que l'agressivité était très faible dans des cagettes neuves, cagettes n'ayant jamais contenu d'abeilles ou lavées à l'alcool. Des cagettes neuves doivent avoir été habitées durant au moins deux jours par des abeilles pour permettre à l'agressivité de se manifester normalement.

Je dois signaler que je n'ai jamais obtenu de résultats positifs en badigeonnant des cagettes neuves avec de l'alcool ou de l'éther ayant servi à laver une cagette habitée. Mais ces solvants entraînent divers corps en provenance $\mathrm{du}$ bois de chêne dont sont faites mes cagettes, en particulier des tannins, et il n'est donc pas possible de tirer une conclusion de ces résultats négatifs.

Si je laisse séjourner dans une ruche, des cagettes neuves et vides pendant au minimum trois jours et que je les peuple ensuite, les abeilles se comportent d'emblée comme si elles se trouvaient dans une cagette habitée depuis longtemps. Ceci est vrai dans le cas où les ouvrières sont originaires de la ruche qui abritait les cagettes et aussi dans le cas contraire. Il ne s'agit donc pas d'une substance à effet limité à la colonie mais d'une substance de familiarisation générale.

Acceptant cette hypothèse d'une substance de familiarisation, j'ai essayé de tapisser des cagettes neuves avec du papier filtre ayant séjourné dans une ruche; je me suis heurté alors à la difficulté suivante : les abeilles ne tolèrent pas la présence de papier filtre à l'intérieur de la ruche. Elles le découpent très rapidement en petits fragments qu'elles expulsent ensuite. Il ne m'est arrivé qu'une fois de recueillir suffisamment de papier filtre intact et ceci dans une ruche relativement peu peuplée. D'autre part, du papier filtre maintenu dans la ruche mais séparé des 
ouvrières par un grillage s'est révélé inactif malgré un séjour assez long, ce qui me permet d'affirmer que le contact est indispensable.

\section{TABLEAU $\mathrm{X}$}

Nombre moyen d'attaques sur un leurre de laine marron i I2.

Moyenne de 20 essais effectués sur 5 cagettes de chaque catégorie. Notation A.

\begin{tabular}{|c|c|}
\hline Cagette ayant séjourné 8 jours dans une ruche $\ldots \ldots$. & Io attaques \\
\hline 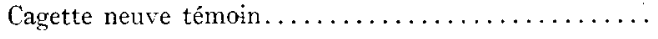 & 3 attaques \\
\hline $\begin{array}{l}\text { Cagette tapissée de papier filtre ayant séjourné } 5 \text { jours } \\
\text { dans une ruche (avec contact) } \ldots \ldots \ldots \ldots \ldots \ldots \ldots \ldots\end{array}$ & 5 attaques \\
\hline Cagette neuve témoin $\ldots \ldots \ldots \ldots \ldots \ldots \ldots \ldots$ & I attaque \\
\hline $\begin{array}{l}\text { Cagette tapissée de papier filtre ayant séjourné } 5 \text { jours } \\
\text { dans une ruche (sans contact) } \ldots \ldots \ldots \ldots \ldots \ldots \ldots\end{array}$ & I6 attaques \\
\hline Cagette ayant été habitée...$\ldots \ldots \ldots \ldots \ldots \ldots$ & 60 attaques \\
\hline Cagette neuve témoin $\ldots \ldots \ldots \ldots \ldots \ldots \ldots \ldots$ & I5 attaques \\
\hline $\begin{array}{l}\text { Cagette tapissée de papier filtre ayant séjourné } 8 \text { jours } \\
\text { dans une ruche (sans contact) } \ldots \ldots \ldots \ldots \ldots \ldots \ldots\end{array}$ & 2 attaques \\
\hline Cagette neuve témoin $\ldots \ldots \ldots \ldots \ldots \ldots \ldots \ldots$ & 4 attaques \\
\hline
\end{tabular}

Malgré le nombre insuffisant d'essais effectués avec du papier filtre maintenu en contact avec les abeilles, il ressort nettement de ce tableau qu'il doit exister une substance de familiarisation nécessaire pour le plein développement de l'agressivité. Je rappellerai à ce sujet que toute la vie de la ruche est soumise, semble-t-il, à des substances récemment découvertes ou supposées.

C'est ainsi que Vuillaume (I957) en étudiant l'élevage des reines par les ouvrières à partir de jeunes larves présentées dans les cupules de cire a montré qu'il existait des variations importantes des pourcentages de réussite.

L'acceptation ou le refus de ces cupules royales artificielles tiendraient à un équilibre entre deux substances incluses dans la cire, l'une inhibitrice de l'acceptation, l'autre facilitatrice. Il est impossible de résumer les importants travaux relatifs à la substance sécrétée par la reine, Ectohormone de PAIN (I954-I959), "Queen substance " de BUTIER (I954). Signalons seulement que cette substance joue un rôle considérable dans la ruche en maintenant l'ensemble des ovaires des ouvrières en état d'atrophie. De son côté, DARCHÉn (I959) estime que le comportement de construction des rayons par les ouvrières semble bien être sous la dépendance d'une substance sécrétée par la reine et distribuée à toute la ruche.

Il faut aussi rappeler l'existence des substances qui jouent un rôle dans le comportement de Butinage (LECOMTE r957), substances sur lesquelles j'aurai à revenir.

La liste est loin d'être close et il est indéniable que la substance de familiarisation nécessaire pour le plein développement de l'agressivité 
s'inscrit dans un ensemble dont nous commençons à peine à percevoir la complexité.

En ce qui concerne l'origine de cette substance, il est très vraisemblable qu'elle se trouve, nous allons voir pourquoi, dans la Propolis ou résine recueillie sur les bourgeons des arbres par les abeilles.

En effet, des abeilles maintenues dans une cagette neuve contenant de la propolis ne présentent aucune différence significative avec des abeilles maintenues dans des cagettes ayant déjà été habitées, en ce qui concerne leur comportement agressif. Un fragment de rayon de cire remplit le même office, mais la cire de rayons contient toujours un peu de propolis. D'autre part, dans tous les cas, les cagettes contiennent de la nourriture à base de miel et possèdent fortement l'odeur de cette substance (qui serait par conséquent inefficace).

Par ailleurs, il est des cas où le gîte présente un caractère bien particulier. Il s'agit des essaims s'installant en plein air. Ces cas sont d'ailleurs bien moins rares qu'on ne le pense, surtout dans les années où les conditions météorologiques sont particulièrement favorables.

Ces essaims, s'ils sont installés depuis peu, sont généralement d'une grande douceur, il en est de même s'ils ont construit quelques rayons de cire vierge. Au contraire, s'ils pos sèdent du couvain âgé, leur agressivité est remarquable.

Je désire présenter ici une observation typique : le I $^{\text {er }}$ août 1954 , il m'a été donné de recueillir un essaim installé dans les branches d'un Ginkgo biloba à environ 4 mètres de hauteur. Cet essaim, installé depuis au moins un mois, avait construit de nombreux gâteaux de cire et possédait au moins la valeur de quatre cadres Dadant de couvain operculé. Son agressivité était extraordinaire. Les abeilles attaquant sans provocation à près de trois mètres. Durant l'opération de cueillette, des spectateurs furent attaqués à plus de soixante mètres. Ce premier jour, il ne me fut pas possible de retirer autre chose que la cire et le couvain et je dus laisser les abeilles qui s'étaient dispersées. Le lendemain, quand je revins, l'essaim était de nouveau groupé, mais son agressivité avait complètement disparu et il fut possible de le recueillir sans faire usage de l'enfumoir. Cet exemple n'est pas isolé et les apiculteurs qui réduisent une ruche à l'état d'essaim, pour lutter contre une maladie du couvain, par exemple, ont pu noter d'aussi spectaculaires changements de comportement.

Les causes de ces changements sont sans doute multiples, signalons comme probable la rupture de l'organisation sociale de la ruche, la perte du couvain et de la cire ancienne, donc contenant de la propolis. La présence de ces deux derniers facteurs donnant à l'installation en plein air, le caractère d'une ruche. 


\section{Organisation spatiale et agressivité.}

I1 devient maintenant opportun d'étudier en détail les variations du comportement agressif en fonction de 1'organisation spatiale de l'abeille. Peut-on parler de territoire défendu par l'abeille? Je pense que l'on peut répondre par l'affirmative. Mais, l'abeille butineuse rencontrée isolée, à distance de son lieu de travail, n'est jamais agressive. L'agressivité est limitée à la ruche et aux environs immédiats et aussi à quelques lieux que nous allons passer en revue.

Les caractères du gîte, considéré comme une ruche et défendu comme tel par l'abeille venant d'être étudiés, je chercherai à mettre en évidence les limites dans lesquelles il est possible d'observer un comportement agressif en dehors de la ruche.

\section{Le périmètre défensif et les chemins de butinage.}

Il est indiscutable qu'un certain périmètre défensif existe autour de la ruche. Ce périmètre est de dimensions variables, il peut être nul ou au contraire être éloigné d'une dizaine de mètres et plus, de la ruche. Ces

$$
\text { d }
$$
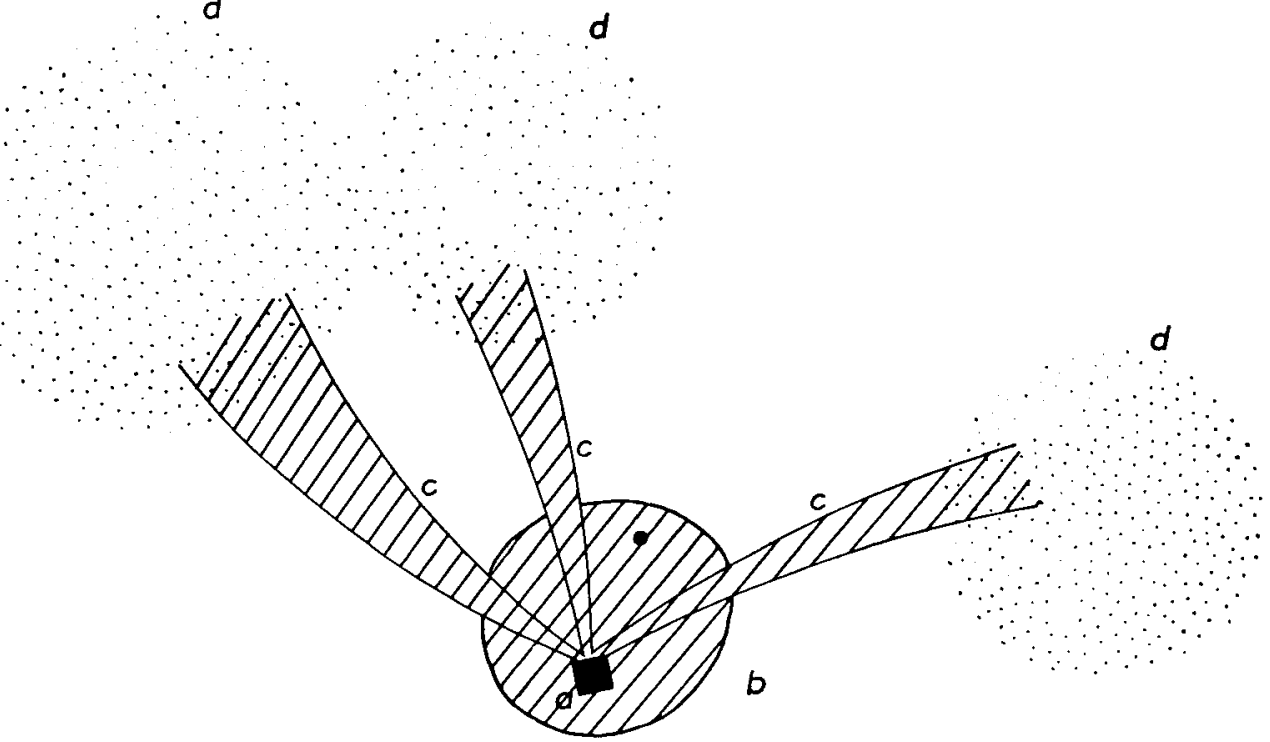

FIG. 7. - $a$ : Ruche. $-b$ : Périmetre défendu, le point symbolise les exemples de défense d'un nourrisseur. $-c:$ Chemins de butinage. - $-d:$ Aires de butinage.

variations sont dues à l'influence de facteurs externes et internes que j'étudierai par la suite. La figure géométrique délimitée par ce périmètre n'est pas un cercle ; elle se rapproche grossièrement d'un ove. L'extrémité 
la plus petite de cet ove est occupée par la colonie, le trou de vol étant tourné vers l'extrémité de plus grand rayon (fig. 7).

En dehors de la zone ainsi défendue, des phénomènes certainement apparentés à l'agressivité se rencontrent le long des chemins de butinage. J'ai déjà fait allusion à ces chemins, il semble bien qu'aux périodes de miellée, ils soient constants. Ils consistent en ligne de vol suivie par la majorité des butineuses et déterminés par trois facteurs :

ro Le relief environnant (bâtiments, végétation, accidents de terrain).

$2^{\circ}$ La position du trou de vol (toutes choses étant égales d'ailleurs il y a plus de lignes de vol du côté où s'ouvre la ruche).

$3^{\circ}$ La position des ressources mellifères et pollinifères.

Le long de ces lignes de vol, il est possible d'observer vis-à-vis d'objets mobiles, toute une série de réactions de la part des butineuses. Ces réactions peuvent aller jusqu'à des attaques caractérisées. Ces attaques peuvent aller jusqu'à la piqûre, mais sont le plus souvent limitées à un vol circulaire autour de l'objet. Parfois, il s'agit simplement d'un changement de direction de vol de la butineuse, celle-ci tend à suivre l'objet quand il se déplace rapidement. J'ai étudié ces réactions optomotrices, en relation certaine avec l'agressivité, au moyen de leurres suspendus à un ballon d'enfant gonflé à 1'hydrogène. Des réactions très nettes sont observables à une assez grande distance de la ruche, Ioo mètres et plus. Ces réactions ne sont observables que si le leurre traverse ou suit le chemin de butinage ou s'il s'en approche à très petite distance, environ 50 centimètres. Ces chemins sont très généralement situés à une altitude comprise entre 5 et Io mètres; ils ont une largeur de 2 à 4 mètres et vont en s'élargissant à partir de la ruche.

Le long de ces chemins, les facteurs capables de déclencher des réactions agressives sont les mêmes que ceux que nous avons mis en évidence en présentant des leurres au trou de vol. En particulier, les leurres de petites tailles ne sont jamais attaqués. Dans les conditions naturelles, il est possible de voir des oiseaux poursuivis après avoir traversé des chemins de butinage. J'ai observé un passereau assailli de la sorte et il m'a été signalé par un apiculteur colombophile qu'il perdait, chaque année, des jeunes pigeons, piqués après avoir traversé un chemin de butinage.

Enfin, ces chemins peuvent dans certaines circonstances, relief particulier, vent violent, se situer à moins de deux mètres du sol. Ces lignes de vol anormalement basses sont sans doute l'explication de cas, souvent relatés, d'attaques par les abeilles d'êtres humains ou d'animaux à de très grandes distances du rucher. Par ailleurs, les limites dans lesquelles une abeille peut, non plus attaquer, mais poursuivre une attaque commencée dans le périmètre normal de défense, peuvent être très étendues.

A plusieurs reprises, j'ai pu observer des poursuites jusqu'à une dis- 
tance de l'ordre d'une centaine de mètres. De même une butineuse peut s'écarter de sa ligne de vol pour poursuivre un objet mobile, mais la distance ainsi parcourue excède rarement deux à trois mètres.

\section{L'agressivité sur les lieux de récolte.}

KaL,Mus (I94I) a montré qu'il était possible d'observer la défense d'une source de nourriture par les abeilles. Dans le cas étudié par KaLmus, il s'agissait d'un nourrisseur contenant de l'eau sucrée, vers lequel les abeilles étaient guidées par dressage. Le phénomène était d'ailleurs sensiblement plus intense quand les individus défenseurs étaient d'une autre race que celle des intruses. J'ai pu observer un comportement semblable, à plusieurs reprises en nourrissant des abeilles avec du miel contenu dans une coupelle située à quelques mètres de la ruche. Des essais systématiques effectués à plusieurs époques de l'année m'ont permis de constater qu'il n'est possible d'observer ces comportements agressifs qu'aux époques de très faible miellée et à courte distance de la ruche, une dizaine de mètres au maximum. Des nourrisseurs placés plus loin étaient butinés avec ardeur par des ouvrières de provenances diversessansincidents. En ce qui concerne le nourrisseur où s'observaient des phénomènes d'agressivité, le nombre et la violence des attaques semblaient d'ailleurs varier en fonction inverse de la distance entre le nourrisseur et la ruche. Un comportement similaire a été observé en serre par G. D. GLYNNE JONES (I954).

Ainsi que 1'a fait remarquer KaLMUS, il semble que le comportement hésitant des abeilles étrangères incite les butineuses à les attaquer. D'autre part, j'ai pu constater que sur les bords du nourrisseur, les abeilles étrangères étaient examinées par des abeilles ayant un comportement typique d'abeille gardienne, bien que venant sur le nourrisseur pour y chercher de la nourriture. Ce dernier fait n'a d'ailleurs rien d'étonnant puisque comme nous le verrons par la suite, les ouvrières alternent les deux tâches de gardiennage et de butinage dans un grand nombre de cas. J'ai pu observer un comportement de défense d'un nourrisseur contenant, non plus du miel ou du sirop de sucre, mais du pollen. Dans ce dernier cas, des colonies étaient maintenues en activité durant l'hiver dans des serres chauffées. Ces colonies avaient accès à des fleurs et aussi à un nourrisseur contenant du pollen en poudre (LECOMTE I95.5).

Dans un premier temps, set1le une ruche se trouvait placée dans une des serres en question. Elle s'habitua rapidement à venir butiner la boîte de Petri contenant le pollen. Deux jours après, une deuxième ruche fut introduite, la première étant de race italienne, la deuxième de race noire commune. Il me fut alors possible d'observer de très curieux phénomènes de défense du nourrisseur par les abeilles de la première ruche. 
Quand une butineuse de la deuxième ruche s'approchait de la boîte de Petri contenant le pollen, elle le faisait généralement en effectuant le vol pendulaire caractéristique des pillardes, comportement bien spécial que nous examinerons par la suite.

A ce moment, les butineuses de la première ruche, présentes sur le nourrisseur, s'envolent et chassent les intruses en s'approchant d'elles brusquement. Leur comportement, notons-le, rappelle beaucoup celui des abeilles s'approchant des leurres suspendus à un ballon le long des chemins de butinage. Cette manœuvre a d'ailleurs permis à la ruche italienne de garder l'exclusivité du nourrisseur pendant toute la durée de l'expérience, soit trois jours. Cependant, il n'y eut jamais de combats réels comme ceux que l'on a pu observer dans les cas de défense de non1risseurs contenant des matières sucrées.

Par ailleurs, N. WEAVER (I957) étudiant le comportement de butinage des abeilles sur une vesce : Vicia villosa, RoTH, a décrit un très curieux phénomène que l'on peut sans doute rattacher aux comportements d'agressivité. D'après cet auteur, il est fréquent d'observer une abeille rentrant en collision avec une de ses congénères ou volant vers elle de manière brusque, sans pour cela rentrer en contact avec elle. Dans ces circonstances, il est possible de constater que l'agresseur continue dans tous les cas à butiner dans les environs immédiats, tandis que l'autre abeille peut, suivant les cas, fuir à quelques mètres ou rester elle aussi butiner aux environs immédiats.

Parfois, il peut y avoir une rencontre agressive entre deux butineuses qui se trouvent en vol après avoir quitté une fleur pour en visiter une autre. Plus rarement, une abeille peut être attaquée pendant le butinage d'une fleur. Selon WEAVER, ces comportements sont liés à la possession par l'abeille d'une aire de butinage.

\section{Les aires de butinage.}

Depuis un travail de MULLER (I882), nous savons qu'une butineuse reste longtemps fidèle à un petit groupe de plantes de même espèce situées dans une aire relativement restreinte et même dans les cas extrêmes à une seule plante.

C'est ainsi que BUTIER, JEFFREF, et KALMUS (I943) ayant marqué Ioo butineuses capturées sur une surface d'environ $4,5 \mathrm{~m}$ sur $7 \mathrm{~m}$, pendant le butinage defleurs de rhododendrons observeront que pendant la journée que dura l'observation, pas une butineuse marquée ne s'éloigna de plus de $4,5 \mathrm{~m}$ du périmètre de l'aire où elle avait été capturée.

La forme et la dimension de ces aires de butinage sont déterminées par un grand nombre de facteurs. D'après Sardar SINGH (I950) la taille 
des aires s'accroît quand la récolte de nectar devient moins abondante. RiBbaNDS (I949) avait déjà mis en évidence cette particularité et montré en outre que le nombre d'abeilles présentes sur le lieu de récolte jouait aussi un rôle. Plus la compétition est grande, plus la zone butinée a tendance à croître. Selon MOMMERs (I948) la forme de l'aire serait liée à la disposition des plantes; dans un verger, une butineuse s'attacherait ainsi plus particulièrement à une portion d'une rangée d'arbres.

Dans l'exemple étudié par WEAVER, il est très intéressant de constater que les manifestations agressives n'ont lieu que quand la densité en butineuses est très faible. Quand le nombre des abeilles atteint ou dépasse $4 \mathrm{au} \mathrm{m}^{2}$ il n'est plus possible de les observer à quelque degré que ce soit.

Ces observations sont tout à fait remarquables, car l'existence d'une défense des aires de butinage n'avait jamais été soupçonnée. La signification de ces faits par rapport aux autres phénomènes d'agressivité est cependant assez ambiguë.

Il est tout à fait important de remarquer la grande similitude qui existe entre le comportement décrit par WEAVER et celui que j'ai pu observer lors de la défense d'un nourrisseur de pollen. Dans les deux cas, il n'y avait pas de véritables combats mais un "vol de menace " très caractéristique d'ailleurs.

Cependant, dans le cas de la défense d'un nourrisseur de pollen, les vols de menace ne se produisaient qu'entre ouvrières de ruches différentes et la concentration en abeilles était bien supérieure à 4 par $\mathrm{m}^{2}$. Dans la même serre, $j$ 'ai pu observer des butineuses visitant des fleurs de Colza ; ces abeilles présentaient un comportement analogue. Il était exceptionnel que deux abeilles butinent en même temps sur la même hampe florale et l'arrivée d'une ouvrière provoquait dans la plupart des cas le départ de l'occupante. Là aussi, il me fut possible d'observer le "vol de menace»; en particulier quand deux butineuses s'approchaient en même temps d'une hampe florale. Ici encore, la concentration en butineuses était très supérieure à celle indiquée par WEAVER comme susceptible d'inhiber ces comportements.

I1 est évidemment assez difficile de comparer des observations faites en serre avec d'autres effectuées dans la nature; mais ces divergences montrent qu'il serait dangereux de formuler des règles générales. D'autre part, ces phénomènes sont relativement rares, ce qui est un obstacle à leur étude systématique. Des butineuses de plusieurs autres ruches placées en serre dans des conditions apparemment identiques, ont exploité des nourrisseurs de pollen en commun sans présenter ancun des comportements ci-dessus décrits.

Cependant, bien que le butinage simultané d'une setule fleur par plusieurs abeilles soit parfaitement possible (c'est en particulier la règle 
pour les grandes fleurs au nectar abondant de Magnolia $s p$.) la règle la plus générale est la répulsivité entre butineuses.

J'ai, en particulier, effectué au mois de mars 1957 entre I4 heures et 15 heures, par beau temps ensoleillé, des observations sur le butinage de Salix caprea. Ces arbres étaient en début de floraison et étant donné le petit nombre d'autres ressources en nectar ou pollen à cette époque, le nombre de butineuses par arbre, était particulièrement élevé.

Dans ces conditions, le temps passé sur chaque châton par une abeille quand elle n'a pas été perturbée par une congénère (c'est-à-dire quand aucune autre butineuse n'est passée dans un rayon arbitrairement fixé à 5 centimètres, autour d'elle) est de I 6,15 secondes. Ce chiffre est la moyenne de 30 observations.

$\mathrm{Si}$, au contraire, une butineuse est passée à l'intérieur de ce rayon, le temps passé sur un châton est pour le même nombre d'observations en moyenne de 4,7 secondes. Cette différence est naturellement très significative. Voulant préciser cette action répulsive de l'approche d'un congénère dans la situation de butinage, $j$ 'ai effectué quelques observations en serre. Une ruchette de race italienne maintenue dans une serre à la température de $20^{\circ}$ avait à sa disposition environ $15 \mathrm{~m}^{2}$ de Colza en pleine floraison; le butinage dans ces conditions était particulièrement intense; $j$ 'ai observé pendant une heure $I \mathrm{~m}^{2}$ de Colza. Un nombre moyen de Io butineuses, estimé par des comptages effectués toutes les minutes, visitait l'aire considérée durant l'observation. Durant cette période, j'ai pu observer à cinq repri:es, le comportement d'une ouvrière se dirigeant vers une butineuse de pollen en action. I'arrivée de la nouvelle venue provoque toujours l'envol de l'ouvrière au travail. Cet envol se produit toujours (suivant mes observations) en direction de la perturbatrice et la rencontre, très brève, suffit toujours à provoquer le départ de l'intruse vers une nouvelle direction. Ce comportement rappelle beaucoup le vol d'intimidation observé par WEAVER, dans ce cas également la nouvelle arrivante est détournée du lieu de la rencontre, tandis que la première occupante peut selon les cas rester sur la même fleur ou s'envoler plus loin.

J'ai ensuite suspendu un cadavre frais d'ouvrière ell provenance de la même ruchette à un fil très fin de $35 \mathrm{~cm}$ de longueur. Le temps moyen de séjour d'une abeille sur une fleur de Colza, lorsque j'approche à $35 \mathrm{~cm}$ d'elle ma main seule, est de 5,5 secondes, moyenne de 30 observations. Par contre, ce temps n'est plus en moyenne que de $I, 45$ seconde lorsque j'approche l'abeille morte à I $\mathrm{cm}$ de la butineuse.

Dans la plupart des cas, l'ouvrière s'envole directement vers une autre fleur; dans 2 cas sur 30 , elle effectue pendant un temps très court, de l'ordre d'une seconde, un vol de menace dirigé vers le cadavre que je lui ai présenté. Si le cadavre d'ouvrière appartient à une colonie diffé- 
rente, le résultat est semblable, le temps de séjour d'une abeille est de I,68 seconde et le pourcentage de vols de menaces n'est pas plus élevé que dans le cas précédent.

Enfin, en juillet I959, en étudiant le comportement des abeilles butineuses de la I,uzerne, j'ai pu à plusieurs reprises observer des vols d'intimidation.

Ici encore, le comportement que j'ai pu observer était le même que celui décrit par WEAVER et en accord avec ce dernier la densité en butineuses n'atteignait pas 4 au $\mathrm{m}^{2}$.

Il est peut-être utile de résumer ces quelques observations pour essayer d'en tirer une conclusion. Nous trouvons donc, soit dans nos propres recherches, soit dans la littérature :

$I^{\circ}$ Des cas de défense contre des ouvrières de colonies différentes, d'un nourrisseur contenant des matières sucrées et situé à peu de distance de la ruche; dans ces cas, le comportement agressif est intense, des combats réels peuvent être observés, ceci d'autant plus que les races diffèrent.

$2^{\circ}$ Un cas de défense d'un nourrisseur contenant du pollen contre une colonie étrangère, mais sans que le comportement agressif dépasse le "vol d'intimidation".

$3^{\circ}$ I a défense d'une aire de butinage au moyen du " vol d'intimidation "à l'extérieur, quand la concentration en butineuses est faible ; dans une serre lors d'un butinage intense.

$4^{\circ}$ Une abréviation notable du temps passé sur chaque fleur lors du butinage soit dans les conditions naturelles, soit en serre, en réponse à l'approche d'une autre ouvrière.

$5^{\circ}$ De nombreux exemples de butinage en commun de nourrisseurs ou de plantes; les abeilles ainsi réunies pouvant être de colonies ou de races différentes.

Les facteurs qui favorisent les comportements agressifs sont donc: la proximité de la ruche, la différence de race, la vue d'un objet mobile.

La question de l'interprétation de la contradiction entre certaines de mes observations et celles de WEAVER sur le nombre de butineuses au mètre carré, susceptibles d'inhiber ces comportements, est délicate.

Il est possible que le facteur important soit la carence en ressources alimentaires, qui est la règle en serre et dont un faible butinage, tel celui observé par WEAVER peut être un des symptômes.

Au contraire, en période de forte miellée et donc de butinage intensif, ces comportements ne seraient pas observables. Un fait est également frappant. J'ai signalé que les butineuses étrangères avaient en approchant d'un nourrisseur un comportement bien spécial qui donne à penser qu'elles reconnaissent ce nourrisseur comme n'appartenant pas à leur propre colonie. 


\section{Le marquage olfactif des sources de nourriture.}

J'ai pensé qu'une étude des facteurs permettant cette reconnaissance s'imposait. On sait depuis fort longtemps que les Abeilles marquent au moyen de leur glande abdominale connue sous le nom d'organe de Nassanof certaines sources de nourriture.

Von FRISCH et Rösch (I926) ont mis en évidence de manière certaine que des sources de nourriture ne possédant pas d'odeur propre, par exemple une coupelle de verre remplie d'eau sucrée, étaient ainsi marquées.

Voulant étudier la substance déposée lors de ces marquages j'ai fait butiner des abeilles appartenant à des ruchettes élevées dans des serres, sur des boîtes de Pétri contenant des billes de verre et remplies de sirop de sucre.

J'ai alors comparé le comportement des butineuses vis-à-vis des différents nourrisseurs. Dans tous les cas l'observation durait au moins dix minutes, le nombre des abeilles présentes étant noté toutes les minutes et la position des nourrisseurs invertie entre chaque comptage afin d'éliminer l'influence d'un effet de position.

Je donnerai sous forme de tableaux le détail des comptages effectués; dans tous les cas où elle n'est pas grossièrement évidente la signification de la différence entre les moyennes observées a été contrôlée par le test $\mathrm{X}^{2}$ de Pearson.

Si l'on effectue la comparaison d'un nourrisseur neuf avec un nourrisseur ayant déjà été butiné pendant une journée par la même ruche, l'on constate une forte prédilection pour le nourrisseur "ancien".

Nombre de butineuses présentes sur le nourrisseur :

\begin{tabular}{cc} 
"Neuf " & "Ancien " \\
\hline I & - \\
I & 3 \\
0 & 5 \\
I & 4 \\
0 & 9 \\
0 & IO \\
0 & II \\
0 & IO \\
0 & IO \\
0 & 6 \\
0 & 8
\end{tabular}

Le nourrisseur " ancien " reçoit donc 7,6 visites en moyenne tandis que le "neuf " n'en reçoit que 0,3 .

Cette différence étant naturellement très significative, $j$ 'ai voulu isoler la substance responsable de cette augmentation d'attractivité. J'ai laissé macérer pendant ro heures, $900 \mathrm{ml}$ de billes de verre, en provenance d'un nourrisseur ayant été visité pendant une journée, dans $500 \mathrm{ml}$ d'alcool éthylique absolu. 
COMPORTEMENT AGRESSIF DES OUVRİ̀RES D'Apis mellifica L. $\quad$ I97

J'ai ensuite comparé l'attractivité d'un nourrisseur dans lequel j'ai laissé s'évaporer $50 \mathrm{ml}$ de cet extrait alcoolique avec celle d'un nourrisseur neuf. Les résultats suivants ont été obtenus :

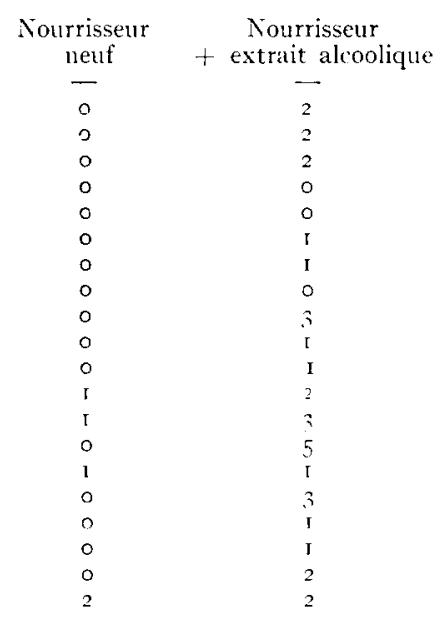

Le nourrisseur supposé imprégné de "substance " reçoit done I,65 visite en moyenne tandis que le nourrisseur neuf n'en reçoit que 0,25 .

Si l'on procède alors à un épuisement de l'extrait alcoolique par de l'éther sulfurique, il est possible de constater que la substance attractive se retrouve en grande abondance dans la phase éthérée.

Un nourrisseur imprégné de cette phase a été mis en compétition avec un nourrisseur neuf et les résultats suivants ont été obtenus :

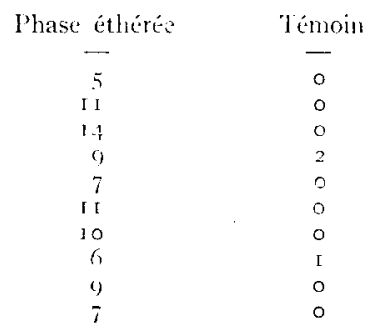

Ainsi un nourrisseur imprégné de la phase éthérée reçoit après évaporation 9 visites en moyenne contre 0,3 pour un témoin. Un autre essai effectué dans les mêmes conditions mais avec un butinage plus faible a donn é une moyenne de 3 visites pour le nourrisseur contenant la substance attractive et o pour le nourrisseur témoin. La phase hydro-alcoolique restante, après l'épuisement par l'éther, ne présente pas une attractivité significativement différente du témoin.

Ainsi, dans un essai, la phase éthérée a été visitée I,75 (moyenne de 20 essais) et un témoin 0,2 fois, la phase hydro-alcoolique ne recevant que 0,3 visite. 
Il faut bien faire remarquer que ce phénomène se maintient si l'on prend soin d'amener le volume de la phase éthérée à celui de la phase hydro-alcoolique.

A ce moment, par suite de la faible activité de butinage de la ruche étudiée, j'ai présenté ces nourrisseurs à une ruche étrangère également maintenue en serre.

Phénomène remarquable, les chiffres observés s'inversent; la substance attractive devient répulsive et ceci d'une manière très frappante.

Le butinage de la ruche B sur un nourrisseur imprégné de la phase éthérée en provenance de la ruch $\mathrm{A}$ a donné dans trois essais les résultats suivants.

I. - Phase éthérée : o visite — témoin constitué par un nourrisseur neuf : 8 visites (moyenne de dix comptages).

II. - Phase éthérée : o visite, témoin : I4,8.

III. - Phase éthérée : o visite, témoin : 43.

Dans le dernier exemple le butinage était particulièrement intense puisque 43 butineuses étaient présentes en moyenne sur le même nourrisseur et il était particulièrement frappant de voir les butineuses voler au-dessus du nourrisseur contenant la substance en provenance de 1'autre ruche, sans se poser.

Il s'agit bien d'une substance répulsive et non d'une absence d'attractivité ou d'un effet répulsif de l'éther. En effet, la comparaison du butinage simultané par la ruche A de 4 nourrisseurs donne les résultats suivants :

\begin{tabular}{|c|c|c|c|}
\hline $\begin{array}{l}\text { I'hase éthérée } \\
\text { de ruche B }\end{array}$ & $\begin{array}{l}\text { Either } \\
\text { seul }\end{array}$ & $\begin{array}{l}\text { Nourrisseur déji } \\
\text { visití par A }\end{array}$ & $\begin{array}{c}\text { Nourrissentr } \\
\text { n?uff }\end{array}$ \\
\hline- & - & - & - \\
\hline$\circ \ldots \ldots \ldots \ldots \ldots$ & 0 & 2 & 0 \\
\hline$\circ \ldots \ldots \ldots \ldots \ldots$ & I & 2 & 0 \\
\hline$\circ \ldots \ldots \ldots \ldots \ldots$ & o & 2 & 1 \\
\hline$\circ \ldots \ldots \ldots \ldots \ldots$ & $\circ$ & 6 & I \\
\hline$\circ \ldots \ldots \ldots \ldots \ldots$ & 1 & 3 & 1 \\
\hline$\circ \ldots \ldots \ldots \ldots \ldots$ & 4 & 3 & 4 \\
\hline$\circ \ldots \ldots \ldots \ldots \ldots$ & 0 & + & 0 \\
\hline o $\ldots \ldots \ldots \ldots \ldots$ & 2 & 2 & 2 \\
\hline o............... & 3 & 3 & 3 \\
\hline$\circ \ldots \ldots \ldots \ldots \ldots$ & 6 & 3 & 1 \\
\hline
\end{tabular}

Ici encore les positions des différents nourrisseurs ont été interverties entre chaque comptage.

Les moyennes sont respectivement de $0,1,6,3, \mathrm{I}, 3$ visites.

Une substance répulsive existe donc dans la phase éthérée mais elle se trouve également présente dans la phase hydro-alcoolique et le butinage simultané de quatre autres nourrisseurs par la ruche A a donné les résultats suivants : 
Lixtrait alcoolique de

Nourrisseur visité par ruche 13

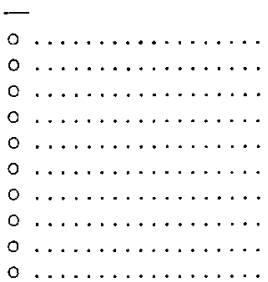

Phase hydro-alcoolique obtenuc is partir de cet extrait

\begin{tabular}{l}
\hline \\
1 \\
0 \\
0 \\
0 \\
0 \\
0 \\
1 \\
0 \\
0 \\
1
\end{tabular}

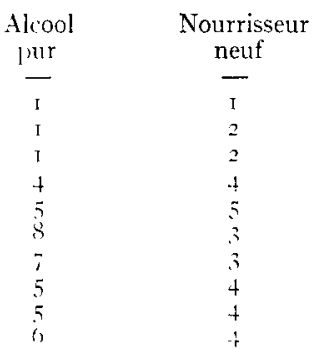

Ce qui donne des moyennes de $0,0,3,4,3$, et 3,2 visites.

Si au lieu d'utiliser des extraits obtenus à partir de nourrisseurs l'on se sert de nourrisseurs, les résultats obtenus sont parallèles.

Voici quels sont les résultats donnés par une comparaison simultanée du butinage de quatre nourrisseurs par les abeilles de la ruche A.

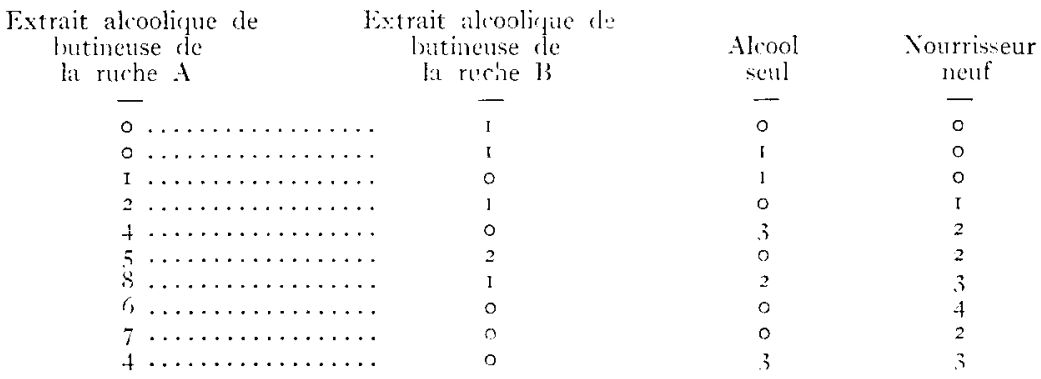

Soit des moyennes de $3,7,0,6, \mathrm{I}, 2$ et $\mathrm{I}, 7$ visites.

Le même effet répulsif est d'ailleurs obtenu, que l'on s'adresse à des extraits alcooliques obtenus à partir d'individus entiers, d'abdomens seuls ou de têtes et thorax seuls.

En faisant butiner différents nourrisseurs à la ruche A l'on obtient les résultats suivants :

\begin{tabular}{|c|c|c|c|}
\hline \multicolumn{3}{|c|}{$\begin{array}{l}\text { Extrait alcoolique de têtes } \\
\text { et thorax de butineuses } 13\end{array}$} & $\begin{array}{c}\text { Alcool } \\
\text { seul }\end{array}$ \\
\hline- & & - & - \\
\hline o & 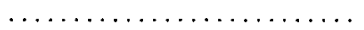 & 0 & 2 \\
\hline o & $\ldots \ldots \ldots \ldots \ldots \ldots \ldots \ldots$ & o & I \\
\hline o & $\ldots \ldots \ldots \ldots \ldots \ldots \ldots \ldots$ & o & 3 \\
\hline I & 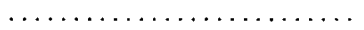 & 0 & 2 \\
\hline 0 & 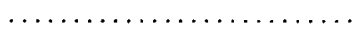 & 0 & 2 \\
\hline 0 & 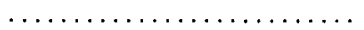 & o & 2 \\
\hline o & 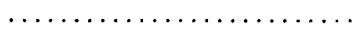 & o & I \\
\hline 1 & 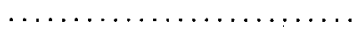 & 0 & 2 \\
\hline 0 & $\ldots \ldots \ldots \ldots \ldots \ldots \ldots \ldots$ & 0 & I \\
\hline 0 & $\ldots \ldots \ldots \ldots \ldots \ldots \ldots$, & 0 & 2 \\
\hline
\end{tabular}

Soit des moyennes de $0,2,0, \mathrm{I}, 8$.

Mais si l'on fait butiner des nourrisseurs contenant des extraits de parties de butineuses à des butineuses en provenance de la même ruche on ne trouve absolument pas l'effet attractif remarqué avec les extraits alcooliques de butineuses intactes. 
L'on obtient en effet les résultats suivants :
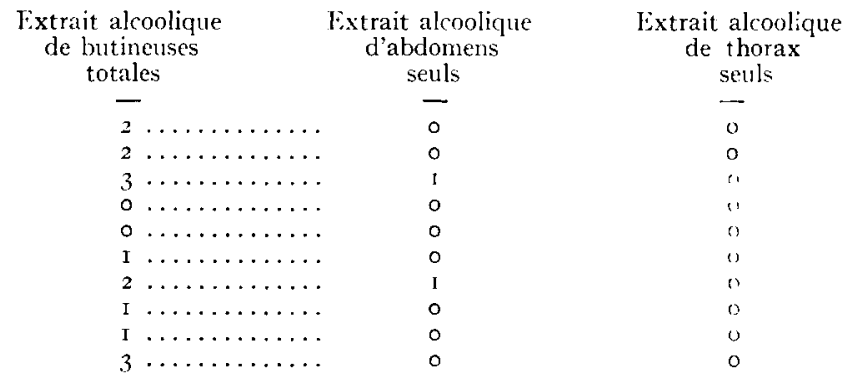

Nourrisseur neuf

Soit des moyennes de $I, 5,0,2,0,0,8$.

A la suite de ces" quelques essais, je pense pouvoir admettre comme hypothèse de travail, l'existence de quatre substances.

Io Une substance attractive générale.

Cette substance doit sans doute être attribuée à la glande de Nassanof, selon la conception classique. Elle ne possède pas de propriétés répulsives ; RENNER (I955) en effet, a mis en évidence par distillation de papiers filtres apposés sur des organes de Nassanof que la sécrétion de cette glande était attractive pour toutes les abeilles quelle que soit leur ruche d'origine.

J'ai pu vérifier ces données de manière très simple : j'ai mis au contact de l'organe de Nassanof d'une dizaine d'ouvrières en train de " battre le rappel " un papier filtre. Ce papier filtre déposé près des nourrisseurs se montre attractif pour les ouvrières de n'importe quelle ruche.

$2^{\circ}$ Une substance répulsive générale.

Cette substance provient des fragments de butineuse; on doit la rapprocher des substances répulsives découvertes par Von FRISCH chez le vairon et dont j'ai parlé en étudiant le rôle joué par l'odeur du venin. En particulier, cette substance pourrait s'identifier avec celle mise en évidence chez l'abeille par HeIN'Tz (I955).

$3^{\circ}$ Une substance répulsive et attractive individuelle.

Ia ruche est ici considérée comme un individu. Cette substance à double action est celle que l'on retrouve dans la phase éthérée et qui est par conséquent déposée par les butineuses sur les nourrisseurs.

$4^{\circ}$ Une substance répulsive individuelle.

Cette substance est celle que l'on retrouve dans la phase hydro-alcoolique. 
Le dépôt de ces detux dernières substances dont l'origine nous est inconnue, peut jouer dans le comportement de butinage, un rôle très important.

En ce qui concerne les comportements d'agressivité au voisinage des nourrisseurs, il semble tout à fait légitime de les mettre en rapport avec la présence de ces deux substances.

Leur présence serait en particulier à la base du comportement hésitant, très caractéristique, des abeilles en provenance d'une colonie étrangère. Je dois cependant signaler, que je n'ai pas trouvé de différences significatives entre les effets répulsifs d'extraits en provenance de butineuses de races différentes. Enfin, j'ai été également incapable de mettre en évidence une action quelconque de ces extraits sur l'agressivité étudiée en cagettes au moyen de leurres.

\section{Le pillage.}

L'abeille peut encore manifester des comportements agressifs en d'autres lieux. En particulier, quand elle se livre au pillage, elle attaque ses congénères dans une ruche qui lui est étrangère et qui peut se trouver à une assez grande distance de la sienne propre. J'ai d'ailleurs l'intention de revenir sur cette question du pillage et de son déterminisme.

Je veux cependant citer ici une curieuse observation de Von FrISCH (1945).

L'on peut constater que les abeilles gardiennes conservent leur comportement typique d'inspection des nouvelles arrivantes, non seulement à l'entrée de la ruche, mais encore dans les dépendances de cette dernière. La planche d'envol, même de grande dimension, et les parois de la ruche semblent pouvoir être considérées comme faisant partie du " gîte ".

Durant l'automne de I945, Von Frisch, alors qu'il étudiait le comportement d'une ruche d'observation, vit des abeilles posées sur le socle à un endroit où les butineuses, lourdement chargées se posaient avant d'entrer dans le tunnel conduisant au trou de vol.

Les pillardes qui appartenaient à une colonie étrangère comme il le fut vérifié par marquage, molestaient les butineuses pour obtenir qu'elles régurgitent leur récolte. Il s'agissait donc d'un pillage en dehors de la ruche, mais dans un de ces prolongements qui doivent être considérés, en ce qui concerne l'agressivité, comme faisant partie intégrante du " gîte " de l'abeille. De pareils faits n'ont, par contre, jamais été signalés sur les lieux de récolte.

Il n'a jamais été signalé chez Apis mellifica de pillages concernant autre chose que les provisions de miel, il n'en est pas de même chez les Melipones. Chez ces insectes, il est possible d'observer non seulement 
des pillages concernant le miel, mais aussi la cire et la propolis (NOGUEIRANETO, I949) et le pollen (HAMLYN-HARRIS, I955).

\section{Le territoire de l'abeille.}

En fonction du lieu où ils apparaissent, différents comportements agressifs peuvent ainsi être distingués. La ruche et ses dépendances et exceptionnellement les nourrisseurs peu éloignés sont le théâtre d'une agressivité intra-spécifique.

Au contraire, l'aire défendue autour de la ruche et les chemins de butinage constituent une zone d'agressivité extra-spécifique. La distinction entre les deux zones apparaît nettement quand on étudie l'influence de la taille du leurre sur l'agressivité. Je rappelle que dans la première plus un leurre est petit, plus il est attaqué. Au contraire, dans la seconde, il ne l'est qu'au-dessus d'une certaine taille.

Nous référant à la définition d'HEDIGER (I949), nous pouvons considérer la première zone comme un territoire, celui-ci étant en effet la "zone défendue par son occupant contre les concurrents de sa propre espèce $\%$.

La deuxième zone forme une partie privilégiée du domaine vital, c'est la zone de l'agressivité extra-sprécifique.

Enfin, dans une troisième zone, constituée par les " aires de butinage " n'existent que des manifestations agressives intra-spécifiques de très faible intensité, dirigées contre les individus sans distinction, semble-t-il, de colonie et seulement dans certaines conditions difficiles à préciser.

La figure 7 donne une vue schématique de l'organisation spatiale d'une colonie d'abeilles en fonction de l'agressivité. Il est d'ailleurs peutêtre bon de faire remarquer que les relations complexes que $j$ 'ai ainsi mises en évidence, sont loin de constituer une exception aux règles généralement admises.

Pour ne citer qu'un exemple, l'on trouve des relations au moins aussi complexes chez le Goeland argenté, Larus argentatus.

Selon GoEThe (I937), FrITSCH (I95I) et d'autres auteurs, l'on trouverait l'organisation suivante :

Le nid et ses abords immédiats sont défendus contre les congénères et les prédateurs de même que 1'est la ruche. I a colonie formée par la réunion des nids, ainsi que ses abords, est défendue collectivement contre les prédateurs et les intrus : agressivité extra-spécifique.

Les lieux de récolte de nourriture, par exemple une plage où se trouvent des coquillages, ne sont pas le théâtre de véritables comportements agressifs, mais 1'on peut y observer une hiérarchie intra-spécifique.

Enfin, un cas assez particulier est celui de certains points de rassem- 
blement sur les plages où existe une certaine agressivité intra-spécifique.

Sans vouloir assimiler étroitement des phénomènes existant dans des groupes zoologiques aussi éloignés, il me paraît cependant intéressant d'attirer l'attention sur ces analogies. Toute étude du comporte-

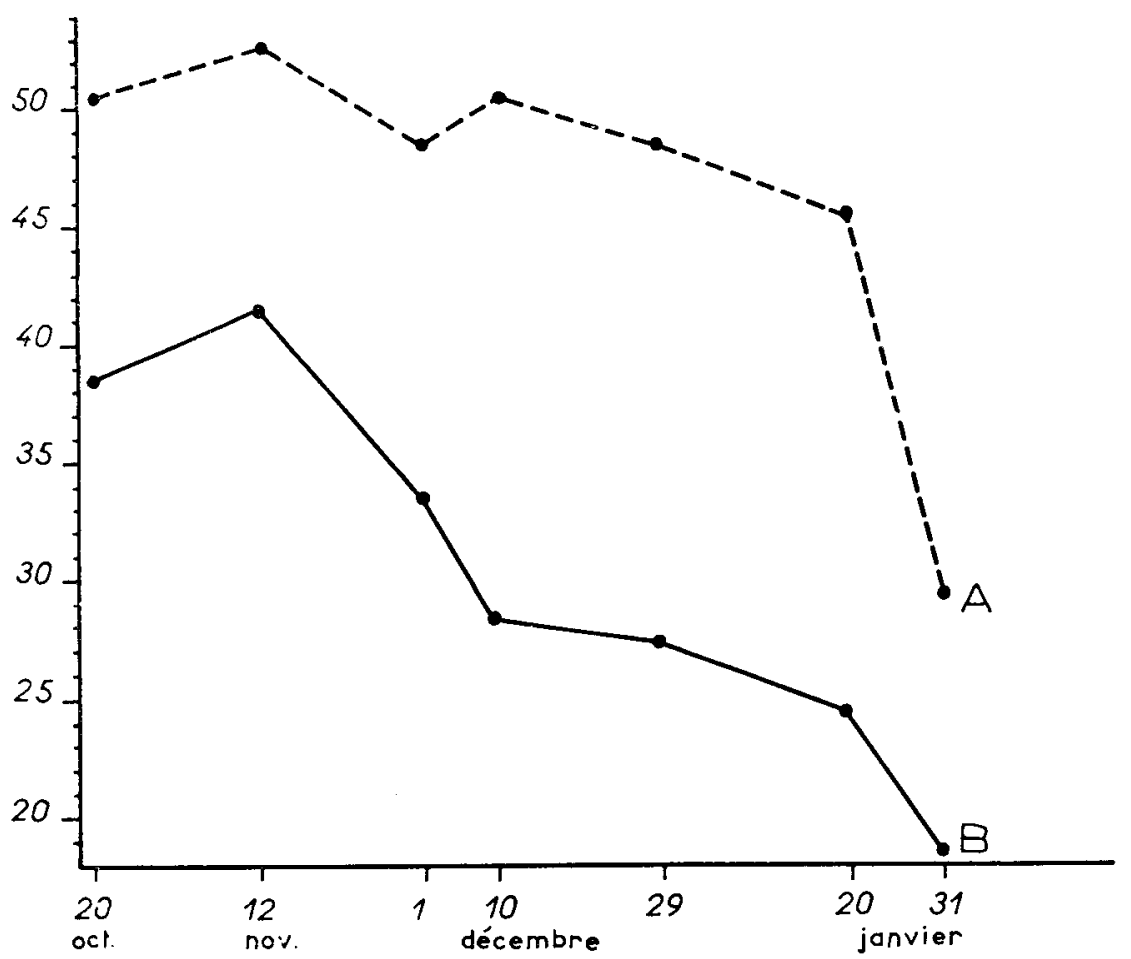

FIG. 8. - Evolution dans le temps de l'agressivité de deux ruches placées côte à côte. Se reporter au texte p. 35 .

ment agressif d'une espèce donnée, révèle d'ailleurs l'importance considérable des facteurs en rapport avec l'organisation spatiale.

\section{Facteurs météorologiques.}

Les facteurs météorologiques jouent certainement un rôle très important; ce rôle a été toujours reconnu par les praticiens de l'apiculture, mais jamais précisé.

Dans ce but, j'ai présenté régulièrement plusieurs fois par semaine un leurre de drap sépia (68I) de Io $\times 4 \mathrm{~cm}$ à une trentaine de ruches durant toute une saison apicole. Ces essais m'ont permis de mettre en évidence l'importance de deux facteurs qui sont le vent et l'orage.

Un vent de plus de $20 \mathrm{~km} / \mathrm{h}$ mesuré à la hauteur du toit de la ruche, élève toujours considérablement l'agressivité. Le deuxième de ces fac- 
teurs a une action également très nette; cette donnée étant également connue depuis longtemps par les apiculteurs.

Schua (1952) a étudié l'action des facteurs météorologiques sur différentes activités de l'abeille. $\mathrm{Il}$ a particulièrement étudié les variations de l'agressivité vis-à-vis d'abeilles étrangères et vis-à-vis de leurres de toile noire présentés à l'entrée de la ruche. Dans ces conditions, l'agressivité est considérablement influencée par un temps orageux. Schus ne sait cependant pas à quel phénomène électrique attribuer cette augmentation. J'ai personnellement pu observer dans des cagettes placées entre deux joues de métal reliées aux bornes d'une bobine de Rumkorf de moyenne puissance, une augmentation invraisemblable de l'agressivité, allant jusqu'à provoquer des combats entre abeilles d'une même colonie. Ceci ne s'observe évidemment jamais dans les conditions naturelles. Le même phénomène est également très facile à observer en soumettant les abeilles à l'action d'un courant à haute fréquence du type employé à des fins thérapeutiques pour le traitement de certains rhumatismes.

Il semble cependant que l'on ne puisse attribuer à l'abeille une sensibilité spéciale au courant électrique et une observation minutieuse plus facile à effectuer sous un faible éclairement montre que les aspérités chitineuses $d u$ corps des ouvrières émettent dans ces conditions, une infinité d'étincelles. Des récepteurs banaux doivent être de ce fait intéressés et de leur excitation découle l'augmentation des manifestations agressives. Un procédé d'obtention du venin à des fins pharmaceutiques est d'ailleurs basé sur cette sensibilité de l'abeille. Un papier filtre humide est placé dans une caissette sur des fils de fer dans lesquels passe un courant électrique, les abeilles placées dans la caissette réagissent en piquant le papier filtre d'où l'on peut extraire le venin (WEIDE, I958).

La température joue, semble-t-il, un assez grand rôle dans la force des manifestations d'agressivité d'autres animaux. En particulier, SrumPER (I92I-I922) a pu montrer que chez Formica rufa les réactions d'agressivité lors de la rencontre de deux ouvrières étaient liées à l'élévation de température en conformité avec la règle de Van't Hoff. STUMPER propose l'explication suivante de ce phénomène; la vitesse de locomotion des fourmis augmente lorsque la température s'élève et la force du choc de la rencontre augmenterait ainsi. Ce ne serait donc pas l'agressivité mais la force du stimulus qui serait en relation avec l'élévation de température.

En ce qui concerne l'abeille, Schua (I952) conclut son étude en disant que l'élévation de la température externe élève l'agressivité. Cette opinion demande, à mon sens, à être discutée. Les tests effectués au trou de vol par temps froid, c'est-à-dire quand l'activité est très réduite, donnent en effet l'impression d'une agressivité très faible. I,es abeilles sont en groupe à l'intérieur de la ruche et ne prêtent aucune attention à 
ce qui se passe à l'extérieur. Il en est de même dans une certaine mesure quand, sans être en grappe, la colonie est à peu près inactive.

Par contre, dans les limites des températures permettant une activité normale de vol, c'est-à-dire à partir de ro à $12^{\circ}$, il ne m'a pas été possible de trouver une liaison entre l'élévation de température et l'agressivité. Les périodes chaudes et non orageuses n'étant en aucun cas celles où les tests d'agressivité donnent les résultats les plus élevés.

En cagette, il n'est pas possible de procéder à de telles expériences. Un groupe d'abeilles, même quand il est très restreint, possède la faculté de régulariser sa température dans de larges limites comme celà a été mis en évidence par LAVIE et RoTH (I953).

Cette régulation thermique rend impossible l'étude du thermopréferendum de l'abeille groupée; elle rend aussi difficile une étude sérieuse de l'influence des variations de température sur le comportement agressif.

\section{Influence de la miellée sur l'agressivité et le pillage.}

L'étude de 1'influence des facteurs météorologiques est d'ailleurs rendue difficile par le fait que la plus ou moins grande abondance de la miellée, c'est-à-dire de la sécrétion nectarifère des plantes visitées par les butineuses, joue un rôle très important. La miellée n'est évidemment pas indépendante des facteurs météorologiques et cette intrication complique une telle étude.

Le niveau de l'agressivité est presque nul en période de grande miellée ainsi que l'atteste un grand nombre d'essais effectués au moyen de la méthode des leurres.

La simple observation montre que durant des périodes, il n'y a que peu d'abeilles gardiennes et souvent pas du tout.

Ces abeilles que nous étudierons en détail par la suite, ont un comportement très typique qui ne se laisse pas confondre avec un autre. Même en période de grande miellée, il est cependant possible de faire apparaitre des gardiennes au moyen d'une perturbation, en frappant brutalement la ruche par exemple. BUTLER et FREE (I952), en opérant ainsi, ont vu au bout de quelque temps, apparaitre sur la planche de vol, des gardiennes au comportement typique qui disparurent après quelques heures.

Un autre comportement, en relation directe avec l'état de la miellée, a une influence considérable sur l'agressivité. Il s'agit du pillage. Le pillage se produit très généralement après la fin de la miellée. Il peut être spontané, 1'on s'aperçoit que les ruches fortes essayent de dérober les provisions des faibles, surtout quand il s'agit de ruches en mauvais état et que l'odeur du miel se répand par les fentes ou les brèches du bois.

I1 peut être aussi la conséquence de l'imprudence d'un apiculteur 
qui abandonne du miel ou des objets portant des traces de miel à proximité $d u$ rucher. Les abeilles commencent par récolter ce miel puis tentent de dérober les provisions des ruches voisines et le pillage devient général. Fn septembre I953, j'ai observé, pendant une période de petite miellée le comportement de deux ruches.

Ces deux ruches ne possédaient pas de gardiennes et il était impossible d'observer la moindre manifestation d'agressivité vis-à-vis d'un leurre agité devant l'entrée. J'ai alors provoqué un petit pillage entre ces deux ruches en les nourrissant avec du miel, à l'extérieur, en un point situé à environ I50 mètres du rucher. L'agressivité, le lendemain, était très forte, de nombreuses gardiennes se tenaient à l'entrée des ruches et un leurre de couleur marron (II2) de Io $\times 5 \mathrm{~cm}$ était attaqué très vivement dans un rayon de trois mètres autour de la ruche.

Les attaquantes étaient particulièrement agressives et poursuivaient le leurre et l'observateur à près de roo mètres de la ruche. Deux jours après la fin du nourrissement et du pillage, les gardiennes avaient de nouveau disparu.

\section{Facteurs divers.}

Dans les facteurs externes qui élèvent l'agressivité, il faut en fait ranger toute perturbation de quelque nature qu'elle soit du moment que l'abeille est susceptible de la percevoir.

L'on peut ainsi noter différentes odeurs, les chocs et les vibrations. Les apiculteurs savent bien qu'une colonie qui vient d'être visitée, même avec douceur, ne doit pas l'être dans les heures qui suivent, car les abeilles lors de la seconde visite sont toujours bien plus agressives. De même après avoir fait accepter une reine à une colonie, les apiculteurs se gardent bien de procéder à son ouverture dans les jours suivants. La nouvelle reine est en effet très souvent mise à mort par les ouvrières lors de cette visite de la ruche. J'ai d'ailleurs mis en évidence que la visite d'une ruche abaissait le seuil d'agressivité des ruches voisines. Le détail de ces essais sera donné plus loin lorsque nous examinerons l'importance pour la compréhension de ces comportements de la notion de rupture de situation. I,e fait qu'un stimulus efficace perd son efficacité si sa durée est trop grande me conduira d'ailleurs à reprendre ces données dans un chapitre spécial de la deuxième partie de ce travail.

Il faut aussi signaler que certaines stimulations ont la propriété de créer une inhibition de l'agressivité. C'est, en particulier le cas de la fumée. La plupart des praticiens de l'apiculture attribuent la baisse de l'agressivité à une prise de nourriture effectuée sous l'action de la fumée.

Pour Golliot (I954), la fumée ne provoque pas de prise de nourri- 
ture. Cet auteur a pu constater que le nombre d'abeilles plongées dans les alvéoles ne varie jamais de plus de 5 p. Ioo en plus ou en moins à la suite d'un enfumage. L'action calmante des fractions actives, essentiellement acide acétique, acétone et alcool méthylique, serait la conséquence de la perturbation importante qu'elles amènent dans un groupe d'abeilles. La baisse de 1'agressivité serait dans cette perspective la conséquence d'une désorganisation passagère de la structure sociale de la ruche.

En fait, mes propres observations m'inclinent à penser qu'à côté d'un facteur perturbateur indéniable, il peut exister aussi une influence de la "prise de nourriture ".

Ce n'est pas dans les alvéoles que l'abeille va chercher cette nourriture comme l'a bien vu GoILIOT, mais il est certain que la fumée provoque parfois, en période de miellée surtout, une régurgitation suivie de réingestion. Dans les expériences de GorL, $\mathrm{O}^{\prime} \mathrm{T}$ et dans la pratique apicole cou-

TABLEAU XI

\begin{tabular}{c|c}
\hline \multicolumn{2}{c}{ Nombre de franchissements de la ligne médiane } \\
\hline Avant l'émission de fumée & Après l'émission dc fumée \\
\hline 23 & $\mathrm{I}$ \\
38 & 19 \\
23 & $\mathrm{1} 6$ \\
25 & 0 \\
29 & $\mathrm{1} 7$ \\
26 & $\mathrm{1} 2$ \\
28 & $\mathrm{16}$ \\
24 & 8 \\
28 & 0 \\
30 & 0 \\
\hline
\end{tabular}

rante, il est bien fait usage de fumées de cellulose ; coton, chiffon, carton, bois, etc. Dans certaines régions, en particulier en Allemagne, la fumée de tabac est employée semble-t-il avec succès. Voulant étudier le mode d'action de cette fumée particulière, $\mathrm{j}$ 'ai réalisé le dispositif expérimental suivant : 5 ouvrières capturées dans une ruche sont déposées dans une boîte en matière plastique de II $\times 7 \times 3 \mathrm{~cm}$. Cette boîte comporte en son milieu une ligne qui la partage en deux parties égales. Après avoir réalisé un éclairage uniforme, je compte le nombre de franchissements de la ligne par les ouvrières pendant une minute. Ensuite, je souffle par une ouverture situcée sur le côté de la boite, une bouffée de fumée de tabac. La plus grande partie de la fumée ne fait que traverser la boîte, celle-ci étant criblée de nombreux petits trous. Le passage de la bouffée produit toujours le même effet : après une période d'agitation, durant quelques secondes au maximum, succède une phase d'activité réduite ou même d'immobilité totale, et non pas de ventilation intense comme dans le cas de la fumée de cellulose étudiée par GoILlót. Dans ro essais effectués 
avec Io groupes différents de 5 ouvrières, les résultats contenus dans le tableau XI ont été obtenus. Le deuxième comptage a été effectué dans les mêmes conditions que le premier, Io secondes après l'introduction de la fumée, aussitôt après la fin de la période d'agitation.

L'effet sédatif est incontestable, il est plus ou moins marqué selon le cas, ce qui correspond sans doute aux différentes doses introduites dans la boîte d'essai par mon procédé assez grossier. A la limite, une forte dose provoque une véritable anesthésie comparable à celle obtenue avec l'anhydride carbonique. Il semble donc légitime de rapporter la baisse de l'agressivité lors de l'emploi de la fumée de tabac à un phénomène d'anesthésie ce qui n'est pas le cas de la fumée de cellulose. 


\section{CHAPITRE III}

\section{LES FACTEURS INTERNES}

Bien que la distinction entre les facteurs internes et externes soit souvent bien arbitraire, il peut être commode de réserver ce dernier terme aux facteurs visiblement liés à des modifications du milieu et de grouper les autres sous le nom de facteurs internes.

\section{Facteurs propres à la race ou à une colonie donnée.}

Il existe incontestablement des différences raciales considérables en ce qui concerne l'agressivité. La question des races d'abeilles domestiques est d'ailleurs compliquée. Les différents auteurs sont loin d'être d'accord et certains aboutissent à des classifications quadrinomiales dont le principal mérite n'est pas la clarté.

SCHMIEDEKNECHT (I930) conserve la distinction établie par FrRESE entre les différentes variétés rencontrées en Allemagne dans les ruchers. Cette classification peut être considérée comme très suffisante en ce qui concerne la France. L'on pourrait ainsi distinguer à côté du type de l'espèce Apis mellifica L. une variété Lehzeni, Von BuTTEL,-REEPEN originaire du nord de l'Europe; une variété Carnica PoLlm. originaire de Carniole et de Carinthie; une variété Ligustica SpIn. plus connue sous le nom d'Abeille italienne; une variété syriaca Von BUTTEL-REEPEN et une variété cypria PoLLM. connues sous le nom de syrienne et de chypriote. Il semble que l'on puisse y ajouter la variété caucasia originaire du Caucase et qui tend à se répandre dans beaucoup de ruchers européens. Un apiculteur anglais (ADAM, I95I-54) après avoir effectué un voyage en Europe et sur le pourtour méditerranéen, a pu porter un jugement de valeur sur les différentes races d'abeilles et en particulier comparer leurs comportements agressifs.

Les abeilles noires communes de France, c'est-à-dire la race mellifica sensu stricto ; les abeilles chypriotes et les abeilles syriennes sont de loin les plus agressives. Elles partagent avec l'abeille d'Afrique du Nord, la tellienne, la particularité d'attaquer " en masse » à l'extérieur de la ruche, avant toute manipulation de celle-ci. Les variétés carnica et ligustica ne présenteraient jamais ce comportement. 
Il faut cependant remarquer avec cet auteur que de grosses différences existent à l'intérieur de ces races ou variétés et qu'il est toujours possible d'y trouver des souches totalement aberrantes en ce qui concerne le caractère agressif. Il existe des Chypriotes douces et des Italiennes agressives.

J'ai pu comparer personnellement le comportement de la race noire commune, de l'abeille italienne et de l'abeille grise du Caucase. Les abeilles caucasiennes ont une réputation de douceur tout à fait justifiée et je les trouve régulièrement moins agressives dans les tests effectués.

Ainsi pour le leurre marron (II2) je trouve les résultats suivants qui sont pour chaque ruche la moyenne de Io essais ; technique de notation $B$.

\section{TABLEAU XII}

\begin{tabular}{|c|c|c|}
\hline $\begin{array}{l}\text { Ruche caucasienne a......... } \\
\text { Ruche caucasienne b......... } \\
\text { Ruche caucasienne c } \ldots \ldots \ldots \ldots\end{array}$ & $\begin{array}{r}30 \\
7 \\
17\end{array}$ & $\mathrm{M}=\mathrm{I} 8$ \\
\hline $\begin{array}{l}\text { Ruche de race noire } a \ldots \ldots \ldots \ldots \\
\text { Ruche de race noire } b \ldots \ldots \ldots \\
\text { Ruche de race noire c......... }\end{array}$ & $\begin{array}{l}45 \\
37 \\
63\end{array}$ & $M=48$ \\
\hline
\end{tabular}

Les ruches $a$ et $b$ de chaque catégorie ont été testées le même jour, les ruches $c$ le lendemain.

L'impression laissée par le comportement des abeilles lors des visites des ruches confirme pleinement les résultats observés en cagette.

En ce qui concerne les deux autres races, le plus souvent j'ai trouvé que les différences entre colonies étaient plus importantes que les différences interraciales. Ce n'est cependant (en accord avec ADAM, I954) que chez la race noire commune, dans un rucher situé en Auvergne, que j'ai pu observer une attaque " en masse » généralisée. Les colonies de ce rucher attaquaient à plusieurs mètres toute personne passant devant le trou de vol, sans qu'aucune manipulation ait été effectuée. Ce comportement relativement rare en général était très fréquent d'après le propriétaire de ces ruches en dehors de toute modification sensible des facteurs externes.

Fin ce qui concerne les différences entre colonies, l'étude suivie d'un rucher de trente colonies pendant plusieurs mois me permet de penser que ces différences sont assez constantes. La figure 8 indique le niveau d'agressivité de deux ruches appartenant à la race noire commune. Ces deux ruches étaient placées côte à côte dans le rucher. Pour chaque essai, j'ai prélevé I50 ouvrières dans les mêmes conditions dans chacune des deux ruches et je les ai réparties dans ro cagettes. L'opération était dans tous les cas effectuée sans anesthésie. Six heures après le prélèvement, je présente à ces cagettes un leurre marron (II2) et je note les résultats selon 
la technique A. Il existe toujours un certain parallélisme entre les variations observées dans différentes ruches. Le parallélisme est très net entre les deux courbes que je présente ; elles se rapportent à des observations d'automne et d'hiver. Mais, des observations analogues effectuées à d'autres saisons ont donné des résultats très comparables.

I1 peut évidemment arriver que le niveau d'agressivité soit très bas et que toutes les ruches soient "douces". Au contraire, il se peut qu'elles soient toutes " agressives " mais il n'arrive jamais qu'une ruche généralement agressive se montre plus douce que les autres ou vice versa, toutes choses étant égales par ailleurs.

Il est cependant très important de remarquer que cette condition d'égalité ne se trouve réalisée dans la pratique apicole que dans de rares occasions. Un grand nombre de facteurs rentrent ainsi en ligne de compte. L'ordre de la visite du rucher, la qualité et la quantité de fumée émise par l'enfumoir ; les fausses manœuvres au cours de la visite, etc... Ainsi, une ruche contenant beaucoup de propolis donne souvent l'impression d'être très agressive. Les cadres sont collés les uns aux autres par cette résine et l'apiculteur ne peut les séparer sans perturber considérablement la colonie.

Tout ceci conduit les apiculteurs à considérer que le hasard préside souvent à la répartition de l'agressivité dans ses ruches. Parfois, il attribue à un emplacement donné la vertu d'élever l'agressivité et dans ce cas, j'ai toujours pu constater qu'il s'agissait de l'extrémité d'un rucher visité dans un ordre immuable. Le fait de visiter une ruche élève incontestablement l'agressivité de la voisine et les dernières colonies visitées paraissent presque toujours plus agressives.

Il n'est donc possible de se faire une opinion qu'en employant la technique des leurres présentés à l'entrée de la ruche. Même en employant cette technique, il sera bon de changer les leurres entre deux présentations à deux colonies différentes et de ne jamais les présenter à deux colonies voisines.

Dans la pratique apicole, un ordre de visite du rucher conçu de manière à espacer au maximum la visite de deux ruches voisines parâ̂t également très souhaitable. Dans un essai, $j$ 'ai procédé de la manière suivante : Tout d'abord, j'ai visité 9 ruches placées en ligne et séparées les unes des autres par un espace relativement faible (un mètre à un mètre cinquante environ). Les visites étaient effectuées avec un enfumoir et consistaient dans le fait de sortir et de remettre en place les 4 cadres centraux. Après la visite de $1 \mathrm{a} 2^{\mathrm{e}}, 3^{\mathrm{e}}, 4^{\mathrm{e}}, 5^{\mathrm{e}}, 6^{\mathrm{e}}, 7^{\mathrm{e}}, 8^{\mathrm{e}}$ et $9^{\mathrm{e}}$ ruches, un leurre était présenté à l'entrée de la ruche et le temps s'écoulant entre le début de la présentation et la première attaque était noté.

Dans un deuxième essai, $j$ 'ai effectué la même opération sur 4 ruches seulement; la $2^{\mathrm{e}}$, la $4^{\mathrm{e}}$, la $6^{\mathrm{e}}$ et $1 \mathrm{a} 8^{\mathrm{e}}$. Chacun de ces essais séparés par 
trois jours d'intervalle au minimum a été répété Io fois sur une période allant d'avril à septembre.

Les moyennes des temps observés présentent des différences très significatives.

\section{TABLEAU XIII}

\begin{tabular}{|c|}
\hline $\begin{array}{c}\text { Premier essai } \\
\text { Moyenne de } 8 \text { ruches. } \\
\text { 'Temps en secondes : } 3,7-4, \mathrm{I}+3-4, \mathrm{I}-5,2-5,23,6-4,6-4,2-4,5 \\
\text { Moyenne de } 80 \text { essais. }\end{array}$ \\
\hline 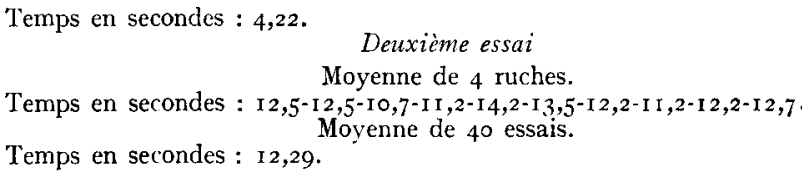 \\
\hline
\end{tabular}

Il semble que l'on puisse conclure de ces données que la visite d'une ruche voisine effectuée dans les mêmes conditions que les visites normales effectuées par un apiculteur mette déjà en alerte la colonie qui devient alors plus agressive lors de sa propre visite.

Je pense avoir ainsi mis en évidence le fait que les différences entre les colonies petuvent être fortement estompées ou accentuées par l'effet de divers facteurs purement externes.

\section{Différences individuelles d'agressivité.}

L es différences de niveau d'agressivité entre les colonies sont certaines et connues en fait depuis toujours. Cependant, à côté de cette hétérogénéité, je pense avoir découvert de très curieuses différences individuelles dont on ne soupçonnait pas l'existence. Les essais qui m'ont amené à conclure à l'existence de différences entre les ouvrières d'une même ruche ont été effectués au laboratoire dans des cagettes. Chaque ouvrière est marquée avec des points de couleur selon un code permettant la reconnaissance sûre d'un individu en mouvement rapide.

Pour éviter la possibilité d'une action perturbatrice due à l'odeur assez persistante des peintures, j'ai employé des disques de papier coloré fixés sur le thorax à l'aide d'une trace de colle cellulosique. I1 s'agit en fait du procédé généralement employé par les apiculteurs pour marquer les reines. Derrière la cagette, lors de la présentation du leurre, se trouvait un miroir destiné à me permettre l'identification des abeilles quelle que soit leur position au moment de l'attaque. Tous ces essais ont été effectués au moyen d'un leurre de laine marron (II2).

Les résultats suivants ont été obtenus sur une population totale de I27 ouvrières de race noire commune, en provenance d'une même ruche 
et réparties en 6 ruchettes. Le leurre a été présenté xo fois à chacune des cagettes pendant une période de 48 heures et le nombre total des attaques pendant ces présentations a été de I99.

\section{TABLEAU XIV}

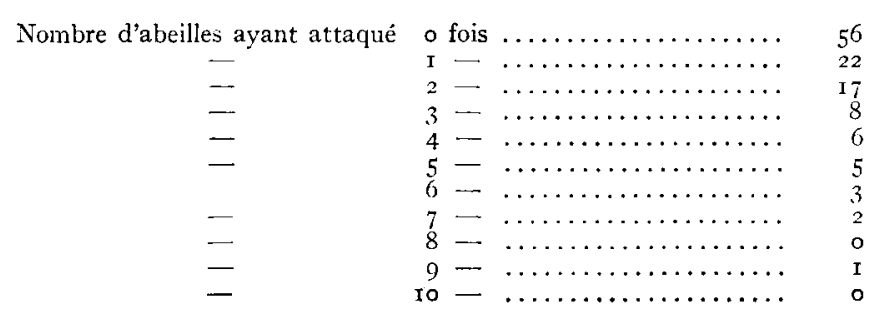

Il faut, tout d'abord, faire remarquer que cette distribution ne peut être le fait du hasard. Toutes les ouvrières ont la possibilité de voir le leurre étant donné la petite taille de la cagette d'expérience. Toutes ont également la possibilité de l'attaquer puisqu'il n'est pas rare de voir quatre ou cinq attaquantes en même temps sur le leurre et qu'il n'y avait qu'une vingtaine d'ouvrières par cagette. Enfin, des attaques d'une durée supérieure à Io secondes sont assez rares pendant la durée de la présentation qui est, rappelons-le, de soixante secondes.

I1 existe donc incontestablement une hétérogénéité. En particulier, il est frappant de constater que 56 ouvrières sur I 27 n'ont jamais attaqué soit près de $50 \mathrm{p}$. Ioo. Dans plusieurs autres essais, effectués avec des ouvrières en provenance de ruches d'un niveau agressif moyen, j'ai retrouvé cette hétérogénéité et le pourcentage des abeilles dépourvues d'agressivité est toujours voisin de 50 p. Ioo.

Ainsi, dans une autre ruche, $j$ 'ai obtenu les résultats qui suivent en étudiant une population de $5 \mathrm{I}$ ouvrières (tableau $\mathrm{XV}$ ).

Ces ouvrières furent réparties, sans anesthésie, entre deux cagettes, puis un leurre de laine marron (II2) leur fut présenté 5 fois au cours d'une période de 48 heures.

\section{TABLEAU XV}

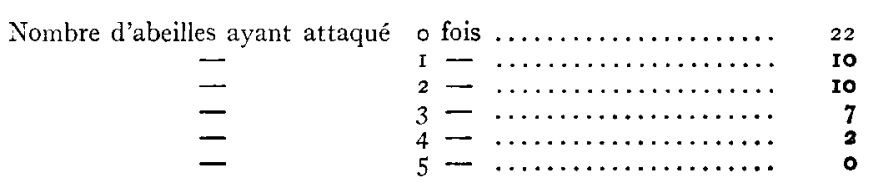

\section{Influence de l'âge.}

Cette hétérogénéité est évidemment attribuable à différentes causes. Il peut s'agir d'une caste génétique ou d'une différence liée à l'âge ou à une particularité physiologique quelconque. Dans le but de me permettre 
un choix entre ces différentes hypothèses, j'ai effectué quelques expériences avec des abeilles d'âge connu. Un rayon de couvain operculé est prélevé dans une colonie et est maintenu dans une étuve à la température de $35^{\circ}$. Dans ces conditions les naissances se produisent normalement, et les jeunes ouvrières préalablement marquées sont élevées par groupe de 20 à 30 du même âge à quelques heures près.

Il faut se garder, dans ces expériences de recourir à la narcose pour faciliter les opérations. L'anhydride carbonique peut avoir pour effet, comme l'a montré RIBBANDS (I950) d'accélérer certains processus physiologiques chez 1'abeille et d'accélérer notablement de ce fait, le vieillissement.

L'agressivité de ces abeilles est alors testée au moyen d'un leurre at par la méthode habituelle. J'ai pu constater que si une ouvrière âgée de quelques heures est capable de se déplacer dans toute la cagette et aussi de piquer un objet pressé contre elle, elle n'attaque pas, par contre, un leurre, si attractif soit-il pour une ouvrière plus âgée.

Les premières manifestations d'agressivité vis-à-vis d'un leurre et dans les conditions de l'expérience apparaissent vers le troisième ou le quatrième jour après la naissance.

Elles apparaissent d'ailleurs dans un ordre précis : d'abord l'agitation puis le fait de se diriger vers le leurre et de le suivre, enfin l'attaque. Une dizaine d'heures sont en général nécessaires pour cette " maturation ". Ensuite, les manifestations agressives apparaissent avec la même intensité que chez des ouvrières d'un âge de $I_{5}$ à 20 jours par exemple.

A l'âge de 3 à 4 jours, la méthode d'observation au moyen des marques colorées ne permet pas de mettre en évidence une hétérogénéité du comportement agressif aussi nette que celle décrite plus haut.

Néanmoins, un faible pourcentage d'une population d'abeilles de cet âge n'attaque pas un leurre. J'ai trouvé au cours de plusieurs essais que ce pourcentage était compris entre I5 à $20 \mathrm{p}$. Ioo. Voici, par exemple, les résultats obtenus en étudiant le comportement d'une population de 20 jeunes ouvrières. Ces ouvrières âgées de trois jours furent soumises à Io présentations d'un leurre de laine marron (II2).

Les résultats suivants furent obtenus :

\section{TABLEAU XVI}

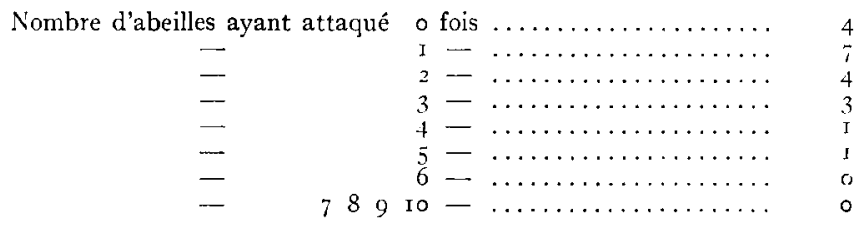


Une comparaison avec les tableaux XIV et XV exposant les résultats obtenus avec des abeilles prises au hasard dans la ruche montre clairement la différence dans la répartition des résultats.

Que se passe-t-il dans une population composée de deux groupes d'abeilles d'âge différent? Pour répondre à cette question, j'ai étudié une cagette contenant I5 abeilles âgées de 5 jours et I5 abeilles âgées de Io jours.

J'ai constaté après de nombreuses présentations d'un leurre que, seules les abeilles les plus âgées (préalablement marquées) attaquaient. Aucune abeille jeune ne semble intéressée par le leurre alors que ces mêmes abeilles séparées des ouvrières plus âgées sont capables d'attaquer ce même leurre.

Pour que le phénomène soit aussi grossièrement évident, il faut que la différence d'âge soit au moins de 5 jours. Un résultat similaire est obtenu avec une population composée d'abeilles âgées respectivement de 20 et 15 jours. Cependant, dans ce dernier cas, il peut y avoir des attaques de la part des ouvrières les plus jeunes. Ces attaques sont toujours très faibles et ne représentent que $5 \mathrm{p}$. Ioo environ des attaques totales de l'ensemble de la population contenue dans la cagette. Avec 20 jours nous atteignons l'extrême limite des possibilités de maintien des abeilles en cagettes. Au-delà de cette limite, la mortalité est très grande et surtout le comportement des individus survivants est altéré de telle manière que les essais n'ont plus aucun sens. D'autre part, j'ai réalisé l'expérience suivante : J'ai retiré de plusieurs cagettes contenant des abeilles prélevées sur des rayons et d'âge inconnu, les ouvrières ayant attaqué plus de trois fois au cours de cinq présentations. Plusieurs attaques au cours d'une même présentation étaient toujours comptées comme une seule.

Ces ouvrières très agressives sont groupées dans un seule cagette et j'ai pu alors constater que le nombre des ouvrières n'attaquant jamais ne représentait plus que io p. Ioo de l'effectif au lieu des $50 \mathrm{p}$. Ioo habituels.

Cette augmentation apparente de l'agressivité correspond d'ailleurs, en fait, à une baisse réelle puisque j'ai peuplé cette cagette d'une population agressive à Ioo p. Ioo.

D'autre part, dans les cagettes d'où l'on a retiré les abeilles les plus agressives, on observe que les abeilles peu agressives dans les premiers tests, le deviennent par la suite.

L'on peut ainsi constituer une population composée de 20 ouvrières choisies parmi celles qui n'ont jamais attaqué le leurre au cours de cinq présentations.

Dans l'exemple choisi, dès la première présentation d'un leurre à cette population artificielle d'abeilles non agressives, deux attaques provenant de deux ouvrières furent constatées.

Par la suite, l'ampleur des phénomènes agressifs s'est accru régulière- 
ment et $4^{8}$ heures après il était possible de retrouver le pourcentage habituel d'abeilles agressives, c'est-à-dire aux environs de 50 p. Ioo.

Le fait que les différences individuelles d'agressivité soient, au moins en grande partie, sous la dépendance de 1'âge, est mis également en évidence par le comportement d'abeilles en provenance de ruches en fin d'hivernage, avant que l'élevage n'ait recommencé. La population de ces ruches est composée en totalité d'ouvrières très âgées, un test effectué avec la technique ordinaire sur des abeilles marquées individuellement donne les résultats suivants.

Une population totale de 47 ouvrières, prélevées dans une ruche au début du mois de février a été répartie entre deux cagettes. J'ai procédé à ro présentations d'un leurre marron (II2).

\section{TABLeau XVII}

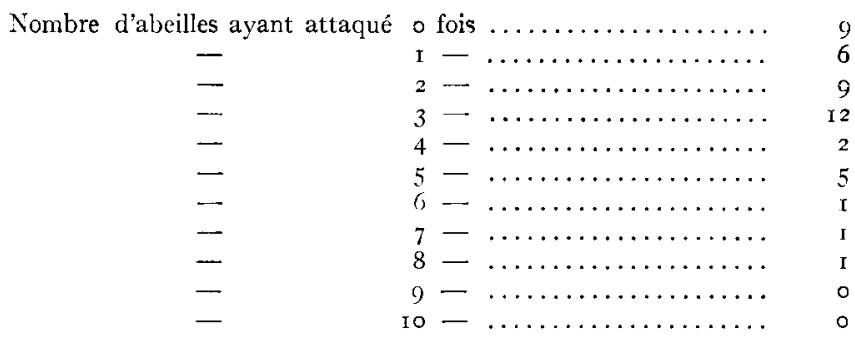

Une comparaison avec les tableaux XIV et XV donnant les résultats obtenus avec des abeilles d'été, est particulièrement significative. L'on s'aperçoit que dans le cas des abeilles d'hiver, comme dans celui d'une population homogène en ce qui concerne l'âge, le nombre des ouvrières n'attaquant pas, est d'environ $20 \mathrm{p}$. Ioo, tandis qu'il est, rappelons-le, toujours voisin de 50 p. Ioo dans le cas des abeilles d'été.

D'autre part, des essais effectués avec des ouvrières en provenance de ruches chauffées artificiellement durant 1'hiver, possédant du couvain et une population d'âge hétérogène, donnent des résultats très voisins de ceux obtenus avec des abeilles d'été. Le pourcentage des ouvrières dépourvues d'agressivité est encore une fois d'environ $50 \mathrm{p}$. Ioo. Le rôle de l'âge est ainsi, à mon sens, clairement mis en évidence, il reste cependant à expliquer pourquoi dans une population d'âge homogène, Io à $20 \mathrm{p}$. Ioo d'ouvrières restent passives. J'ai observé ces abeilles pendant un très grand nombre de présentations du leurre : elles restent le plus souvent sur le fond ou les côtés de la cagette, elles sont souvent occupées à se nourrir et montrent bien moins d'activité que les autres. Le leurre les laisse parfaitement indifférentes, elles peuvent passer tout près de lui sans qu'aucun changement de comportement soit manifesté. Dans cer- 
tains cas, cependant, l'on peut voir des débuts de comportements agressifs, mais ils ne vont jamais jusqu'à un contact avec le leurre.

\section{Agressivité et développement ovarien.}

Peut-être, n'est-il pas impossible de rapporter cette dernière hétérogénéité au développement ovarien des ouvrières?

L'on sait que des ouvrières peuvent présenter de grosses inégalités de développement ovarien. En particulier, dans une ruche dite " orpheline ", c'est-à-dire privée de reine, il existe un assez grand pourcentage d'ouvrières aux ovaires fonctionnels. Même dans une ruche normale des inégalités de développement peuvent être constatées (PaIN et VERGর́, I950).

En étudiant des ruchettes peuplées de 200 ouvrières de même âge et privées de reine, Sakagami (I954) a mis en évidence qu'il existait une relation entre le développement ovarien et certains comportements agressifs entre ouvrières de la même colonie.

Il s'agirait là d'un phénomène bien particulier inexistant dans une colonie normale; les descriptions de SAKAGAMI semblent en fait se rapporter aux premières phases d'un comportement d'agressivité très voisines de celles que j'ai décrites en étudiant les rencontres entre abeilles étrangères, mais observées cette fois entre des ouvrières sœurs.

Ce comportement apparaît en même temps que la ponte des ouvrières dans les ruchettes sans reine. Cependant, les résultats des dissections ne permettent pas d'affirmer que le développement ovarien marche de pair avec 1'accroissement de 1'agressivité et il est possible que ce développement agisse par un autre mécanisme en facilitant le déclenchement de l'agressivité des congénères vis-à-vis de l'individu aux ovaires développés. Il faut aussi citer HAMMAN (I957) pour qui l'agressivité des ouvrières vis-à-vis d'une reine nouvellement introduite est liée au développement de l'ovaire. J'ai voulu vérifier si ce facteur était en relation d'une manière ou d'une autre avec l'agressivité vis-à-vis des leurres.

Dans un premier essai, il s'agissait d'ouvrières ell provenance d'une ruche normale en pleine activité. Les abeilles furent capturées sur les rayons, individuellement marquées sans anesthésie, et déposées dans une cagette. Un leurre de laine marron (II2) leur fut présenté 5 fois et ensuite après dissection leur développement ovarien fut évalué selon la technique de MAurizio (I954). Cette technique consiste à accorder un indice de développement variant entre $I$ et 5 . $L$ indice I correspondant à l'absence de développement et l'indice 5 à la présence d'œufs prêts à être pondus. 
Les résultats suivants ont été obtenus :

TABLEAU XVIII

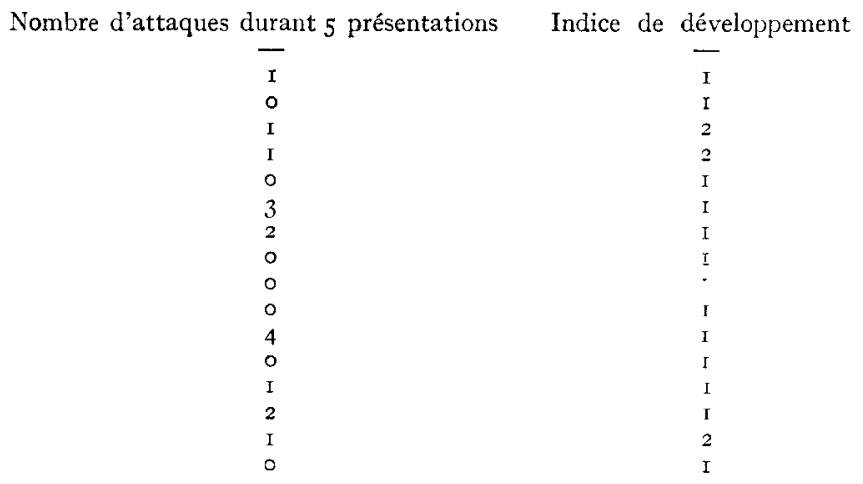

Il n'existe donc dans cet exemple aucune corrélation entre l'agressivité et les très faibles indices de développement ovarien constatés. En est-il de même si le développement des ovaires est plus avancé? Pour répondre à cette question, j'ai effectué une recherche identique en utilisant des ouvrières provenant d'une ruche orpheline, c'est-à-dire privée de reine, depuis trois semaines.

Le tableau suivant donne les résultats obtenus :

\section{TABLEAU XIX}

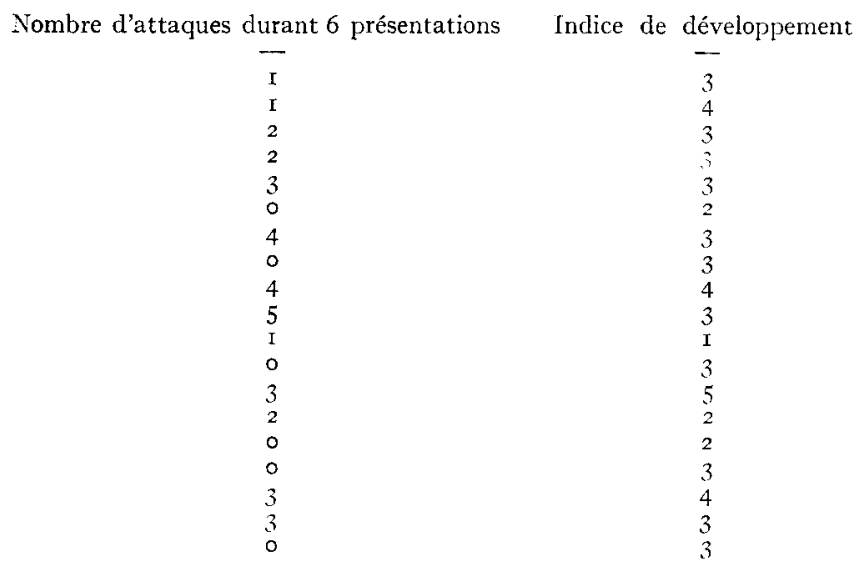

La comparaison de la moyenne des indices de développement des ouvrières n'ayant pas attaqué : 2,28 avec celle de l'ensemble des ouvrières ayant attaqué : 3,I5 et avec celle des ouvrières ayant attaqué trois fois et plus : 3,57 indique clairement une liaison entre l'importance du développement ovarien et l'agressivité vis-à-vis des leurres. 
Dans le cas de la ruche normale précédemment étudiée, la moyenne de l'ensemble des ouvrières était de $\mathrm{r}, 33$, indice de développement trop faible pour influencer les comportements agressifs. Le rôle du développement ovarien dans des conditions normales ne semble donc pas toujours évident, tandis que dans une ruche orpheline, ce facteur peut être incriminé.

L'âge est bien le facteur décisif dans les conditions normales et l'on sait (HUSING et ULRICH, I938) qu'il n'y a aucune corrélation entre l'âge d'une ouvrière et l'état de ses ovaires.

En ce qui concerne 1'hétérogénéité constatée entre les ouvrières de même âge, elle ne peut être rapportée à l'état de développement ovarien. En effet, les pourcentages d'abeilles dépourvues d'agressivité sont les mêmes dans les ruches d'hiver pourvues de reines et dans les cagettes expérimentales contenant une population d'ouvrières élevées sans reine. Mais, dans le cas des ruches orphelines, est-il exact que le développement de l'ovaire soit le facteur élevant le niveau de l'agressivité des ouvrières pondeuses vis-à-vis de leurs congénères, des leurres et d'une reine introduite dans la ruche? I1 semble bien qu'il n'en soit rien. Une très intéressante observation d'HAmmaN (I957) me semble importante à cet égard : cet auteur a, rappelons-le mis en évidence une corrélation entre l'état de développement des ovaires des ouvrières d'une colonie orpheline et leur agressivité envers une reine nouvellement introduite. Mais, si la colonie orpheline est carencée en pollen, les ovaires des ouvrières ne se développent pas et pourtant l'agressivité vis-à-vis des reines s'accroît avec le temps.

Agressivité et développement ovarien, si l'on admet les conclusions d'Hamman, seraient donc sous la dépendance d'un même facteur sur la nature duquel nous n'avons aucun renseignement.

Ce facteur aurait une influence sur 1'ensemble de l'agressivité et spécialement sur une forme particulière d'agressivité dirigée vers les membres de la même communauté. En ce qui concerne cette dernière forme, les deux alternatives proposées par SAKAGAMI seraient exactes. Le développement ovarien augmenterait 1'agressivité des individus et aussi leur faculté de déclencher l'agressivité des autres.

A la limite, la reine serait l'objet capable de déclencher le plus d'attaques et son agressivité devrait être intense. Or, il est exact qu'une reine déclenche facilement l'attaque des ouvrières et ceci d'autant plus que les ovaires de ces dernières sont développés ou du moins que le facteur qui régit ce développement est lui-même plus actif. Mais, il n'est pas exact que la reine soit très agressive. Son agressivité est uniquement dirigée vers d'autres reines. Jamais il n'est possible de voir une reine, vierge ou fécondée, jeune ou âgée, seule ou entourée de sa cour, s’intéresser le moins du monde à un leurre. Il est même exceptionnel de se faire 
piquer en manipulant tue reine. Il semble donc possible de conclure en formulant l'hypothèse que le développement ovarien est parallèle à un développement de l'agressivité générale au début et qu'ensuite cette agressivité se restreint et n'est plus dirigée que vers les porteurs d'ovaires développés, le comportement agressif de la reine constituant un cas limite.

La question du développement ovarien et de ses relations avec l'agressivité nous a amené à constater que dans certains cas les abeilles attaquent des habitants de leur propre ruche. Ces cas sont en fait assez rares ; j'ai déjà signalé que cela se produisait dans des cagettes dont les habitantes sont stimulées par des courants à haute fréquence. LEPPIK (I950) et Schick (I953) ont observé l'agressivité des ouvrières vis-à-vis de cohabitantes intoxiquées par des insecticides et j'ai pu également observer ce phénomène à plusieurs reprises. L'agressivité vis-à-vis d'individus malades est également un fait d'observation courant.

SaKagami (I95I) a observé dans des ruchettes un comportement d'interprétation difficile : une ouvrière attrape avec les pattes de devant une de ses congénères et se met à cheval sur son dos ou sur son côté, elle semble alors tapoter avec ses mandibules différentes parties du corps. BEECKEN (I934) qui avait déjà fait cette observation, pense qu'il s'agit d'un nettoyage par les jeunes abeilles, d'abeilles butineuses recouvertes de poussière de pollen. Cette interprétation est discutable d'autant plus que SAKAGAMr a montré par l'observation d'ouvrières marquées que les abeilles actives, de même que les passives, observées dans ce comportement, sont dans la plupart des cas des abeilles jeunes, n'ayant pas encore effectué leur premier vol. Il serait donc possible qu'il s'agisse des premiers éléments d'un comportement agressif réel. Par ailleurs, SAKAGanr (I95I) a observé un véritable combat et une mise à mort entre ouvrières d'une même colonie sans raisons apparentes. L'agressivité entre cohabitantes pourrait donc n'être pas absolument inexistante et certaines circonstances permettent son apparition à des niveaux plus ou moins élevés.

\section{Agressivité vis-à-vis des mâles.}

Une autre catégorie d'habitants de la ruche peut être également l'objet d'attaques, il s'agit des mâles. Le massacre des mâles par les ouvrières de la ruche est bien connu mais son déterminisme l'est beaucoup moins.

Dans les conditions naturelles, il survient à la fin d'une miellée, à 1a fin de l'été selon les conceptions classiques. J'ai cependant pu observer l'expulsion des mâles d'une colonie au mois de juillet, en période de miellée, par beau temps précédant immédiatement une perturbation orageuse. Dans les cagettes, les mâles sont généralement bien acceptés, qu'ils proviennent ou non de la même ruche que les ouvrières, durant les 
périodes de grande miellée. Au contraire, en fin de saison apicole, ils sont molestés et mis à mort par des abeilles qui possèdent pourtant de la nourriture en abondance. Signalons que certains mâles échappent dans les conditions naturelles au massacre et hivernent dans la ruche (KALNITZKI, I949).

Selon Sakagami (I95I) l'attitude des butineuses vis-à-vis des faux bourdons ne change pas d'une manière abrupte. Le comportement des butineuses passe insensiblement de la plus grande tolérance à l'expulsion de la ruche, en passant par différents stades semblables à ceux que j'ai décrits en étudiant l'agressivité entre ouvrières étrangères. Cette modification dans le cas étudié par SAKAGAMr s'est étalée sur plusieurs jours.

En fait, le déterminisme précis du massacre des faux-bourdons n'est pas connu et nécessiterait une longue étude.

\section{Facteurs physiologiques et facteurs liés à la vie sociale.}

Ia présence d'une agressivité manifeste est liée chez l'abeille à une certaine intégrité physiologique. Dans les expériences effectuées en cagette, il est facile de se rendre compte qu'une nourriture distribuée avec parcimonie diminue considérablement l'activité et de ce fait 1'agressivité. Ceci n'est nullement étonnant puisque l'on sait que quand son taux de sucre sanguin tombe en dessous de I p. roo l'abeille n'est plus capable de voler (BEUTLER, I936).

De même, un séjour prolongé en cagette entraîne tune diminution de 1'agressivité et dans les cas les plus favorables, il n'est guère possible d'espérer un comportement normal à cet égard, d'ouvrières claustrées depuis plus de 20 jours.

Un fait particulièrement important quand il s'agit des essais effectués en cagette doit être souligné. Il arrive fréquemment que les ouvrières s'agglomèrent en grappe soit sur la nourriture, soit en tout autre endroit à l'intérieur des cagettes d'expérience. Les abeilles ainsi réunies ont toujours un niveau agressif très bas, soit vis-à-vis d'un leurre, soit vis-à-vis d'une abeille étrangère. Pour cette raison, il est bon, avant d'effectuer une observation, de souffler légèrement dans la cagette afin de disperser la grappe s'il y en a une et d'égaliser les conditions de l'expérience s'il n'y en a pas. Il est cependant possible de constater, si on laisse la grappe en place, qu'un petit nombre d'abeilles est susceptible de la quitter et d'attaquer le leurre d'une manière normale au point de vue intensité et durée. Les chiffres donnés ci-dessous sont les moyennes du nombre d'abeilles attaquant lors de chaque essai au cours d'une série de 20 essais effectués sur deux cagettes peuplées chacune de 25 ouvrières en provenance de la même ruche. Au cours de cette série, les abeilles étaient formées en grappe à six reprises et dispersées dans les quatorze autres cas. 


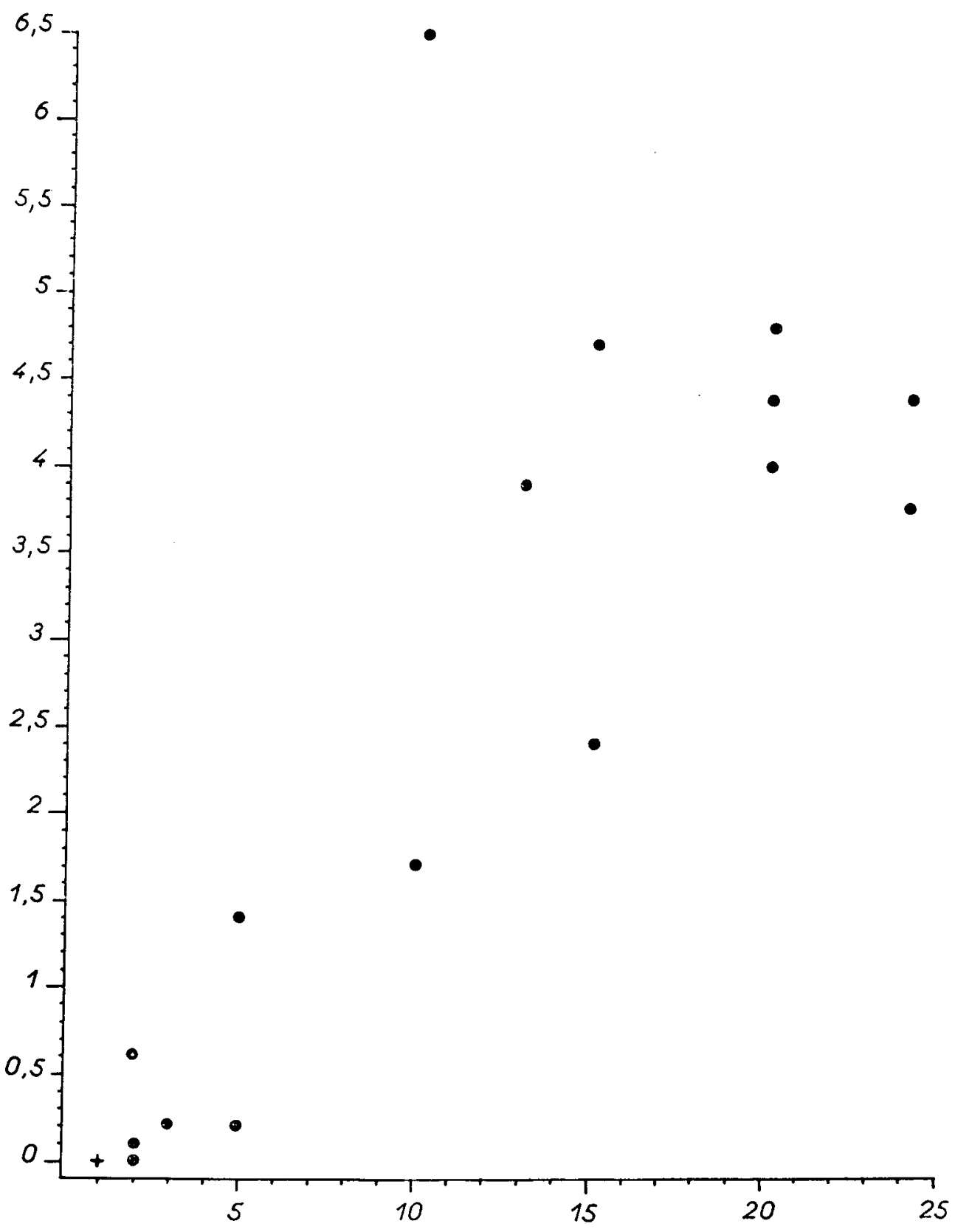

FIG. 0. - En abscisse : nombre d'abeilles présentes dans la cagette. En ordonnée : nombre d'attaques par ouvrière, le signe + représente to points.

Abeilles en grappe : 2,33. Abeilles dispersées : 7,28.

Il est sans doute permis de rapprocher cette passivité de l'abeille lorsqu'elle participe à la formation d'une de ces petites grappes de celle 
que 1'on observe lors de l'essaimage. Dans ce cas, il est constant d'observer que l'essaim accroché en grappe est très peu agressif. Cette particularité est bien connue des apiculteurs qui en profitent pour manipuler les ouvrières avec des risques de piqûres très diminués.

\section{Influence du nombre d'abeilles présentes.}

L'abeille étant un animal social, un grand nombre de ses activités n'apparaissent qu'au sein d'un groupe suffisamment nombreux. L'on retrouve dans un grand nombre de cas, dont Chauvin (I954) a fait la revue, cette notion de nombre limite. De fait, moins de 5 abeilles n'attaquent qu'excessivement rarement en cagette, même s'il s'agit d'un leurre généralement très efficace. Le nombre des attaques croît en fonction du nombre d'abeilles présentes jusqu'à un palier qui est atteint vers 20 à 30 abeilles, voir figure 9 .

Dans la nature, nous avons vu que les manifestations agressives de l'abeille isolée ne dépassent pas le stade du " vol d'intimidation ». Une analyse minutieuse du comportement vis-à-vis d'un leurre, des ouvrières en cagette, permet d'observer, chez une abeille isolée, les premières séquences de 1'agressivité.

L'abeille dans un grand nombre de cas, se dirige vers le leurre; arrivée à son contact, elle repart dans une autre direction et puis recommence son approche. Ce manège peut durer plus d'une minute.

En ce qui concerne les rencontres entre abeilles isolées, étudiées dans $d \in s$ cagettes, $j$ 'ai pu constater que les différences de comportement selon qu'il s'agissait d'individus étrangers ou non, étaient assez faibles. Dans le cas d'une rencontre entre individus étrangers, tout au plus observe-t-on un léger " houspillage ». Il m'a cependant été possible d'observer une fois un combat suivi de mort, mais ce combat était dû à une cause accidentelle. Deux abeilles accrochèrent leurs pattes durant la phase de reconnaissance et ne pouvant les dégager, se servirent de leurs aiguillons.

L'agressivité est donc avant tout un phénomène social : cette donnée ressortait déjà de l'étude des variations de l'agressivité en fonction du lieu où se trouve l'abeille considérée et le rôle du nombre limite renforce singulièrement cette assertion. Pour reprendre l'expression de Grassé et Noirot (I95I) : "La stimulation sociale (autre aspect de l'effet de groupe) n'a pas fini de nous surprendre par ses influences sur la conduite et la physiologie des individus. ") 
CHAPITRE, IV

\section{ANALYSE DES GRANDES CARACTÉRISTIQUES DU COMPORTEMENT AGRESSIF}

\section{Les Séquences.}

L'on sait depuis longtemps qu'un comportement peut se laisser diviser en un certain nombre d'éléments, à la fois isolés et liés entre eux comme les maillons d'une chaîne, auxquels l'on donne le nom de séquence.

En ce qui concerne le comportement agressif de l'ouvrière d'Apis mellifica $\mathrm{I}_{4}$. il semble qu'il y ait au moins quatre séquences à distinguer.

La première, se traduit sur le plan du comportement par une agitation. Il s'agit d'une activité non dirigée, elle est produite par certains stimuli telle l'odeur du venin, des vibrations ou comme l'ont mis en évidence BUTLER et FREE (I952), par la présence d'abeilles étrangères entrées en grand nombre à l'intérieur de la ruche. J'ai appelé cette première séquence agressivité diffuse.

Une deuxième séquence serait constituée par l'approche. L'abeille suit des yeux le mouvement pendulaire du leurre ou l'abeille étrangère et se dirige rapidement dans cette direction en marchant ou en volant. Cette approche que j’ai appelée agressivité dirigée, serait sous la dépendance d'autres facteurs tels que la leucie, la forme et le mouvement dans le cas oì il s'agit d'un leurre.

Des abeilles appartenant à la même colonie peuvent très bien déclencher ces séquences en dehors des exceptions déjà signalées, puisqu'il n’est pas rare de voir des gardiennes appréhender des butineuses rentrant à la ruche.

Ceci nous amène à la troisième séquence qui en fait, correspond à la reconnaissance et consiste surtout en un examen antennaire.

Cette troisième séquence échappe à l'analyse effectuée au moyen de leurres. En effet, elle n'existe pour ainsi dire pas lors de l'attaque de ces objets et ne s'observe que dans l'agressivité entre ouvrières. Les facteurs qui rentrent ici en jeu sont certainement très complexes. L'accent a été mis sur les différences d'odeur entre colonies (RIBBANDS, I954) et sur des différences de comportement entre ouvrières (BUTLER et FREE, I952). 
Cette question ne peut être traitée légèrement et nécessite un chapitre particulier que 1'on trouvera par la suite.

La quatrième séquence est le combat proprement dit auquel j'ai réservé le terme d'agressivité effective. Elle est, en ce qui concerne les leurres, sous la dépendance d'autres stimuli, tels que la structure physique ou le volume. Les différents facteurs que j'ai passés en revue n'intéressent pas toujours les mêmes séquences; ainsi l'effet inhibiteur du " nombre limite " que j'ai signalé plus haut, ne semble s'exercer que sur les dernières.

Il est de même remarquable que les différentes séquences n'apparaissent pas en même temps lors du développement individuel. Si l'on suit de près l'évolution du comportement d'une abeille marquée, depuis le jour de sa naissance au sein d'une population d'âge homogène, l'on voit apparaitre successivement les quatre séquences, la première pouvant se manifester plusieurs heures avant la dernière.

Il faut ici rappeler que la division de certains comportements en séquences placés sous la dépendance de stimuli bien séparés est chose bien connue. Ainsi BAERENDS (I950), a mis en évidence que les différentes séquences du comportement de chasse de Notonecta glauca sont évoquées par différents stimuli : l'approche par des stimuli vibratoires, le saut sur la proie par des stimuli optiques et la piquire par des stimuli tactiles.

De même, pour s'en tenir aux insectes, chez Philantus triangulum d'après TINBERGEN (I932), la réaction de chasse est évoquée par tout objet mobile de la taille d'une abeille, il n'attaque cependant cet objet que s'il a l'odeur d'une abeille et enfin la piqûre elle-même n'est déclenchée que par d'autres stınıuli qui seraient cette fois de nature tactile.

\section{Suppléance des stimuli et hiérarchie des leurres.}

Dans le chapitre qui traite des facteurs olfactifs, j'ai déjà signalé le fait que des stimuli d'origines diverses voyaient leur action s'ajouter et même se multiplier si l'on considère l'intensité globale d'un comportement agressif.

Il est évidemment assez difficile d'étudier sous cet angle les facteurs internes ou ceux dont le contrôle nous échappe. Par contre, les caractères propres aux leurres peuvent dans une large mesure être expérimentalement modifiés et permettent de mettre de tels phénomènes en évidence. A part le cas, déjà exposé, de la superposition de l'effet de la leucie et de l'odeur de venin, j'ai étudié les suppléances qui peuvent exister entre la leucie et la vitesse d'agitation du leurre.

Lors de la présentation simultanée, à l'intérieur d'une cagette d'un leurre blanc et d'un leurre marron (II2) il est constant d'observer un nombre bien plus élevé d'attaques dirigées vers le leurre marron. Mais, 
si au moyen d'un artifice, l'on agite le leurre blanc environ deux fois plus rapidement que le leurre marron, il est possible de constater que les deux leurres sont attaqués de manière sensiblement égale. Ia règle de la pluralité des stimuli (Grassé, I942) semble donc vérifiée en ce qui concerne le déterminisme du comportement qui nous occupe.

Un autre fait caractéristique est celui de la hiérarchie des leurres. Un leurre donné est attaqué plus ou moins, non seulement en fonction de ses propres caractéristiques, mais aussi en fonction d'un ensemble de facteurs très complexes. En dehors de ces variables, il faut signaler que l'étalement des résultats peut être très différent suivant les colonies envisagées.

Ainsi, dans un essai portant sur six colonies, $j$ 'ai obtenu les résultats suivants. Il s'agit de la comparaison de la moyenne des attaques lors de vingt essais portant chacun sur 2 cagettes de 25 ouvrières de chaque colonie. Dix essais ont été effectués avec un leurre blanc et dix avec un leurre marron. Les essais étaient effectués toutes les 30 minutes.

TABLEAU XX

\begin{tabular}{|c|c|c|c|c|c|c|}
\hline & \multicolumn{6}{|c|}{ Nombre moyen d'attaques - Notation A } \\
\hline & Ruche I & Ruche II & Ruche III & Ruche IV & Ruche V & Ruche VI \\
\hline $\begin{array}{l}\text { Leurre blanc } \ldots \ldots \ldots \ldots \\
\text { Leurre marron }(\operatorname{II} 2) \ldots \ldots\end{array}$ & $\begin{array}{l}\circ \\
7\end{array}$ & $\begin{array}{l}\text { I } 2 \\
23\end{array}$ & $\begin{array}{l}2 \mathrm{I} \\
45\end{array}$ & $\begin{array}{r}\text { I } \\
39\end{array}$ & $\begin{array}{l}\text { I } \\
9\end{array}$ & $\begin{array}{l}\text { I I } \\
26\end{array}$ \\
\hline
\end{tabular}

Les ruches I et V sont faiblement agressives, les ruches II et VI sont des ruches à agressivité moyenne, la ruche III est très agressive. La ruche IV enfin, est une ruche dont l'agressivité est très "spécialicée ".

Ce dernier type d'agressivité se rencontre d'ailleurs assez fréquemment sans que l'on puisse dire qu'il constitue une caractéristique de la colonie. D'un jour à l'autre, il est possible d'observer des variations considérables. Quoi qu'il en soit, la hiérarchie des leurres est toujours respectée et bi $\mathbf{n}$ qu'ayant expérimenté sur plus de cent colonies de races et d'agressivité diverses, je n'ai jamais trouvé une colonie attaquant plus le leurre blanc que le leurre marron lors d'une présentation simultanée ou lors de plusieurs présentations alternées effectuées dans l'espace de quelques heures.

\section{Effets de la prolongation et de la répétition d'un stimulus.}

Si l'on agite un leurre efficace pendant très longtemps, les réactions agressives diminuent en quantité et en qualité.

Le tableau suivant donne les résultats de deux essais effectués avec un leurre de laine marron (II2) du type habituel. I,es cagettes étaient 
peuplées de 25 ouvrières de race noire commune en provenance de deux ruches.

\section{TABLEAU XXI}

\begin{tabular}{|c|c|c|}
\hline Temps & $I^{\text {re }}$ Ruche & ${ }_{2}^{\mathbf{e}}$ ruche \\
\hline $\mathrm{I}^{\mathrm{re}}$ minute. & 80 attaques & 95 attaques \\
\hline $55^{\mathrm{e}}$ minute $\ldots \ldots \ldots \ldots \ldots \ldots \ldots \ldots$ & $64-$ & $44 \quad-$ \\
\hline ro minute $\ldots \ldots \ldots \ldots \ldots \ldots \ldots \ldots$ & 42 & - \\
\hline $15^{\circ}$ minute $\ldots \ldots \ldots \ldots \ldots \ldots \ldots$ & 24 & - \\
\hline$z^{\mathrm{e}}$ minute $\ldots \ldots \ldots \ldots \ldots \ldots \ldots$ & -- & - \\
\hline $25^{\mathrm{e}}$ minute $\ldots \ldots \ldots \ldots \ldots \ldots \ldots \ldots$ & - & - \\
\hline $\mathrm{j}^{\mathrm{e}}$ minute $\ldots \ldots \ldots \ldots \ldots \ldots \ldots \ldots$ & - & - \\
\hline $35^{\mathrm{e}}$ minute $\ldots \ldots \ldots \ldots \ldots \ldots \ldots \ldots \ldots$ & - & - \\
\hline $0^{\mathrm{e}}$ minute $\ldots \ldots \ldots \ldots \ldots \ldots \ldots \ldots \ldots$ & - & - \\
\hline$+5^{\mathrm{e}}$ minute $\ldots \ldots \ldots \ldots \ldots \ldots$ & - & - \\
\hline $55^{\circ}$ minute. & - & \\
\hline $60^{\mathrm{e}}$ minute $\ldots$ & - & \\
\hline $65^{\mathrm{e}}$ minute $\ldots \ldots \ldots \ldots$ & - & \\
\hline
\end{tabular}

L'on voit que dans le premier cas le leurre est devenu parfaitement inefficace au bout de 55 minutes et dans le deuxième au bout d'une demiheure. Cette inefficacité semble d'ailleurs, du moins dans les limites de mon expérience, être irréversible. L'on peut obtenir un effet analogue non plus en prolongeant la présentation d'un leurre mais en prolongeant l'action de l'un des facteurs externes que nous avons vu susceptible de jouer un rôle dans l'élévation du niveau de l'agressivité. Jarvis (I950) a montré qu'une colonie s'habituait rapidement à une perturbation continuelle. Dans son expérience, un poids d'une centaine de grammes tombait d'une hauteur d'un mètre, toutes les dix minutes sur le plancher de bois où était posée la ruche et à peu de distance de celle-ci. La perturbation était mesurée par l'enrsgistrement du volume de l'ensemble des sons émis par la ruche aussitôt après le choc expérimental. Dans ces conditions, JARVIs a pu noter que la perturbation s'affaiblissait régulièrement et qu'au bout de 7 jours il n'était plus possible d'en distinguer aucune trace.

J'ai effectué des expériences similaires en laisiant tomber toutes les 4 secondes un poids de 20 grammes d'une hauteur de ro centimètres directement sur le plateau couvre-cadre d'une ruche. L'effet perturbateur est tout d'abord énorme, les abeilles sont très agitées et des ruches ne possédant auparavant aucune agressivité au trou de vol deviennent très agressives. Au bout de peu de temps, de deux heures à vingt-quatre heures, suivant les cas, la situation redevient exactement ce qu'elle était avant le commencement de l'expérience. De même, j'ai pu observer 1'agressivité d'abeilles soumises à un courant d'air continut. Il s'agissait d'un essaim ayant construit des rayons de cire à l'air libre, mais à l'intérieur d'une serre. L'agressivité initiale était relativement très faible, cє qui est très normal, l'agressivité étant très souvent réduite au minimum dans une 


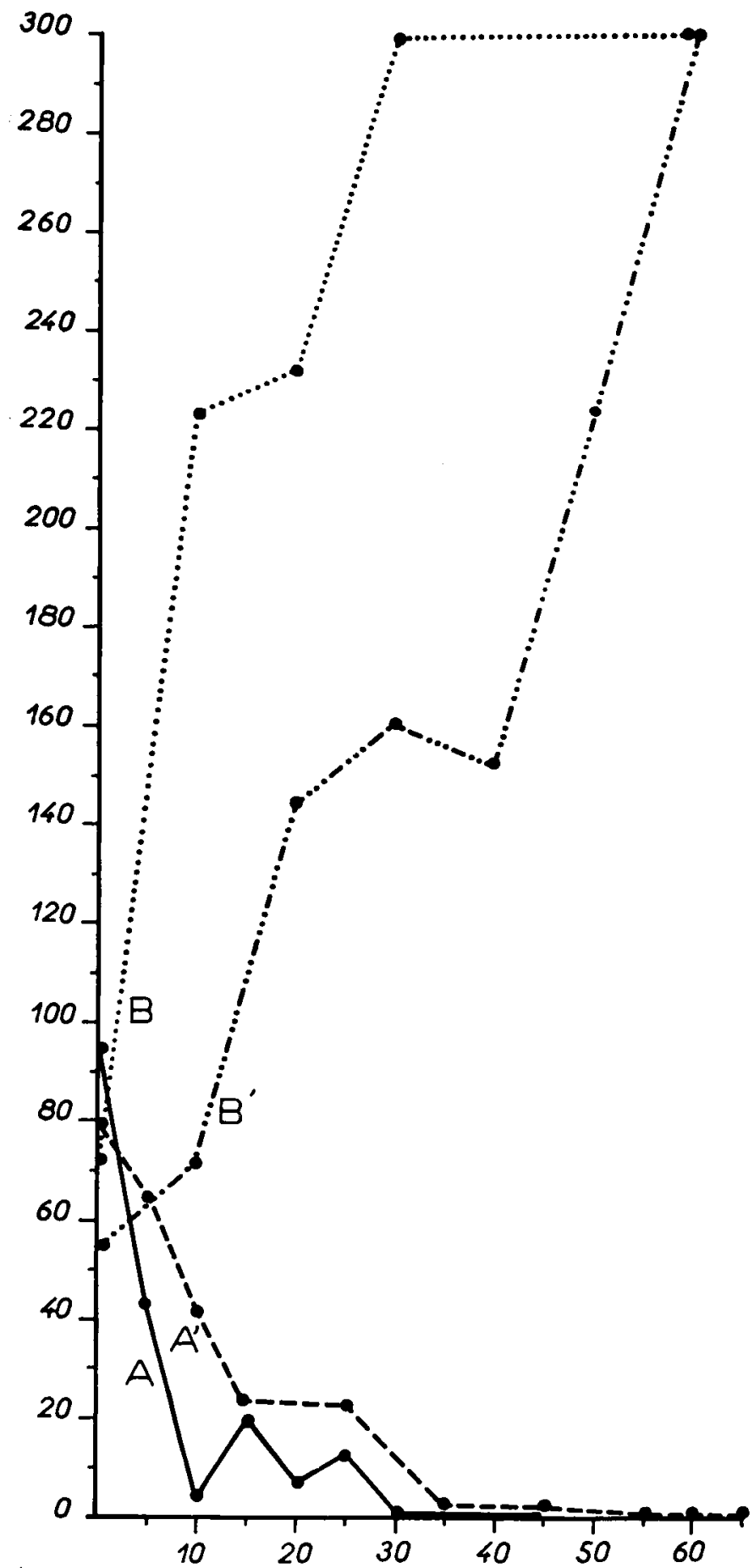

FIG. Io. - Évolution de l'agressivité au cours de la présentation continue et discontinue d'un leurre En ordonnée : nombre d'attaques pendant une minute.

En abscisse : échelle des temps en minutes.

$A$ et $A^{\prime}$ : exemples de présentations continues.

$B$ et $B^{\prime}$ : exemple d'une présentation d'une minute toutes les dix minutes. 
serre sans que les différentes explications que l'on en propose, puissent être confirmées par une série d'expériences décisives.

L'essaim fut alors soumis à l'action d'un courant d'air d'une vitesse de Io $\mathrm{km} / \mathrm{h}$ environ. L'agressivité vis-à-vis d'un leurre agité à une dizaine de centimètres des abeilles augmente notablement mais ici encore, après quelques heures, il n'est plus possible d'observer une quelconque différence avec l'état antérieur.

Cependant, si le stimulus efficace survient d'une manière discontinue, et qu'il existe un intervalle suffisant entre les différentes apparitions de ce stimulus, le niveau d'agressivité augmente beaucoup, au moins pendant un certain temps. Par exemple, un leurre de laine marron présenté pendant une minute toutes les dix minutes entraîne une augmentation considérable du nombre des attaques.

Dans le tableau ci-dessous, l'on trouvera les résultats d'un essai effectué sur deux cagettes. Notation B.

TABLEAU XXII

\begin{tabular}{|c|c|c|}
\hline & Cagette $B^{\prime}$ & Cagette $B$ \\
\hline I $^{\text {re }}$ présentation..... & 54 & 72 \\
\hline $2^{\mathrm{e}}$ présentation..... & $7 \mathrm{I}$ & 223 \\
\hline $3^{\text {e }}$ présentation..... & 144 & $23 I$ \\
\hline $4^{\mathrm{e}}$ présentation..... & 160 & + de 300 \\
\hline $5^{\mathrm{e}}$ présentation..... & $15^{2}$ & + de 300 \\
\hline $6^{e}$ présentation...... & 224 & I de joo \\
\hline $7^{\text {e }}$ présentation...... & + de 300 & + de 300 \\
\hline
\end{tabular}

Sur la figure Io, l'on trouvera une représentation graphique de l'évolution des comportements dans les deux cas envisagés : présentation continue de longue durée et présentation discontinue à intervalle de dix minutes.

La figure II donne l'allure du phénomène observable quand l'intervalle entre deux présentations est réduit à trois minutes. Dans ce dernier cas, l'on n'observe plus ni la disparition progressive des attaques, ni l'augmentation constante de leur nombre, mais une série de variations considérables du niveau d'agressivité.

Les différences entre les trois types de courbes que l'on peut voir sur les figures Io et II sont très frappantes et appellent quelques réflexions. Les courbes $A$ et $A^{\prime}$ sont la représentation graphique des variations du comportement agressif lors d'une présentation continue. I1 s'agit indiscutablement ici d'un phénomène de satiété et l'on trouverait en psychologie humaine plus d'un exemple de phénomène très certainement apparenté. KARSTEN (I928) en étudiant l'effet de l'exécution continue d'une tâche quelconque trouve des courbes analogues en ce qui concerne l'attention au travail et la qualité du travail effectué. Pour Lindzer (I954) 
l'explication de ces phénomènes de satiété réside dans le fait que l'exécution continuelle d'une action donnée conduit à un abaissement du niveau de teision dans le système correspondant à une action. Il n'est peut-être pas non plus sans intérêt de constater avec ALLPORT (I920), SENGUPTA et SrNkA (I926) que la satiété s'observe avec une intensité particulière dans les comportements de groupes humains. La facilitation sociale devient bien moins effective au fur et à mesure que l'action considérée se

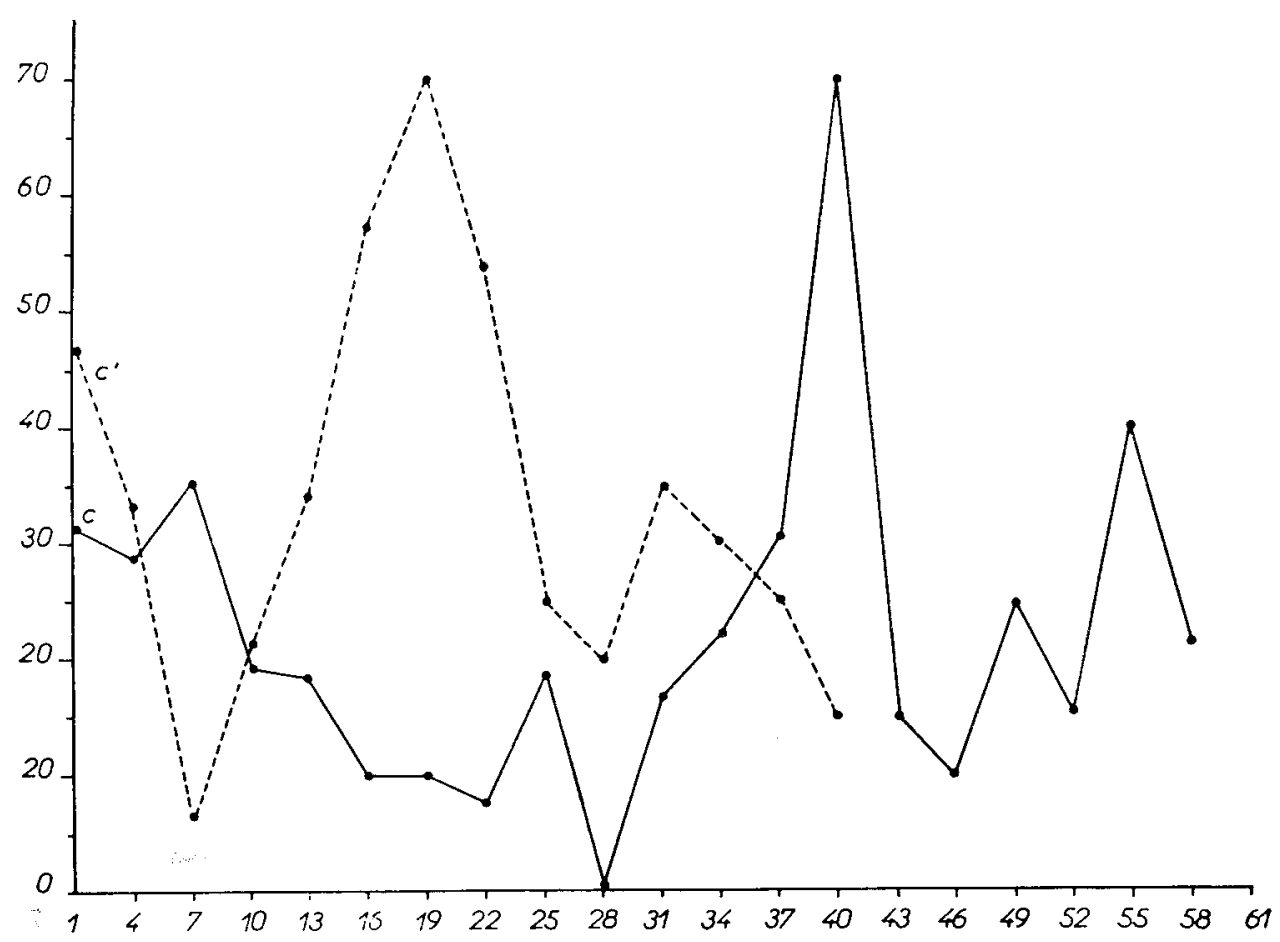

FIG. I . - Évolution de l'agressivité au cours d'une présentation discontinue du leurre a intervalles de trois minutes.

En ordonnée : nombre d'attaques pendant une minute.

En abscisse : échelle des temps en minutes.

prolonge. Le comportement agressif de l'abeille ayant un caractère éminent social, il peut paraître légitime d'effectuer ces rapprochements entre nos observations et celles effectuées par les psychologues at sociologues s'occupant de l'homme.

I a satiété a été également observée chez l'animal par KilLing, MitTEl ment de Mantes appartenant aux genres Parastagmatoptera et Hierodula vis-à-vis de leurres ou de mouches vivantes aperçues à travers une paroi transparente. Un enregistrement des réactions de cette détente des pattes ravisseuses d'une Mante en direction d'une Mouche ainsi présentée, montre que le nombre de ces réactions tend à décroître de manière régu- 
lière au cours d'une présentation prolongée. La courbe donnant la représentation graphique de la moyenne de 5 essais effectués par KILLING et ses collaborateurs ressemble beaucoup à celles que j'obtiens à chacun de mes essais. Il est d'ailleurs bon de faire remarquer que je travaille sur des groupes de 20 ouvrières et que mes résultats sont en fait une intégration.

Dans le cas des Mantes, l'on n'obtient pas, du moins dans les limites de l'expérience qui est da l'ordre de cinq heures, d'extinction totale du comportement alors que dans le cas de l'Abeille, cette extinction est obtenue après 40 minutes de présentation (moyenne de Io essais).

Dans le cas de la Mante, un changement de stimulus et dans le cas de l'Abeille un bref arrêt du mouvement du leurre suffisent pour provoquer une augmentation ou une reprise des attaques ce qui conduit à penser qu'il ne s'agit en aucune manière seulement d'une fatigue musculaire, mais surtout d'une "fatigue " propre au système nerveux en accord avec I INDZEY (I954).

Nous reviendrons d'ailleurs sur l'interprétation de ces phénomènes.

En ce qui concerne les courbes B et B' traduisant les variations du comportement lors de présentations à intervalles de dix minutes d'un stimulus significatif, il semble que l'on soit en droit d'effectuer un rapprochement avec ce que les auteurs anglo-saxons ont appelé " after effect".

TiNBERGEN (I948), dans un de ses travaux sur 1'Epinoche, a mis en évidence un phénomène comparable. Chez $c_{2}$ poisson, quand les réactions de combat du mâle ont été évoquées par un leurre efficace, la réaction ne cesse pas brusquement après le retrait du leurre. Il est bien évident que le poisson ne combat plus puisque son adversaire n'est plus présent, mais pendant plusieurs minutes après le retrait du leurre, le seuil d'excitation reste anormalement bas, la pulsion d'agressivité est encore activée et le niveau du seuil ne remonte que peu à peu. Durant cette période, un leurre peu efficace se comporte comme un leurre très efficace. Cette constatation conduit naturellement à espacer les présentations du leurre d'au moins une demi-heure afin d'éviter l'interférence de cet "effet à postériori " avec l'expérience en cours.

I,e tableau ci-dessous est significatif à cet égard.

TABLEAU XXIII

\begin{tabular}{|c|c|c|}
\hline Nature du leurre & ; Nombre d'attaques & $\begin{array}{l}\text { Moyeme de } \\
\text { 20 essais }\end{array}$ \\
\hline $\begin{array}{l}\text { Leurre marron }\left(\begin{array}{lll}1 & 2\end{array}\right) \ldots \\
\text { Leurre blanc présenté } 5 \\
\text { après le leurre marron } \\
\text { Leurre blanc présenté } 30^{\circ} \\
\text { après le leurre marron }\end{array}$ & & $\begin{array}{l}30 \\
24 \\
11\end{array}$ \\
\hline
\end{tabular}


Cet effet de la répétition n'est d'ailleurs absolument pas général; très souvent, la réaction diminue d'intensité sous l'action de la répétition, même quand celle-ci n'a lieu que deux ou trois fois, et nous nous retrouvons en face du phénomène de satiété.

Ainsi, en étudiant le comportement du papillon Eumenis selene, Tinbergen, Meuse, Boerema et Varossieau (I942) ont mis en évidence une baisse rapide de l'efficacité d'un leurre capable de déclencher le vol de poursuite sexuel chez le mâle. Entre chaque présentation d'un même leurre quand les intervalles ne dépassent pas vingt secondes, l'on assiste à une baisse très significative du nombre moyen de réponses positives. TINBERGEN (r95I) attribue ces modifications, non pas à une fatigue musculaire mais à une "fatigue " du système nerveux central. Il rejoint ainsi les idées ayant cours en psychologie humaine telles qu'elles ont été par exemple exprimées par LINDZEY (I954).

Les exemples d'effets semblables sont d'ailleurs très nombreux, citons le travail de LORENZ (I937) qui a montré que la réaction d'imitation de blessure à l'approche d'un prédateur chez un passereau n'est plus déclenchée à la troisième ou quatrième répétition d'un stimulus. Citons encore l'observation effectuée par PrEChTL, (1953) qui a trouvé un net affaiblissement de la réaction d'ouverture du bec chez les jeunes passereaux lorsque l'on effectue des présentations trop rapprochées des leurres efficaces.

Cependant, THORPE (I956) fait remarquer que cet affaiblissement des réactions peut simplement être dî au fait que l'animal reconnaît le caractère artificiel du leurre. Il cite à l'appui de cette thèse plusieurs observations entre autres, celle de RAND (I94I) qui a mis en évidence que si les réactions de crainte d'un oiseau s'émoussaient lors de la présentation répétée d'un serpent artificiel en caoutchouc, rien de tel ne s'observait en présence d'un authentique reptile.

Cette question est donc particulièrement complexe ; en ce qui concerne l'abeille, le troisième type de courbe qu'il m'a été possible d'obtenir ne vient fas faciliter 1'interprétation de ces phénomènes.

En effet, les courbes $\mathrm{C}$ et $\mathrm{C}^{\prime}$ de la figure II qui correspondent à une présentation discontinue des leurres avec un intervalle de temps de trois minutes ont une allure oscillante très frappante. Cette allure semble traduire une lutte entre detux tendances : celle se rapportant à 1' " after effect " et celle en relation avec la satiété.

Dans le cas du comportement agressif de l'Abeille, nous observons dons trois phénomènes différents :

Io Dans le cas d'une stimulation continue, l'intensité de la réaction diminue rapidement et devient même inexistante. Il est bon de préciser que les premières séquences du comportement sont les dernières à disparaître (ainsi l'agitation est la dernière séquence à disparaître). 
$2^{\circ}$ Dans le cas d'une stimulation discontinue, lorsque les intervalles de temps entre les présentations sont de dix minutes, il n'y a plus de satiété mais un effet prolongeant la réaction qui a pour résultat un abaissement considérable du seuil d'excitation. Cet effet se traduit par une augmentation considérable du nombre des attaques soit à l'encontre d'un leurre habituellement très significatif soit à l'encontre d'un leurre généralement pei significatif.

$3^{\circ}$ Dans le cas d'une présentation discontinue, lorsque les intervalles de temps entre les présentations sont réduits à trois minutes, il existe apparemment une balance entre les deux phénomènes décrits en $\mathrm{I}^{\mathbf{0}}$ et $2^{\circ}$. Cet ensemble de faits se laisse assez difficilement intégrer avec les conceptions de l'école objectiviste telles qu'elles ont été exprimées par HINDE (I954). Cet auteur, en effet, s'est entièrement attaché à ne considérer que les cas où la répétition agit en élevant le seuil de la réaction.

Si l'assertion de HINDE selon laquelle un stimulus constant présenté à intervalles à un animal n'évoque pas une réponse constante est tout à fait exacte, il n'en reste pas moins vrai que le sens de ce changement peut être variable.

J'ai indiscutablement mis en évidence lors d'une présentation discontinue un abaissement considérable du seuil de réaction tandis que Hinde ne considère en fait que les réponses qui disparaissent sous l'effet de la répétition. I'extinction de la réponse pouvant d'ailleurs être définitive ou transitoire. Les deux types de réponses me paraissent également importantes et mériteraient d'être mieux étudiées, avant que l'on puisse intégrer en une seule théorie tous ces phénomènes.

\section{Signification de l'agressivité diffuse.}

L'on se souvient que j'ai appliqué le terme d'agressivité diffuse à la première séquence du comportement agressif.

Quand le niveau de l'agressivité est élevé, il y a plusieurs issues possibles : houspillage, morsure, piqûre, qui ne correspondent pas à des séquences telles celles que nous avons passées en revue, mais à des niveaux d'excitation différents. La pulsion (drive) peut être excitée, dans certains cas par des stimuli qui constituent par eux-mêmes des issues convenables pour la pulsion, ou en d'autres termes qui peuvent être attaqués. Dans d'autres cas, l'excitation peut être provoquée par des stimuli inattaquables qui ne peuvent produire que la première séquence : l'agitation.

Dans le premier cas, la pulsion trouve une issue au fur et à mesure qu'elle est excitée.

Dans le second cas, elle ne peut trouver d'issue. Par exemple, dans le cas où l'on diffuse dans la cagette une odeur de venin, il n'y a rien à attaquer et cependant la pulsion agressive est fortement excitée et son 
seuil est très bas. Il est possible de le vérifier expérimentalement en présentant un leurre. Par rapport à des cagettes témoins, le nombre moyen d'attaques est toujours supérieur dans ces conditions.

La forte activité motrice qu'il est constant d'observer au début de tout comportement agressif peut-elle être considérée comme une issue pour la pulsion agressive? I1 semble bien que non.

En effet, elle ne fait pas remonter le seuil d'agressivité conme nous venons de le voir et d'autre part, il est possible d'observer cette agitation pendant une très longue période à l'intérieur d'une cagette. Ce maintien de la réaction à un niveau constant pendant une longue période contraste avec le déclin rapide des attaques proprement dites, que j'ai étudiées précédemment.

Une autre question est celle de 1'identification de cette agitation avec une activité de substitution. L'on sait que l'école de LoRENz désigne ainsi des activités en apparence hors de propos, appartenant à une pulsion autre que celle qui est en jeu et apparaissant dans les cas de conflits. I1 semble bien que 1'on puisse écarter définitivement cette hypothèse. Tout d'abord, l'agitation ne peut être considérée comme une issue, elle n'épuise pas la pulsion comme le fait l'activité de substitution. Ensuite, elle fait incontestablement partie du comportement normal d'une Abeille dont la pulsion agressive est stimulée. J'ai, en effet, montré que l'agitation était le premier phénomène observable dans une cagette après l'introduction d'une ouvrière étrangère. 


\section{CHAPITRI: $V$}

\section{LA RECONNAISSANCE DU PARTENAIRE SOCIAL ET LE ROLE DE L'ABEILLE GARDIENNE}

Que ce soit en cagette ou à l'entrée de la ruche, les phénomènes d'agressivité entre Abeilles postulent de la part de l'Abeille habitante une possibilité de reconnaissance de l'étrangère.

Dans mes premières publications, j'attribuais un rôle essentiel au mouvement. En effet, un cadavre d'Abeille très frais agité mécaniquement dans une cagette est tout aussi bien attaqué s'il provient de la population contenue dans la cagette ou s'il en est étranger.

D'autre part, il est une tradition bien établie chez les apiculteurs qui veut que chaque ruche possède son odeur propre et que cette odeur soit à la base de la reconnaissance entre membres d'une même colonie.

Une telle hypothèse a d'ailleurs été formulée, il y a longtemps, par BETHE (I898) et Von BUTTEL-REEPEN (I9O0). Durant ces dernières années, cette question a fait l'objet d'études approfondies qui méritent un examen sérieux.

\section{Travaux de Butler et Free.}

Étudiant le comportement des ouvrières à l'entrée de la ruche, Bu'lLER et FREE (I952) attribuent un rôle considérable au vol pendulaire de l'Abeille pillarde. Ce type de mouvement est celui reproduit dans mes expériences effectuées avec un agitateur mécanique. Ce comportement mettrait en alerte les Abeilles gardiennes qui interceptent les intrus ət leur font alors subir un examen prolongé. A ce deuxième stade, l'odeur de 1'Abeille jouerait un rôle important et une fois la reconnaissance effectuée l'attaque proprement dite aurait lieu en fonction des réactions de 1'Abeille examinée. En accord avec mes observations effectuées en cagettes, l'Abeille passive ne serait pas l'objet de vives attaques.

Ces Abeilles passives lors de l'examen, se laissent inspecter et même molester par les gardiennes sans chercher à s'enfuir. Parfois, quand l'examen est prolongé, une Abeille au comportement passif peut offrir de la nourriture aux gardiennes. Très souvent la nourriture est acceptée par 
les habitantes, mais si elle ne l'est pas, l'Abeille passive présente un très curieux comportement. I1 est possible de la voir se livrer à un long et minutieux nettoyage de sa propre langue à l'aide des tarses des pattes antérieures. Ce comportement qui n'apparait jamais dans les échanges de nourriture entre Abeilles d'une même colonie a très justement été rapproché par BUTLLER et FREE (I952) des comportements de substitution.

En effet, ce nettoyage qui n'a jamais été observé immédiatement après un comportement alimentaire normal rentre bien dans la définition donnée par THORPE (I95I) qui décrit les comportements de substitution comme étant l'exécution d'un schéme de comportement en dehors de son contexte naturel. Contrairement à l'agitation que nous avons précédemment rejetée de cette catégorie, il s'agit d'un de ces " actes hors de propos » qui de tous temps ont excité la curiosité des naturalistes.

Un autre point remarquable est la propriété présentée par certaines abeilles étrangères de se mettre en état de thanatose lors d'un houspillage prolongé. Ce comportement est très rare à l'intérieur des cagettes, sa fréquence est alors très inférieure à $x$ p. Ioo ; par contre, il est relativement plus fréquent à l'entrée des ruches.

BUTLER et FREF (I952) ont ainsi observé des a beilles étrangères se laissant transporter par des gardiennes sans effectuer un seul mouvement si ce n'est. un très léger battement des antennes. Après avoir été relâchées par les gardes, ces aheilles pénètrent dans la ruche sans difficulté semblet-i1. Cet état de thanatose avait d'ailleurs déjà été décrit par GrozdANIE (I95I) mais cette fois, chez des abeilles habitantes et à la suite de l'entrée d'un grand nombre d'étrangères dans la colonie. La thèse de BUTLER et FREE (I952) et FREE (I954) peut donc se résumer ainsi : les gardiennes reconnaissent les membres de leurs propres colonies par leur odeur, les abeilles pillardes sont reconnues par leur comportement particulier au moment où elles vont atterrir sur la planche de vol. L'identité de ces pillardes est confirmée par examen au sol; de même les autres abeilles étrangères sont l'objet d'un examen sans doute de nature olfactive.

Les abeilles autres que les pillardes peuvent prendre deux attitudes: l'attitude dominante, l'attitude passive.

Les abeilles étrangères qui sont des butineuses égarées, rentrent sans hésitation dans la ruche grâce à leur attitude dominante. Les autres sont soumises à un examen attentif et à un houspillage plus ou moins intense. Si elles conservent. leur attitude passive et à fortiori si elles rentrent en état de thanatose, elles sont acceptées par la ruche. J'ai signalé le premier (LECOMTE, I95I) cette importance des réactions de l'étrangère pendant qu'elle subit l'examen des habitantes. Cette attitude de soumission a également éte étudiée par MEYERHOFF (I955). Cet auteur, qui d'ailleurs ne daigne citer ancune antériorité, ni donner la moindre source 
bibliographique, met en évidence les différences de comportement entre : $I^{0}$ les Abeilles pillardes à 1'approche hésitante, prêtes à s'envoler quand elles sont attaquées par les gardiennes; $2^{\circ}$ les Abeilles abandonnant la colonie orpheline qui tente de se faire accepter par une autre ruche en ventilant et en exposant leur organe de Nassanof ; $3^{\circ}$ les Abeilles atterrissant par erreur sur la planche de vol d'une colonie étrangère. Cette dernière catégorie adopte le plus souvent l'attitude de soumission qui lui assure la vie sauve.

MEXERHOFF fait justement remarquer que ce n'est pas l'immobilité à elle seule qui inhibe l'agressivité car des abeilles mortes sont rapidement expulsées par les gardiennes. I1 faut donc admettre que 1'attitude propre des ouvrières passives joue un rôle privilégié. Cette attitude ne pourrait être prise d'ailleurs que par des abeilles âgées et les jeunes abeilles déposées sur la planche de vol d'une ruche étrangère en seraient incapables. Je dois dire que d'après mes propres observations effectuées dans des conditions un peu différentes, il n'en est rien, et que les jeunes abeilles introduites soit dans des cagettes soit dans des ruchettes sont toujours accueillies avec le minimum de signes d'agressivité.

\section{La théorie " olfactive " de Ribbands.}

En face des tenants d'une reconnaissance effectuée grâce à des éléments en partie fournis par des différences d'odeur et en partie par des différences de comportement, nous trouvons C. R. RibBands qui, dans un travail paru en I954, affirme qu'en aucune circonstance, le comportement des intruses ne peut par lui-même provoquer une attaque. S'appuyant sur toute une série d'expériences tendant à mettre en évidence le fait que les abeilles peuvent reconnaître si un individu appartient ou non à leur propre ruche d'après l'odorat (ce que personne n'a jamais songé à nier) RrBbands (I954) écarte toute intervention d'un autre procédé. Les arguments de cet auteur sont à vrai dire assez faibles, citons le fait que l'odorat serait un sens bien plus développé que la vision chez l'abeille ou qu'il paraît incompréhensible que les pillardes adoptent un comportement spécial susceptible de les faire reconnaitre. Sur ce dernier point, RiBBANDS est formel, selon lui, le vol pendulaire des abeilles pillardes est la conséquence de la reconnaissance et non sa cause. C'est le fait d'avoir déjà été attaqué st sérieusement molesté à l'entrée d'une ruche étrangère qui par conditionnement donnerait à ces abeilles le vol hésitant que l'on observe.

Confondant d'ailleurs cette " hésitation " avec le comportement passif déjà décrit, RibBands n'hésite pas à prétendre que ce vol particulier serait plutôt de nature à inhiber le comportement agressif des abeilles gardiennes. 


\section{Discussion.}

Un travail de FiREE (I954) remet les choses au point; tout d'abord, il constate que les abeilles peuvent piller une ruche ne contenant pas d'abeille ou contenant des abeilles enfermées, sans présenter pour autant le comportement de vol pendulaire des pillardes. Ce vol pendulaire serait provoqué par la vue d'un grand nombre de butineuses stationnant sur la planche de vol ; cet engorgement est la règle dans les cas de pillage où la planche de vol est encombrée par les gardiennes et les ouvrières interceptées.

Ce comportement serait inné et apparaîtrait à la première rencontre avec une telle situation; des expériences effectuées avec des colonies élevées dans le plus parfait isolement en font foi.

Une autre expérience est très instructive : l'on habitue une colonie à se nourrir en pillant une ruche vide d'abeilles mais contenant des cadres de miel. Ensuite, l'on sépare en deux cette colonie et l'on peuple la ruche vide avec une des deux moitiés de la colonie. Les abeilles qui n'ont pas été déménagées continuent à venir chercher de la nourriture dans cette ruche, mais, bien qu'il s'agisse d'une colonie sœur, les pillardes présentent le comportement de vol pendulaire, et ceci seulement deux heures après la séparation.

Daus ce dernier cas un grand nombre d'ouvrières est relâché par les gardiennes comme si la parenté était reconnue après l'interception et dans ce cas, FREE admet comme très probable le rôle de l'odeur. J'ai d'ailleurs retrouvé cette possibilité d'évocation du vol pendulaire par un rassemblement d'abeilles dans une circonstance tout autre. Ayant été amené lors d'un travail sur l'orientation des butineuses à retourner des ruches de $180^{\circ}$, j'ai constaté qu'à la suite de cette rotation se formaient souvent des rassemblements de butineuses à 1'emplacement de l'ancien trou de vol. Dans ce cas, il est possible d'observer que les arrivantes effectuent avant de se poser le vol pendulaire caractéristique des pillardes, mais comme il n'existe pas de gardiennes à cet emplacement, il n'y a ni interception ni combat. La seule objection qui puisse être faite aux conclusions de FrEE est celle-ci : souvent en été, il se forme d'importants rassemblements d'abeilles au trou de vol, les apiculteurs disent que la ruche "fait la barbe ", or, l'on n'observe pas que ces rassemblements provoquent un comportement de pillardes chez les butineuses.

Peut-être existe-t-il une différence significative entre ces différents types de rassemblements : bien que je n'aie effectué aucune étude expérimentale de ce point précis, je pense pouvoir suggérer que dans un cas : "celui de la barbe ", les individus sont peu mobiles alors que les constituants des rassemblements de gardiennes et interceptées d'une part et des butineuses désorientées dans mon expérience d'autre part, sont très agités. 


\section{Théorie personnelle.}

Je pense clarifier la question et concilier les thèses de BuTLER et FREE avec les observations de RiBBANDS en distinguant deux types de reconnaissance.

$I^{\circ}$ La reconnaissance d'une ouvrière en tant qu'étrangère.

$2^{\circ}$ La reconnaissance d'une ouvrière en tant qu'indésirable.

Ia reconnaissance en tant qu'étrangère se ferait grâce à des stimuli olfactifs, tandis que la reconnaissance en tant qu'indésirable serait due à des différences de comportement.

Dans des conditions naturelles, une abeille pillarde serait identifiée comme indésirable par son vol pendulaire et comme étrangère après son interception grâce à son odeur.

Dans les conditions artificiellement créées par FREE (I954), l'abeille provenant de la colonie sour est identifiée comme indésirable par suite de son comportement mais après interception son odeur indique à la gardienne qu'il ne s'agit pas d'une étrangère et dans beaucoup de cas, le comportement agressif est inhibé. L'exemple des leurres montre que l'odeur ne suffit pas toujours à contre-balancer un comportement significatif puisque le cadavre frais d'une compagne est attaqué intensément.

Dans le cas d'ouvrières atterrissant par erreur sur la planche de vol d'une autre colonie, l'identification en tant qu'étrangères s'effectue par l'odeur et leur comportement selon les cas déclenche ou inhibe la chaîne des réactions d'agressivité. En ce qui concerne les butineuses rentrant dans leur propre ruche, dans les cas, assez fréquents, où elles sont interceptées par les gardiennes leur odeur et leur comportement suffisent à éviter le déclenchement de l'agressivité.

L'odorat joue bien, comme le veut RiBBANDs, un rôle important mais reconnaître ce fait ne veut pas dire que les différents stimuli visuels ou tactiles ne jouent pas un rôle considérable ; l'erreur consisterait à vouloir simplifier à l'outrance un comportement complexe. Il est même probable que le schéma que j'en donne est encore trop simple. Peut-être, faut-il aussi y ajouter des stimuli vibratoires comme le veut KöHLER (I955) qui attribue un rôle aux vibrations produites par les battements d'ailes.

\section{L'odeur de la ruche.}

En ce qui concerne la question de la différenciation parl'odeur entre différentes colonies, un certain nombre de travaux permettent d'éclairer cette question.

Tout d'abord de quelle durée doit être la séparation pour que des abeilles issues d'une même colonie se considèrent comme des étrangères. KaJaus et RiBBANDS (I952) utilisant la propriété présentée par les buti- 
neuses de préférer un nourrisseur visité par leur propre colonie ont mis en évidence que des différences significatives d'odeur existaient entre deux moitiés d'une ruche 72 heures après la séparation.

J'ai, pour ma part, mis au point une technique permettant de suivre l'évolution de cette différenciation.

Dans tous ces essais, j'ai employé une cagette composée de deux cagettes du modèle habituel accolées, chacun des deux compartiments contient de l'eau et de la nourriture et est peuplé d'environ 25 ouvrières prises au hasard sur les rayons de la même ruche. Ces deux populations se trouvent séparées l'une de l'autre par une double cloison vitrée distante d'environ 2 centimètres. Fìn soulevant ces deux cloisons, l'on provoque une réunion des deux populations dont il est facile de suivre les réactions.

Pour pouvoir donner des résultats numériques, les conventions suivantes ont été adoptées :

$\mathrm{o}=$ comportement normal de rencontre entre individus appartenant à la même colonie ;

$I=$ examen poussé du corps à l'aide des antennes en effectuant des mouvements mandibulaires;

$2=$ l'examen se prolonge, l'examinatrice grimpe sur l'examinée et la poursuit;

$3=$ morsure des pattes ou des ailes;

$4=$ combat réel.

Selon les temps écoulés depuis la séparation, les résultats suivants ont été obtenus :

TABLEAU XXIV

\begin{tabular}{c|ll}
\hline \multirow{2}{*}{ Nombre d'heures } & \multicolumn{2}{|c}{ Résultats } \\
\cline { 2 - 3 } I2 à 24 & 0 & Moyenne de I2 cagettes \\
35 à 48 & M,2 & Moyenne de 10 cagettes \\
69 à 73 & I & Moyenne de 26 cagettes \\
82 à 105 & I,6 & Moyenne de 10 cagettes \\
I I6 à 127 & 2,85 & Moyenne de 7 cagettes \\
I90 à 200 & 3,66 & Moyenne de 6 cagettes \\
\hline
\end{tabular}

Il existe donc indiscutablement une différenciation qui varie proportionnellement avec le temps passé depuis la séparation et cette différenciation se répercute sur l'intensité des phénomènes agressifs lors d'une réunion.

Mais cette différenciation, du moins en ce qui concerne l'agressivité, est-elle bien comme le veut RibBands, de nature olfactive? Pour le savoir, j'ai réalisé une série d'expériences utilisant les mêmes cagettes que précédemment mais avec différents types de cloisons. I,e premier type est constitué comme précédemment par deux plaques de verre ; 1e second par une cloison unique constituée par une tôle perforée de trous d'un 
millimètre de diamètre; dans le troisième cas, il s'agissait d'une tôle perforée de trous de 4 millimètres de diamètre.

Ces cagettes furent peuplées comme dans les essais précédents d'environ 25 ouvrières dans chaque compartiment.

Trois essais furent effectués avec des individus en provenance de trois colonies différentes. Les résultats sont évalués comme précédemment par réunion des deux populations après une séparation de 72 heures.

TABLEAU XXV

\begin{tabular}{|c|c|c|c|}
\hline & Cloison de verre & Petits trous & Tôle perforée gros trous \\
\hline $\begin{array}{l}\text { Ruche } A \ldots \ldots \\
\text { Ruche } B \ldots \ldots \\
\text { Ruche } \mathrm{C} \ldots \ldots\end{array}$ & $\begin{array}{l}\text { I, } 2 \text { moyenne de } 5 \\
\text { I,8 moyenne de } 8 \\
2,7 \text { moyenne de } 4\end{array}$ & $\begin{array}{l}0,2 \text { moyenne de } 5 \\
2,2 \text { moyenne de } 5 \\
2,2 \text { moyenne de } 3\end{array}$ & $\begin{array}{ll}\text { o,4 moyenne de } 5 \\
2 \text { moyenne de } 5 \\
2 \text { moyenne de } 4\end{array}$ \\
\hline
\end{tabular}

Les différences ne sont absolument pas significatives et ne permettent pas d'attribuer un rôle quelconque à une communauté d'odeur.

Dans 1'hypothèse de travail qui m'avait servi à préparer cette expérience, la cloison vitrée était destinée à interdire toute communication entre les deux populations, la tôle perforée de petits trous devait permettre l'échange d'odeur et la tôle perforée de gros trous l'échange de nourriture. Les résultats obtenus permettent d'éliminer de manière certaine le fait qu'une odeur commune puisse s'établir sans contact.

Une question se pose alors, y a-t-il échange de nourriture entre les populations placées de part et d'autre de la cloison de tôle perforée de trous de $4 \mathrm{~mm}$. Cette communication est certainement possible puisque FREE et BUTLER (I958) ont montré que des échanges de nourriture peuvent être pratiqués à travers des ouvertures de $2,5 \mathrm{~mm}$.

Dans une première expérience de contrôle, je me suis aperçu que si ses abeilles d'un compartiment n'avaient pas de nourriture à leur disposition, elles pouvaient en obtenir de celles situées de l'autre côté de la grille. Les mortalités n'étaient en effet pas significativement différentes dans le compartiment sans nourriture et dans le compartiment avec nourriture. J'ai constaté alors qu'il existait une différence très importante lors des réunions effectuées entre populations séparées par une grille perforée de trous selon que les deux populations possèdent ou non chacune leur propre réserve de nourriture.

Le tableau suivant donne les résultats numériques exprimés comme précédemment. La séparation ayant été de 72 heures.

TABLEAU XXVI

\begin{tabular}{l|c|c}
\hline & Nourriture de chaque côté & Nourriture d'un seul côté \\
\cline { 2 - 3 } $\begin{array}{l}\text { Ruche A } \\
\text { Ruche B }\end{array}$ & $\begin{array}{l}3,6 \text { moyenne de trois cagettes } \\
2,3 \text { moyenne de trois cagettes }\end{array}$ & $\begin{array}{l}\text { O moyenne de trois cagettes } \\
\text { o moyenne de trois cagettes }\end{array}$ \\
\hline
\end{tabular}


Cette constatation m'a amené à formuler deux hypothèses :

Io Que des abeilles séparées par des cloisons perforées de larges trous (4 $\mathrm{mm}$ ) ne procédaient pas à des échanges de nourriture si elles en avaient de part et d'autre à leur disposition.

$2^{\circ}$ Que les échanges de nourriture étaient à la base de la communauté d'odeur dans la ruche.

\section{Étude des échanges nutritifs à l'aide des radio-isotopes.}

Pour vérifier la première de ces hypothèses, j'ai été amené à employer une nourriture marquée à l'aide d'un radio-isotope.

J'ai employé les cagettes doubles déjà décrites et une tôle perforée de trous de $4 \mathrm{~mm}$ comme séparation. La nourriture était constituée par un sirop de sucre. Chaque population d'abeilles était constituée de 20 ouvrières. I,e marquage est très facile à réaliser au moyen d'un radioisotope : le phosphore 32 présenté sous forme d'une solution d'orthophosphate que l'on mélange au sirop de sucre.

L'activité du radio-isotope contenu dans chaque nourrisseur est d'environ 50 à IoO microcuries. Dans deux essais, un des compartiments contenait de la nourriture marquée et l'autre n'en contenait pas ; dans un troisième, un des compartiments contenait de la nourriture marquée et 1'autre de la nourriture non marquée.

Après un séjour de 40 heures dans ces cagettes, les ouvrières furent tuées et examinées à l'aide d'un compteur de Geiger Muller type Cloche, sous château de plomb.

Le bruit de fond dans ces conditions était d'environ Ir coups à la minute.

Les résultats suivants ont été obtenus :

\section{TABLEAU XXVII}

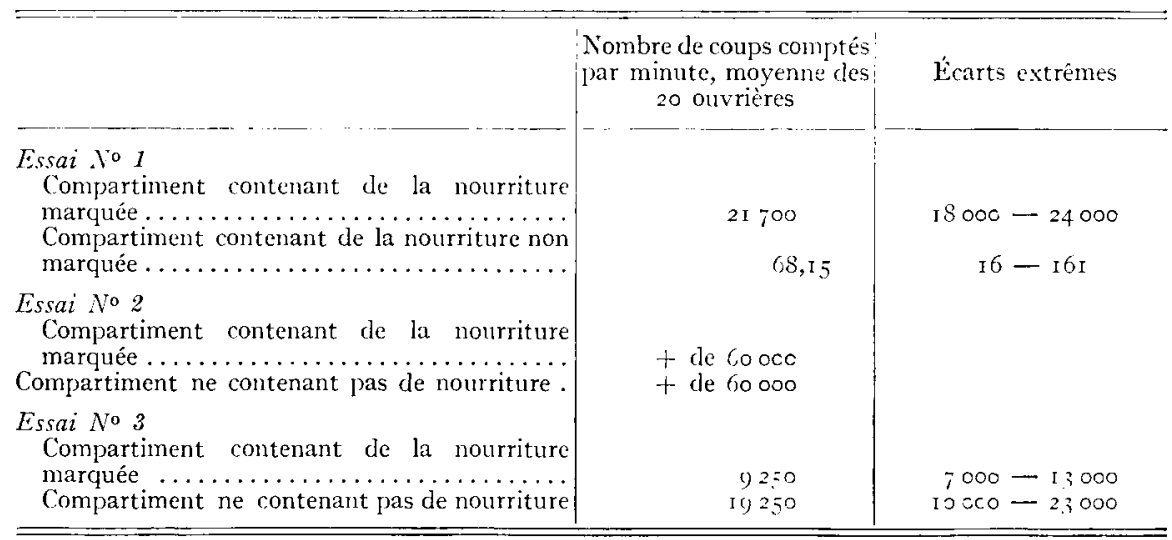


$I_{i}$ 'on constate aisément que les échanges sont très importants dans le cas ou l'une des deux populations ne possède pas sa propre source de nourriture puisque, en effet, la radioactivité est au moins aussi importante dans le compartiment sans nourriture que dans celui où a été distribué le radioélément. Au contraire, dans le cas oì les deux populations disposent de leur propre source de nourriture, les échanges sont négligeables. Les chiffres donnés ci-dessus sont très significatifs et il est même permis de supposer qu'il n'y a aucun échange de nourriture et que la faible radioactivité constatée dans le compartiment où le radioélément n'a pas été distribué provient d'une contamination par voie externe à travers les perforations de la cloison; de nombreuses expériences de contrôle ont confirmé les rísultats dı1 tableau XXVII.

De toute manière, la lecture des deux derniers tableaux ne permet plus de douter que la différenciation de deux populations soit due aux échanges de nourriture puisque deux populations d'abeilles vivant côte à côte dans le même microclimat et dans une atmosphère commune, recevant de plus la même nourriture, deviennent rapidement étrangères tandis que le transport de nourriture à travers la cloison suffit pour empêcher tout comportement agressif lors de la réunion.

Il en est ainsi pour la différenciation, il en est de même pour l'uniformisation. Si dans les cagettes doubles, l'on garnit les deux compartiments avec des populations issues de ruches différentes, l'on obtient lors d'une réunion de violents comportements agressifs. S'il y a échange de nourriture, et c'est toujours le cas quand une des populations est affamée, la réunion se passe sans incidents. Le tableau XXVIII donne les résultats numériques observés après un temps de séjour dans les cagettes d'environ 75 heures.

\section{TABLEAU XXVIII}

\begin{tabular}{l|l|l}
\hline & Nourriture de chaque côté & Nourriture d'un côté \\
\hline Jissai No $1 \ldots \ldots \ldots$ & 3,7 moyenne de 4 cagrettes & c,2 moyenne de 4 cagrettes \\
issai No $2 \ldots \ldots \ldots$ & 3,3 moyenne de 3 cagettes & 0 \\
\hline
\end{tabular}

L'échange de nourriture qui paraît nécessaire est donc suffisant pour établir ou entretenir entre deux populations d'abeilles un lien évitant l'apparition de comportements agressifs lors d'une réunion. Rappelons d'ailleurs que l'abeille étrangère "passive " offre de la nourriture aux abeilles habitantes.

\section{Rôle de l'odeur du corps.}

Il n'est pas impossible que d'autres procédés secondaires viennent ajouter leur action mais je n'ai pu les mettre en évidence. Je signalerai 
cependant comme procédé secondaire probable, le contact corporel, l'on sait depuis Steinhoff (I948) que la cuticule de l'abeille retient remarquablement les odeurs et au cours des contacts incessants qui ont lieu dans la ruche il est fort possible que "l'odeur commune " soit sans cesse distribuée.

Cependant, d'après KALTOFEN (I95I) les ouvrières ne sauraient distinguer par l'odeur du corps si une ouvrière appartient ou non à leur propre colonie. Cet auteur attribue un rôle capital à la glande de Nassanov ou plutôt à la substance déposée par les abeilles lors du butinage. KALMUS et RiBbaNds (1952) arguant du fait que durant leurs expériences, nombreuses furent les butineuses vues en train d'exposer leur glande de Nassanov, estiment qu'il doit s'agir du principal facteur de reconnaissance mais pas nécessairement du seul. En particulier, les abeilles pillardes qui, pour citer l'auteur (RIBbands I954) " ne voudraient pas faciliter leur propre déconfiture en exposant leur glande " seraient teconnues grâce aux cellules glandulaires isolées situées d'après JACOBS (I924) sur tout leur tégument.

Ces auteurs tiennent compte d'une expérience de Von Firisch et Rösch (I926) qui recouvrirent de laque l'orifice de la glande de Nassanov d'ouvrières sans constater de différences dans l'attractivité des nourrisseurs. Mais ils estiment que le fait de couvrir l'orifice ne supprime pas complètement l'émission d'odeur. Malheureusement, pour cette théorie RENNER (I955) et moi-même par la suite, avons mis en évidence que les ouvrières paraissaient semblablement attirées par la sécrétion de la glande de Nassanov, qu'elle provienne d'une ouvrière de la même colonie ou d'une colonie étrangère.

Il faut donc chercher ailleurs la substance responsable de la reconnaissance. L'étude que $j$ 'ai faite dans le chapitre III de la première partie de ce travail, sur les substances déposées par l'abeille sur des nourrisseurs peut sans doute servir de point de départ pour cette recherche. Il est très probable que l'élimination de la substance émise par la glande de Nassanov et de celle contenue dans l'ensemble du corps ne laisse de place qu'à une substance contenue dans la phase éthérée des extraits des dépôts laissés par les butineuses sur les nourrisseurs. L'on se souvient que j'ai pu ainsi mettre en évidence deux substances : l'une qui attire les butineuses de la même ruche et qui repousse les étrangères, l'autre qui possède un effet répulsif uniquement pour les étrangères. L'origine de ces substances est très certainement céphalique, puisque je les retrouve même quand j'empêche l'abeille de rentrer en contact avec les billes de verre du nourrisseur au moyen d'un treillage métallique. Cette hypothèse s'accorde d'ailleurs très bien avec le fait que les échanges de nourriture sont à la base de la reconnaissance en tant qu'ouvrière sœur. 


\section{La formation de l'odeur de la ruche.}

Une question peut encore être posée, comment se fait-il que les glandes céphaliques de l'abeille, si l'on adopte cette hypothèse, aient la possibilité de créer une odeur typique pour chaque ruche.

Pour RibBands (I952), la différenciation se fait en première analyse grâce aux différences de régime alimentaire. L'on sait que deux ruches, même placées côte à côte ne récoltent jamais exactement le nectar et le pollen des mêmes plantes (voir par exemple Louveaux, 1957) et les échanges de nourriture créent à partir de ces apports "1'odeur commune ». Dans une autre publication, (KALMUs et RIBBANDS, I952) ces auteurs attribuent également un rôle différenciateur à la reine qui selon l'importance de sa ponte, pourrait faire varier la vitesse de consommation de la nourriture.

Pour moi, il s'agit de différences tout autres.

En effet, deux groupes pris en hiver dans la même ruche, c'est-à-dire alimentés de la même manière depuis plusieurs mois, et placés dans deux cagettes semblables pourvues de la même nourriture, ne se reconnaissent plus au bout de quelques jours.

D'autre part, je n'ai jamais pu obtenir de différences significatives entre les comportements agressifs de paires de groupes nourris avec la même nourriture ou avec les nourritures les plus dissemblables possibles. Des miels différents, du sirop de sucre, des parfums artificiels ou naturels très concentrés furent employés sans que jamais ces différences de nourriture ne donnent de résultats significativement différents de ceux obtenus avec des nourritures semblables. La différence réside donc dans l'abeille et dans son métabolisme et non dans sa nourriture elle-même.

I es seules différences d'origines externes que j'ai pu observer sont celles amenées par l'application d'une odeur sur la surface du corps d'une ouvrière. Une abeille fraîchement marquée avec de la peinture peut être attaquée quand elle rentre dans la ruche, je l'ai observé plusieurs fois. Par contre, quel que soit le parfum absorbé en même temps que sa nourriture par une ouvrière, il ne lui arrive rien de tel. Le simple bon sens indique d'ailleurs que s'il en était autrement, les exploratrices rentrant à la ruche après la découverte d'une nouvelle provende seraient mises à mort ce qui est évidemment absurde.

\section{Comment s'opèrent les échanges?}

Sur la réalité de ces échanges de nourriture dans les conditions de vie normale d'une colonie, nous avons déjà un certain nombre d'informations.

Nixon et Ribbands (I952) ont effectué un certain nombre d'expériences en étudiant la répartition dans la ruche de la radioactivité d'un

Annales de l'Abeille. - ז96. 
radio-isotope : le Phosphore 32 , distribué à un petit nombre d'abeilles. Dans un premier essai, ces auteurs donnèrent à 5 ouvrières une dose de 20 microcuries et ils constatèrent que sur un échantillon prélevé parmi les I2 800 ouvrières de la colonie, $64 \mathrm{p}$. Ioo présentaient des traces très nettes de radioactivité au bout de 24 heures. Dans un deuxième essai, ils donnèrent à neuf abeilles une dose de Ioo microcuries; parmi les 2500 abeilles composant la ruchette, 92 p. Ioo au bout de 24 heures et $9^{8} \mathrm{p}$. Ioo après 48 heures se révèleront radio-actives. Enfin, dans un essai effectué sur une ruche de population plus normale, bien qu'encore faible puisqu'elle n'était que de 24600 individus, les auteurs distribuèrent Ioo microcuries à six butineuses. Au bout de 4 heures, 62 p. Ioo des butineuses étaient marquées; ce pourcentage atteignant $76 \mathrm{p}$. Ioo au bout de 24 heures.

D'autre part, voulant utiliser cette distribution de la nourriture afin de réaliser un marquage destiné à une étude du butinage, CourTors et LECOMTE (I958) ont utilisé un autre radio-isotope : 1'or I98. La technique consiste à donner à une ruche de population normale, c'est-à-dire d'environ 40 ooo ouvrières, un nourrisseur contenant deux litres de sirop de sucre et une dose de 40 millicuries.

Dans un premier essai, la distribution de cette nourriture à l'intérieur de la ruche fut très rapide, puisqu'au bout de 15 heures, 63 p. Ioo des butineuses étaient marquées. Ce pourcentage passant à $90 \mathrm{p}$. Ioo au bout de 24 heures et à Ioo p. Ioo après 48 heures. Un essai préliminaire effectué avec une dose de un millicurie distribué à I ooo abeilles contenues dans une ruchette, avait abouti encore plus vite à un marquage total de la population.

Cependant, un troisième essai effectué avec la même technique donna des résultats notablement différents.

En effet, bien que le sirop de sucre ait été absorbé avec plus de rapidité que dans le premier cas, les pourcentages de butineuses marquées furent loin d'être aussi importants.

Après 15 heures, $12 \mathrm{p}$. Ioo des butineuses seulement présentaient des traces décelables de radioactivité. Ce pourcentage atteignait $62 \mathrm{p}$. xoo au bout de 24 heures et 68 p. Ioo après 48 heures. Après ce laps de temps les quantités de radioactivité contenues par les abeilles, deviennent trop faibles pour qu'un pourcentage puiss être établi.

La seule différence importante entre ces deux essais réside dans le fait que dans le premier cas, la miellée était très faible tandis que dans le second, elle était assez importante. Un examen de la ruche mit en évidence que le sirop de sucre radioactif avait été stocké et l'on peut penser qu'il n'y eut que peu d'échanges entre les butineuses rapportant le nectar de l'extérieur et celles ayant recueilli les deux litres de sirop de sucre contenus dans le nourrisseur placé à l'intérieur de la ruche. 
Bien que ces expériences préliminaires ne permettent en aucune manière de conclure de manière définitive et que ces phénomènes d'échanges doivent encore faire l'objet de longues recherches avant d'être bien compris, il n'est pas impossible d'avancer que l'uniformisation n'existe pas toujours de manière parfaite dans la ruche. Ceci doit être le cas en période de grande miellée, les différents groupes de butineuses travaillant sur des plantes différentes n'ont peut-être pas beaucoup de contacts.

En dehors de nos essais, plusieurs faits viennent confirmer ce point de vue. Tout d'abord, le fait que le nectar régurgité par les abeilles danseuses, guide par son parfum les butineuses vers telle ou telle plante est à la base des idées de Von FrISch. Nous avons vu également que les butineuses possédaient dans un très grand nombre de cas, des aires limitées de travail et ne visitaient le plus souvent, qu'une seule espèce de fleur. I1 paraît donc vraisemblable que les butineuses se divisent, au moins en période de miellée, en " groupe de travail " possédant un même objectif et n'absorbant pas une nourriture possédant un parfum différent.

D'autre part, KALTOFEN (I95I) a constaté avec surprise que des groupes de butineuses en provenance de la même ruche pouvaient distinguer par l'odeur si un nourrisseur avait été butiné au préalable par leur propre groupe ou par un groupe frère.

Enfin, il est possible de considérer que le fait que les phénomènes agressifs sont réduits à leur strict minimum durant la miellée est dî en partie à ce que la colonie ne possède pas à ce moment une odeur unique. Non pas du fait des parfums des différentes provendes mais du fait que les nécessités du butinage empêchent les butineuses de pratiquer les échangas alimentaires sur une aussi large échelle. Toutes ces suppositions ne reposent pas sur une base expérimentale suffisante pour que je puisse les soutenir davantage, néanmoins, il existe suffisamment de données convergentes pour que 1'on puisse estimer qu'il s'agit d'autre chose que d'une vue de l'esprit. I a reconnaissance et le maintien de l'unité de la colonie seraient donc basés sur une série de phénomènes assez complexes.

\section{Le rôle possible de l'interattraction.}

Ici, il convient sûrement de faire une place aux phénomènes d'interattraction.

Dans des travaux antérieurs (I EComTE I950-I956) j'ai cherché à mettre en évidence l'existence d'une interattraction vraie, c'est-à-dire, due à l'influence de stimuli émis par les individus eux-mêmes. Après avoir dispersé dans une caisse de bois obscure d'environ $37 \mathrm{dm}^{3}$ un certain nombre d'ouvrières endormies à l'anhydride carbonique, j'ai étudié les conditions de leur réunion en une grappe unique, après leur travail.

Dans les conditions de l'expérience, le nombre des ouvrières pré- 
sentes joue un rôle certain. Un amas stable n'est formé que par un nombre d'individus égal ou supérieur à 50 et le nombre de chances pour qu'un tel amas soit formé, augmente proportionnellement avec le nombre d'individus présents. Des amas sont souvent formés par des petites quantités d'individus mais ces amas sont très peu stables et se détruisent au bout de quelques minutes. Dans ces amas, les individus ne sont pas accrochés les uns aux autres et restent très mobiles, les chaînes d'abeilles caractéristiques des amas importants n'existent pas. Pour obtenir avec Ioo p. Ioo de succès une véritable grappe, il est nécessaire que le nombre des ouvrières soit de roo. 75 ouvrières forment cependant encore la grappe dans un très grand nombre de cas, dans les conditions réalisées.

Dans une autre série d'expériences, la caisse de bois contient deux cages de grillage de $\mathrm{I} 2 \mathrm{~cm}$ de hauteur et de $6 \mathrm{~cm}$ de diamètre, 1'une contient des abeilles vivantes, l'autre rien. Dans ce cas, si I5o ouvrières se trouvent ainsi encagées, et si je dépose 75 ouvrières endormies entre les deux cages, je constate dans tous les cas, qua les abeilles libres se groupent autour des ouvrières encagées. Par une analyse de stimuli émis par les “ appelantes " encagées, j'ai pu mettre en évidence que ceux responsables de l'interattraction étaient relativement complexes. Il existe indiscutablement une composante olfactive, localisée dans l'abdomen ; et tune composante vibratoire transmise uniquement par le substrat. Ces deux composantes sont indispensables, l'une n'ayant aucune signification sans l'autre dans les conditions de mon expérience; mais elles peuvent être artificiellement émises par deux populations différentes (par exemple, abeille morte + abeilles enfermées qui émettent odeur + vibration) et restent ainsi efficaces.

J. B. Free et C. G. Butrek (I955) ont mis en évidence, dans des conditions expérimentales très proches, qu'il était possible d'ajouter la température propre des " appelants " à ces deux stimuli. D'après ces auteurs, odeur, vibration et température sont de nature (pourvu qu'ils soient suffisamment intenses) à attirer les abeilles séparément.

Ils ont par ailleurs abouti à des conclusions très voisines des miennes en ce qui concerne le nombre limite, indispensable pour que l'interattrac. tion se manifeste. Il existe donc une interattraction vraie chez les ouvrières d'A pis mellifica. Le caractère social de ce comportement est mis manière en évidence par le fait très important que le stimulus n'est perçu d'une manière efficace par un individu que si celui-ci est intégré dans un groupe nombreux.

A côté de l'interattraction, telle que nous l'avons définie, l'on a coutume de distinguer avec PICARD (I933) et RABAUD (I929) des effets de foule. Dans ce dernier cas, les stimuli sont extérieurs aux individus et ceux-ci ne sont rassemblés que parce qu'ils sont attirés par les mêmes stimuli extérieurs. Il a pu paraître tout à fait logique de ranger dans 
cette catégorie, les rassemblements d'ouvrières autour d'une même source de nourriture. Nous devons cependant à la suite d'un travail de Kalmus (I954) faire quelques remarques. Cet auteur a montré que si l'on disposait en un lieu situé près de la ruche, des coupelles de sirop de sucre, ces coupelles étaient très inégalement visitées.

La raison de ces inégalités réside de manière indiscutable dans la présence d'une attraction mutuelle, les premières butineuses attirent celles qui surviennent par la suite. Sur des coupelles situées au même emplacement, mais vides cette fois, il se forme une grappe et ici aussi, il est indispensable que les premières butineuses qui se posent attirent leurs congénères. Kalmus a étudié les différents facteurs à la base de cette attraction. Ces facteurs sont essentiellement visuels, olfactifis et vibratoires.

Ders abeilles enfermées derrière un verre, des silhontettes d'abeilles en mouvement, l'image de leur corps dans un miroir, l'odeur laissée à de précédentes visites, des vibrations artificielles, eurent un effet attractif certain sur des butineuses. En accord avec mes conclusions (LECOMTE, I95I) les vibrations n'avaient aucun effet sur des butineuses en vol, mais seulement lorsqu'elles étaient transmises par un substrat.

FREE et BUTLER (I955) ont également mis en évidence que des abeilles peuvent être attirées par la vue de congénères enfermées dans des boîtes vitrées. Un rassemblement d'abeilles butineuses sur une source de nourriture ne peut donc plus être considéré comme une foule à l'égal d'un vol de Phalènes tourbillonnant autour d'une lampe. L'interattraction mise en évidence par mes précédents travaux et par ceux de FrEE et BUTLER, lors de la formation de la grappe dans une boite obscure, joue également un rôle important dans la formation des rassemblements étudiés par KaLmus. Il est même possible que dans certains cas, le rôle joué par cette attraction mutuelle est prépondérant. Le cas des récolteuses d'eau est probablement le plus typique qu'il soit à cet égard. I1 est possible de voir des butineuses aller chercher de l'eau dans des bassins ou sur des plages et se réunir en très grand nombre dans un très petit espace pour effectuer la récolte. Le seul motif qui semble justifier ces " points de récolte " est l'attraction sociale, car dans de nombreıx cas observés il ne semble pas possible de déceler en quoi un autre point non fréquenté, diffère.

Il est très probable que ce grégarisme au sens de Grassé (1952), c'est-à-dire la tendance à réaliser un groupement sous l'empire de l'attraction réciproque, joue un rôle encore méconnu dans la vie de l'abeille. Nous avons ainsi signalé (LECOMTE, I956 a) l'existence de routes précises suivies par les butineuses qui sont sans doute en partie liées à ce grégarisme. Nous avons également montré (LECOMTE, I956 c) que les abeilles regagnent de manière très différente l'entrée de leur ruche (après rotation 
de $180^{\circ}$ de celle-ci) suivant qu'il y a ou non dans les premières minutes formation d'une grappe composée d'un nombre suffisant d'individus.

En ce qui concerne plus particulièrement l'agressivité, je rappelle que l'interattraction exerce une forte inhibition sur les manifestations de ce comportement. L'abeille, quand elle fait partie d'une " grappe ", n'est en effet que très rarement agressive.

I a cohésion et le maintien de l'unité de la colonie se trouvent ainsi sous l'influence des divers facteurs que nous avons passés en revue. I'interattraction sociale joue un rôle à l'échelle spécifique et les stimuli qui rentrent alors en jeu permettent à l'ouvrière de reconnaître la présence de ses congénères.

La reconnaissance d'une ouvrière en tant qu'indésirable est due, semble-t-il, à des stimuli visuels ou tactiles assez simples.

La reconnaissance en tant qu'étrangère est basée sur la perception de l'odeur d'une ou de plusieurs substances. Cette substance est distribuée en même temps que la nourriture et à un degré plus ou moins grand selon les circonstances. L'odeur commune de la colonie serait dans cette perspective réalisée par le brassage perpétuel des substances sécrétées par chaque individu.

I1 est, d'autre part, probable que ces substances proviennent des glandes en relation avec les pièces buccales.

\section{Les abeilles gardiennes.}

Chez Apis mellifica la défense de la ruche et de ses abords immédiats incombe dans des conditions normales à une catégorie bien particulière d'ouvrières que l'on appelle les gardiennes. Dans la superfamille des Apoides, l'on peut trouver des traces de cette fonction dès l'apparition des premiers phénomènes sociaux.

Chez les Halictes, Pseudagapostemon divaricatus Vachal peut avoir un comportement solitaire ou subsocial. Selon Michener (I956), de deux à quarante femelles peuvent posséder un nid commun. Dans ce nid, l'entrée est unique, mais chaque femelle possède en propre une chambre latérale; cette entrée unique est toujours gardée par un individu qui bloque le passage avec sa tête. Cette gardienne n'est d'ailleurs pas toujours le même individu. La défense ne s'effectue pas contre les congénères des nids voisins, mais contre d'autres espèces. Ainsi, le nid est efficacement défendu contre les Mutillides.

Chez Lasio glossum stultum Cresson toujours d'après MICHENER (I956) les reines après avoir hiverné, établissent un nid de printemps. Si la reine est unique, le nid n'est pas gardé, si au contraire, il y en a plusieurs, il y a généralement une gardienne. Par la suite, après la naissance des ouvrières, c'est l'une d'elles qui se charge de cette besogne. La garde 
d $\mathbf{u}$ nid chez les Halictes se ferait donc par obturation de l'entrée à l'aide de la tête et uniquement contre des individus appartenant à d'autres espèces.

Chez les Bombinae, les phénomènes de défense du nid ont fait l'objet d'une étude très intéressante de FrEE (I958). D'après cet auteur, les colonies possèdent des gardiennes à leur entrée. Un certain nombre d'ouvrières jouent le rôle de gardiennes pendant plusieurs jours consécutifs et ces périodes de "gardiennage " peuvent alterner avec des périodes d'activité de butinage ou de travaux effectués à l'intérieur du nid.

Dans le cas des petits nids, l'on n'observe pas de véritables gardiennes, mais certains individus semblent avoir plus facilement propension à attaquer les intrus que les autres. FREE met cette particularité en rapport avec la présence d'ovaires très développés, mais il ne s'agit que d'une hypothèse qu'il ne semble pas avoir tenté de vérifier. Ces observations portent sur six espèces différentes de Bombus et peuvent sans doute être considérées comme de portée générale. En ce qui concerne les Meliponinae, il existe d'énormes différences entre les espèces quant à l'ampleur de leur comportement agressif. La seule espèce que j'ai etı l'occasion d'observer : Meliponula bocandei, ne présentait aucun comportement agressif en dehors de son nid et aucune apparence de gardienne n'était visible. Par contre, d'autres espèces seraient très agressives : ainsi Trigona heideri Friese, selon DuckE (I9I6-1925) serait capable d'attaquer à plusieurs mètres de son nid sans aucune provocation.

De toute manière, il ressort des chapitres consacrés à la division du travail et aux comportements de défense chez les Melipones dans l'ouvrage de SchWARz (I948) que toute tentative de généralisation est prématurée. Les contradictions entre les auteurs abondent et le stade de l'observation n'a jamais été dépassé. Il en est tout autrement en ce qui concerne l'abeille.

\section{La division du travail chez l'abeille.}

C'est indiscutablement à Rösch (I925-27-30) que revient le mérite d'avoir mis en évidence le rôle joué par l'âge dans la détermination de la division du travail entre les ouvrières.

Les travaux de Rösch peuvent se résumer ainsi : pendant une première période, les abeilles ne quittent pas la ruche. Les abeilles qui viennent d'éclore nettoient les cellules puis après le second jour, nourrissent les larves les plus âgées. Vers le $6 \mathrm{e}$ jour et jusqu'aux environs du quinzième jour, les glandes nourricières sont fonctionnelles et les ouvrières sont activement occupées par le nourrissement des jeunes larves. Dans une deuxième période qui est inaugurée par le vol d'orientation, les ouvrières s'occupent de stocker les récoltes rapportées par les butineuses; leurs 
glandes cirières sont très actives et elles construisent les rayons; enfin, vers la fin de cette période qui dure environ dix jours, elles peuvent jouer le rôle de gardes à l'entrée de la ruche.

La troisième période, d'une durée moyenne de 20 à 30 jours, est celle du butinage, tâche qui occupe l'abeille d'été jusqu'à sa mort. Si les travaux récents, ceux de LiNDAUER (I952), RibBands (I952) ou SAKAGAMI (I953) ont confirmé dans l'ensemble les travaux de Rösch, ils ont montré que la répartition des tâches est non seulement sous l'influence de l'état physiologique des abeilles mais encore commandée par les besoins de la colonie.

Il est d'ailleurs juste de signaler que Rösch, dans ses dernières publications, avait commencé à mettre l'accent sur de pareils faits. Cette possibilité de régulation entrâne une très grande fluidité de la répartition du travail et il ne convient pas d'attribuer une grande valeur aux chiffres précis que l'on trouve encore dans les manuels de vulgarisation; chiffres qui donneraient à penser qu'à un moment donné toutes les ouvrières d'un même âge changent brutalement d'occupation. Nous ne nous occuperons ici que des gardiennes, seules à rentrer dans 1a cadre de notre travail.

\section{Quel est l'âge de l'abeille gardienne?}

La méthode la plus fructueuse consiste à faire vivre dans une ruche normale, des abeilles marquées lors de leur naissance. Pour l'observation des gardiennes, il est bon que les ruches soient d'un modèle particulier. Les ruches les plus couramment employées en Firance par les apiculteurs professionnels ne comportent pas de plancher dépassant à l'emplacement du trou de vol et tous les phénomènes intéressants se déroulent hors de la vue de l'observateur. BUTLER et FREE (I954) ont utilisé un modèle de ruche courant en Grande-Bretagne et comportant une "planche de vol " de grande dimension. Ein utilisant la technique ci-dessus décrite, ces auteurs ont pu déterminer quel était l'âge des ouvrières gardiennes. Ils ne purent jamais observer d'ouvrières gardiennes âgées de moins de II jours et cet âge semble une exception par sa précocité puisque seulement I4 ouvrières sur un total de 400 marquées deviennent gardiennes avant l'âge de $I 6$ jours. Le plus grand nombre ne devient effectivement gardiennes que bien plus tard et il semble bien qu'il y ait alternance des deux occupations de gardiennage et de butinage.

Toutes les abeilles ne passent pas d'ailleurs par ce stade puisque dans l'exemple donné par BUTLER et FREE, seulement I6o ouvrières sur 400 , réparties entre deux ruches, purent, à un moment où à un autre être observées en train d'agir en tant que gardiennes.

Pour un autre auteur, IINDAUkR (I952) le pourcentage des gardiennes serait plus faible, 23 sur 200 , et d'après ses observations, la 
plus grande partie des ouvrières sauterait le stade "gardienne ". LINDAUER a étudié, non pas des ruches normales mais des colonies de taille réduite, ce qui rend difficile une comparaison des résultats d'autant plus que ceux-ci comme nous le verrons tout à l'heure sont soumis à des fluctuations d'origine externe. Il me paraît assez important ici de souliguer le décalage important entre la maturation du comportement agressif et son apparition normale dans la colonie.

J'ai mis en évidence le fait qu'une abeille âgée de trois jours peut avoir un comportement agressif normal, vis-à-vis d'un leurre présenté dans une cagette pourvu qu'elle soit placée au sein d'une population d'ouvrières de son âge. D'autre part, cette agressivité ne trouvera son emploi dans le cadre de la vie sociale qu'à un âge bien plus avancé, situé après le onzième jour.

Incontestablement, nous nous trouvons ici en présence d'un phénomène se rapportant à la loi de l'anticipation des fonctions. Cette loi a été définie par CARMichaEL (I95I) de la manière suivante : une possibilité de fonctionnement peut être mise en évidence expérimentalement dans beaucoup de systèmes d'actions appartenant à des organismes en croissance, bien avant le moment où la fonction en question est normalement appelée à jouer un rôle actif et significatif dans l'économie vitale de l'organisme. Cette loi dans l'esprit de CARMichaEL se rapporte au développement foetal; mais il me semble que le comportement agressif puisse très bien rentrer dans ce cadre.

Dans la partie de ce travail qui traite de l'influence de la miellée, nous avons vu combien ce facteur influait sur la présence des gardiennes. Cependant, il est très possible même durant les périodes de grande miellée, de faire apparaitre les gardiennes normalement absentes. Il faut donc probablement distinguer soigneusement les abeilles gardiennes dont le comportement agressif est effectif et les abeilles capables de présenter un comportement agressif. Le comportement agressif peut très bien ne pas s'exprimer ; soit qu'il soit inhibé chez les ouvrières les plus jeunes par la présence d'ouvrières âgées, soit que les différents facteurs externes agissent eux aussi par inhibition.

Le facteur essentiel, en ce qui concerne les abeilles gardiennes, me semble être le BESOIN DE IA COLONIE; il peut toujours y avoir recrutement dans le stock formé par les abeilles à potentialité agressive. I.es gardiennes apparaissent toujours quand la colonie a besoin de se défendre, ou pour parler plus exactement quand elle est traumatisée de quelque manière que ce soit.

Une visite, une intoxication par insecticide, une variation de température, sont aussi de nature à faire apparaître des gardiennes sur la planche de vol d'une ruche qui n'en possédait pas. Ces variations en fonction de ces facteurs expliquent les différents pourcentages observés par les 
différents auteurs. Ces pourcentages (40 p. IOO pour BUTLER et FREE (I954), I2,9 pour LiNDAUER (I952), 20 p. Ioo dans une observation que j'ai effectuée dans les mêmes conditions que BUTLER et FREE) n'ont probablement aucune signification par eux-mêmes, ils sont seulement l'indice de la souplesse d'adaptation des éléments constituants de la ruche aux diverses circonstances. Nous nous rappelons que dans des circonstances extrêmes (abeilles de même âge, âgées de $\Upsilon^{5-20}$ jours) un leurre significatif déclenche l'agressivité de près de 90 p. Ioo des individus.

\section{CONCLUSIONS GENERALES}

Arrivé au terme de l'exposé des faits, il me semble opportun de poser la question de la signification des phénomènes que nous venons de passer en revue.

Il est absolument nécessaire de replacer dans un contexte plus général l'étude d'un comportement aussi particulier, sans pour autant perdre de vue les dangers que l'on peut courir en tentant d'assimiler les uns aux autres des comportements analogues, ou en y cherchant une finalité précise.

\section{Les séquences du comportement et leur organisation.}

Un premier aspect du comportement agressif de l'ouvrière d'abeille mérite d'être souligné. I1 s'agit de la multiplicité des stimuli capables de déclencher le comportement ou de jouer un rôle dans ce déclenchement.

Cet état de fait contraste singulièrement avec les exemples de comportements déclenchés par des stimuli précis et spécialisés, tels ceux, si bien mis en évidence par les objectivistes. La raison de ce contraste me semble évidente et tient surtout à la différence entre les objets d'étude. L,e partenaire sexuel, ou le jeune qu'il s'agit de nourrir, reste toujours semblable à lui-même ; aussi, n'est-il pas étonnant, dans ces conditions, que des caractères anatomiques donnés, des mouvements précis, puissent constituer des stimuli signaux spécifiques.

Tout se passe comme si les situations monotones engendraient les évocateurs rigides décrits par l'"École de L,orenz et de Tinbergen ". Dans le cas de l'agressivité de 1'Abeille, il en est tout autrement; l'objet de l'attaque, le prédateur, peut revêtir les aspects les plus divers, il peut s'agir tout aussi bien d'une autre Abeille que d'un Ours, en passant par des quantités d'intermédiaires.

I e facteur commun à ces différents objets de l'agressivité est évidemment le mouvement; nous avons va le rôle primordial joué par ce stimulus.

Pour le reste, il ne peut s'agir d'un système simple de réactions 
mais bien de l'intégration d'une série de stimulations par un mécanisme central.

Les différentes stimulations que nous avons passées en revue peuvent se cumuler; ou plutôt, comme nous l'avons vu, leurs effets peuvent se multiplier.

Il ne s'agit pas, pourtant, d'un comportement d'un type nouveau et l'on peut trouver dans la littérature des exemples similaires. L'on connaît d'autres comportements dans lesquels il est impossible de prétendre mettre en évidence un stimulus précis, noyé dans une multitude d'autres dénués de signification.

Chauvin (I956) en étudiant les caractéristiques des comportements constructeurs d'un certain nombre d'animaux peut ainsi parler de "l'indétermination des stimuli " qui rentrent en jeu.

L'on a cependant trop souvent tendance à ne considérer que les comportements à déclenchement automatique placés sous la dépendance de stimuli très nettement individualisés et pour cette raison il importe de souligner qu'il ne s'agit absolument pas d'une loi générale.

Le comportement agressif est-il un comportement de type caténaire? Est-il indispensable qu'une séquence soit précédée d'une autre séquence pour pouvoir apparaître?

Ici encore, ce qui semble une règle quasi générale dans certains comportements, en particulier en ce qui concerne le comportement sexuel de certains vertébrés, ne parait pas aussi important en ce qui concerne le comportement agressif de l'Abeille.

Indiscutablement, l'agressivité peut se laisser diviser en séquences; ces séquences, que nous avons décrites, ont une certaine individualité et nous avons vu qu'elles apparaissent dans un ordre fixe lors du développement de l'individu.

Nous avons également vu que les séquences disparaissent dans un ordre non moins fixe lorsque l'on provoque le phénomène de satiété.

Il est donc impossible de nier l'existence de ces séquences et il n'est que d'observer le comportement des ouvrières habitantes d'une cagette après l'introduction d'ouvrières étrangères pour s'en convaincre.

Mais, très souvent aussi, les séquences sont invisibles et si elles existent encore c'est sous une forme tellement contractée que l'observateur le plus averti ne peut les apercevoir.

Nous voici loin de la ritualisation, caractéristique indiscutable de nombreux comportements, mais encore une fois caractéristique nullement obligatoire.

C'est d'ailleurs une simple remarque de bon sens que de faire constater le rôle néfaste que pourrait jouter l'observance stricte de l'ordre des séquences pendant un comportement de défense. 


\section{L'aspect social de l'agressivité.}

Cependant, l'aspect le plus important du comportement agressif de l'abeille est en relation avec le caractère social de cet insecte. Il est indispensable d'y penser pour réussir à intégrer n'importe quel aspect de son comportement dans un contexte général.

La société constituée par la colonie d'Abeilles est en partie basée sur une certaine répartition du travail chez les individus. Cette répartition ne se fait pas en fonction de différents caractères morphologiques, mais en fonction de l'âge de l'individu. L'étude de la fonction précise que constitue l'agressivité permet justement de préciser la nature des relations qui existent entre les ouvrières. Dans une colonie normale, il existe un assez grand nombre d'ouvrières âgées à potentialités agressives et selon les circonstances un plus ou moins grand nombre de ces ouvrières est employé en tant que gardiennes.

Dans certains cas, quand la stimulation atteint un certain niveau, un très grand nombre d'Abeilles peut présenter un comportement agressif et bien que l'on manque de données précises sur ce point particulier, l'on peut estimer que l'ensemble de la population d'ouvrières d'extérieur, c'est-à-dire l'ensemble des ouvrières qui, selon les données classiques, ont un âge supérieur à 20 jours, est susceptible de présenter un comportement agressif au sein de la ruche normale.

Mais, c'est dans de petites colonies, constituées de 20 à 30 ouvrières d'âge connu, qu'il est le plus facile d'étudier la nature des relations entre les ouvrières.

Tout se passe comme si la présence d'Abeilles âgées inhibait complètement l'agressivité des plus jeunes, cette inhibition cessant dès que les ouvrières âgées sont retirées.

\section{Agressivité et « dominance ».}

L'on ne peut parler ici de dominance au sens où on l'entend chez les vertébrés, car l'agressivité ne s'adresse qu'à des objets étrangers au groupe. Cependant, cette situation doit avoir en commun avec la dominance au moins un caractère, à savoir l'existence de signaux permettant à un individu de connaitre la position d'un autre ; position dans la hiérarchie dans le cas des vertébrés présentant ce caractère, position dans une catégorie d’âge en ce qui concerne les Abeilles.

Les Abeilles les plus jeunes n'étant dénuées d'agressivité que par suite de la présence des plus âgées, il existe donc une stimulation issue de ces dernières et susceptible de provoquer cette inhibition. Sur la nature du stimulus, nous ne savons rien encore; mais, il est très probablement produit par un comportement particulier.

J'ai été en effet amené à éliminer l'action de différents stimuli, tels 
une odeur ou un échange de nourriture, par la constatation du fart que des ouvrières jeunes en relation avec un groupe plus âgé à travers une toile métallique à larges mailles, se comportent, en ce qui concerne l'agressivité, comme si elles étaient isolées.

Dans l'état actuel de la question, il est simplement possible de supposer, sans aucune sorte de preuves à l'appui, que les incessants contacts antennaires entre ouvrières ne sont pas étrangers à ce transfert d'informations. D'autre part, il est très probable que le mécanisme responsable de l'existence $d u$ " stade agressif " n'est pas différent de ceux responjables des autres stades correspondant aux diverses fonctions de la ruche; dans ces conditions l'on entrevoit quel intérêt il y aurait à poursuivre des recherches sur ce problème.

\section{Agressivité et nombre limite.}

En rapport étroit avec le caractère social de l'Abeille se trouve le fait que le comportement agressif n'apparaît pleinement que dans un groupe assez important d'ouvrières. J'ai montré que le nombre de réponses était proportionnellement plus grand au fur et à mesure que le groupe grandissait et j'ai rapproché ce fait de la notion de nombre limite que l'on retrouve si souvent en étudiant l'Abeille. Je soulignerai, cependant, un fait de nature à nous éclairer sur la nature du comportement étudié. Dans les groupes peu importants, composés de deux à cinq ouvrières, les comportements agressifs allant jusqu'à l'attaque du leurre sont très rares; par contre, les séquences de début sont assez fréqueinment visibles. Lion peut voir les ouvrières s'orienter vers le leurre et le poursuivre sans arriver à son contact. Leur comportement rappelle beaucoup celui des très jeunes ouvrières placées dans ù groupe de même âge et se différencie notablement de celui d'ouvrières inhibées par la présence d'ouvrières âgées.

Dans le premier cas, l'on observe, en effet, quelque chose qui rappalle une maturation et pendant un certain temps, seulement les premières séquences sont visibles.

Dans le second cas, les ouvrières les plus jeunes d'un groupe comprenant aussi des ouvrières âgées sont absolument indifférentes au leurre et ne présentent en aucune manière les premières séquences du comportement.

L'inhibition due à l'isolement et celle due à la présence d'ouvrières plus àgées ne semble pas de même nature, l'une agissant sur les dernières séquences, l'autre sur l'ensemble du comportement.

\section{Agressivité et territoire.}

Un autre point très important est la variabilité des comportements observés en fonction du lieu où ils apparaissent et en fonction du lieu où sont produites les stimulations. 
Il est même possible de se servir du comportement agressif comme d'un réactif qui permet d'étudier comment l'espace est organisé par l'Abeille.

Au centre de cet espace, se trouve le gîte, généralement constitué par la ruche. Le gîte est défendu contre tout ce qui est étranger à la ruche et doit cette défense à la présence d'un caractère spécial, la présence d'une odeur caractéristique.

En ce qui concerne d'autres points de l'espace de l'Abeille, nous avons constaté l'existence d'autres points dotés d'une signalisation olfactive.

I1 s'agit de sources de nourriture particulièrement abondantes et bien localisées. Ces sources sont signalées par un ensemble de substances qui semble particulièrement complexe, puisque pour tenir compte des résultats expérimentaux, je me suis trouvé amené à faire 1'hypothèse que quatre substances rentraient en jeu.

Cette question des substances actives mérite d'ailleurs d'être examinée avec soin.

Les récents travaux effectués par différents auteurs sur différents points de la biologie de l'Abeille aboutissent à une même conclusion, celle de l'existence de substances possédant une action spécifique.

J'ai évoqué ces différentes recherches au cours de mon travail en étudiant la nature de ce qui est considéré comme gite par l'Abeille, mais je voudrais revenir sur cette importante question.

Récemment, deux auteurs (P. KARLSON et M. Luscher (I959)) ont voulu intégrer une série de substances très diverses sous le terme général de pheromones, il s'agit de substances produites et sécrétées par des glandes spéciales et servant à la communication entre les individus de la même espèce.

Cette dernière notion permet de différencier les pheromones de ce que BETHE (I932) avait nommé les ectohormones, substances stimulantes dont les effets peuvent être extraspécifiques ou même se faire sentir entre des règnes différents.

KARLSON et LUSCHER d'ailleurs, admettent que dans certains cas, les phéromones peuvent avoir une action entre espèces voisines. En ce qui concerne les huit ou dix substances soupçonnées chez l'Abeille, it ne me semble pas spécialement avantageux de parler de Phéromones et de rattacher par le fait même ces substances à des stimuli tels que les attractifs sexuels des Lépidoptères, ou les substances d'effroi.

Des substances analogues existent chez 1'Abeille, j'ai parlé des substances d'effroi, en étudiant le rôle de l'odeur du venin et nous avons vu que l'effet répulsif produit par des fragments d'Abeille pouvait être rapporté à la présence d'une substance similaire.

D'autre part, il est possible qu'il existe un attractif sexuel chez 
1'Abeille, similaire à ceux que l'on connait chez de nombreux Apides (HAAS, I949) (KULLENBERG, I956).

Mais les substances présentes dans la ruche possèdent un caractère original lié au phénomène social. Les substances de la ruche existent en effet pour la plupart de manière permanente, d'autres existent tout le long de la période de vie active de la colonie. Elles ne sont pas liées à un événement limité dans le temps comme peut l'être l'acte sexuel ou la fuite d'un congénère blessé.

D'autre part, les constructions de la colonie jouent ici un grand rôle, soit qu'elles servent de support aux substances actives, soit qu'elles constituent par elles-mêmes la substance active.

Nous avons vu en effet que l'odeur de la Propolis, résine rapportée en abondance par les butineuses, était responsable de la notion de gite.

Tout ceci nous rapproche singulièrement des caractères fondamentaux d'une société d'insectes, tels qu'ils ont récemment été mis en évidence par GRASSÉ (I959).

Ces caractéristiques fondamentales sont au nombre de trois, 1'on trouve ainsi l'Interattraction, la stimulation due au compagnon social et la stimulation provoquée par les produits de l'industrie des insectes sociaux, cette dernière stimulation se faisant sentir aussi bien sur le constructeur que sur ses compagnons.

Les substances de la ruche ne peuvent se comprendre en dehors de ce cadre. Elles sont en rapport étroit avec 1'Interattraction, nous avons vu que l'attraction mutuelle des ouvrières était partiellement sous la dépendance d'une substance. Elles constituent une grande partie de la stimulation provenant du compagnon social et une partie de la stimulation issue des produits de l'industrie de la ruche.

Ceci, ajouté au fait qu'on ne peut imaginer leur absence, qu'elles ont un caractère obligatoire et qu'elles sont soit permanentes, soit de très longue durée, permet de les ranger dans un groupe particulier.

Je propose de réserver le nom de substances sociales à ces substances et à celles qui peuvent exister chez d'autres insectes sociaux.

Ce terme a le mérite de ne pas préjuger de l'avenir, car il serait vain de se cacher qu'un très gros travail reste à faire pour comprendre exactement quel est le mode d'action de ces substances, leurs relations, et même, quel nombre d'entre elles pourra être mis en évidence et individualisé, Cependant, il est évident qu'au fur et à mesure que les données expérimentales sont plus nombreuses, il sera possible de préciser les rapports entre ces substances. C'est ainsi que ChaUvin dans un travail non encore publié distingue sous le nom d' "Epagines " les substances d'interattraction et de familiarisation, des substances à effets répulsifs qu'il nomme "repellines".

Si nous poursuivons l'examen de l'organisation spatiale des envi- 
rons de la ruche, des chemins et des aires de butinage, nous nous apercevons que les analogies avec ce qui a pu être observé chez les vertébrés sont très grandes. J'ai montré ces analogies en comparant ce que l'on connaît de l'organisation du territoire par le Goeland argenté avec ce que j'ai pu observer chez l'abeille. Même s'il ne s'agit pas de phénomènes superposables mais de simples convergences, il n'en reste pas moins que le degré de complexité de l'organisation de l'espace par une société d'insectes est au moins aussi grand, sinon plus, que ce que l'on peut rencontrer de similaire chez les vertébrés.

Si la description des comportements est chose relativement aisée, le mécanisme de ces comportements est plus difficile à déceler. De même, s'il est tentant de considérer la colonie d'Abeille comme un organisme et si l'on peut en étudier les comportements globaux, il n'en reste pas moins indispensable de connaître les relations interindividuelles et d'essayer d'en pénétrer les mécanismes.

\section{La reconnaissance du partenaire.}

C'est ce que j'ai tenté de faire en étudiant le processus de reconnaissance du partenaire social.

Du moins, s'agit-il d'un des aspects de cette reconnaissance, i1 s'agit de l'interception des individus par les abeilles gardiennes, interception qui a pour but de savoir si l'intercepté doit ou ne doit pas rentrer dans la ruche. Mais, il est bien évident que des mécanismes encore inconnus sont à la base de tous les comportements sociaux de 1'Abeille. Ein particulier, j'ai signalé que la division du travail dans la ruche nécessitait l'existence d'un moyen de reconnaître à quelle catégorie de travailleuse appartient un individu.

Ce qui est incontestable pour l'exercice de la fonction agressive doit l'être aussi pour les autres fonctions de la ruche. Comment la jeune butineuse sait-elle qu'il n'y a plus de nourrices dans la ruche et qu'elle doit revenir à la fonction qu'elle vient de quitter? Voilà la question qui est posée par la fameuse expérience où Röscr sépare une ruche en deux parties ne contenant pas les mêmes catégories d'ouvrières. Faute de pouvoir apporter une réponse à l'ensemble de ces questions, je ne peux encore formuler d'hypothèse générale ; cependant, il est possible de se représenter le mécanisme d'un cas particulier, la reconnaissance des arrivantes à l'entrée de la ruche.

J'ai étudié en détail cette reconnaissance, aussi je me contenterai de rappeler brièvement qu'il est possible de distinguer deux types de reconnaissance à l'entrée de la ruche. L'une est la reconnaissance de l'arrivant en tant qu'étranger ou non, l'autre la reconnaissance en tant qu'indésirable ou non. 
Ia première de ces reconnaissances se ferait sous l'influence de stimuli olfactifs. Il s'agirait de la célèbre odeur de la ruche, d'une substance répartie entre les ouvrières de la même ruche grâce aux échanges de nourriture, mais ne provenant pas de la nourriture. Enfin, d'une substance qui peut avoir autant de variétés, impossibles à confondre, qu'il existe de ruches.

L'autre reconnaissance serait au contraire sous la dépendance de différences de comportement. Si certaines de ces différences nous sont connues, s'il est possible de distinguer grossièrement une abeille passive d'une autre qui ne l'est pas, nous devons cependant reconnaître nos ignorances dans ce domaine.

Les catalogues de gestes, l'inventaire des mouvements des pattes et des antennes, tout ce qui permet une étude objective des comportements individuels, restent à faire chez l'Abeille. Quand il sera possible de dresser un tableau de ces activités, quand on connaîtra aussi bien les mouvements effectués par deux ouvrières qui se rencontrent que les parades sexuelles des vertébrés ou d'un insecte comme la Drosophile, alors bien des questions recevront leur réponse.

E,n dehors de son intérêt propre, nous reconnaîtrons donc au comportement agressif l'avantage de fournir un réactif très sensible. Cette sensibilité permet de l'utiliser pour étudier un grand nombre d'aspects de la vie sociale de l'Abeille.

I'étude que j'en ai faite permet à elle seule, non pas de comprendre la structure fine de l'organisation de la ruche, mais de nous éclairer sur la direction qui doit être prise pour comprendre cette structure fine.

Après une phase destinée à prendre conscience de la complexité de la colonie d'Abeille, après une étude das comportements globaux, il faudra de plus en plus s'attacher à l'étude des relations interindividuelles dans le contexte de la ruche.

C'est alors qu'il faudra tenir compte des stimuli dus aux substances sociales et de ceux provenant des comportements différenciés des ouvrières.

Négliger 1'un ou l'autre de ces facteurs ne pourrait que nous conduire à des erreurs.

\section{RÉSUME}

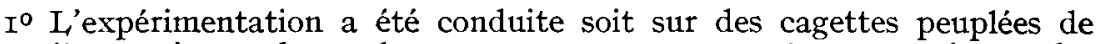
25 ouvrières, soit sur des ruchettes en contenant I 000 à 2000 , soit sur des ruches normales.

$2^{\circ}$ L'observation du comportement des habitantes d'une cagette en réponse à l'introduction d'abeilles étrangères permet de distinguer plusieurs comportements : l'agitation, l'approche, le houspillage, le combat.

$3^{\circ}$ Afin d'éviter l'influence des variations de comportement des étrangères, la méthode des leurres a été employée. Le comportement des ouvrières vis-àvis de ces leurres est très proche de celui induit par les étrangères.

Annales de l'Abeille. - i $96 \mathbf{r}$. 
$4^{\circ}$ La recherche des stimuli significatifs a mis en évidence le rôle primordial du mouvement.

Le rôle de la Leucie et dans une moindre mesure celui de la structure physique, de la forme et de la taille sont également visibles.

Le leurre mobile, foncé, pileux, aux formes découpées et de petite taille, est le plus significatif.

$5^{\circ}$ L'étude des composantes olfactives a mis particulièrement en évidence le rôle de l'odeur de venin.

Cette odeur cumule son effet avec celui des autres facteurs et joue un rôle important de mise en état d'alerte des ouvrières.

$6^{\circ}$ A l'extérieur de la ruche, les stimuli significatifs sont semblables, sauf en ce qui concerne la taille. Un leurre de taille égale ou inférieure à celle d'une ouvrière n'est pas attaqué.

$7^{\circ}$ I a notion de "gîte " chez l'abeille est étudiée. L,es phénomènes agressifs sont très faibles dans des cagettes neuves.

Une substance de familiarisation, déposée par contact, est nécessaire pour que se manifestent les comportements agressifs normaux.

$8^{\circ}$ L'agressivité peut se rencontrer : dans l'intérieur de la ruche, dans les limites d'un périmètre défensif de taille variable, le long des lignes de vol des butineuses, près de nourrisseurs contenant des matières sucrées ou du pollen et situés à peu de distance de la ruche, sur les aires de butinage.

$9^{\circ}$ L'étude des substances déposées par les butineuses sur les nourrisseurs permet de supposer l'existence de quatre substances. Une substance attractive générale provenant de la glande de Nassanof. Une substance répulsive générale dégagée du corps de l'ouvrière quand il y a lésion.

Une substance attractive pour la colonie dont elle est issue et répulsive pour les autres. Une substance répulsive pour les colonies étrangères.

Io $^{\circ}$ L'influence de certains facteurs météorologiques est certaine, en particulier celle du vent et celle de l'orage. L'influence de la température paraît moins certaine.

II Le niveau de l'agressivité est presque nul en période de grande miellée.

$\mathrm{Au}$ contraire, l'apparition du pillage élève considérablement le niveau de l'agressivité.

I2 ${ }^{\circ}$ Il existe de grandes différences entre le niveau d'agressivité de deux colonies.

Les différences raciales sont peu constantes sauf en ce qui concerne l'abeille caucasienne particulièrement douce.

Fn général, les différences entre les colonies surpassent dans une ruche les différences raciales.

$13^{\circ}$ Dans une population d'ouvrières prises au hasard dans une ruche, 1'on constate de fortes différences individuelles quant à 1'agressivité. Environ $50 \mathrm{p}$. Ioo des individus de ces populations n'attaquent pas un leurre agité dans une cagette.

I $4^{\circ}$ L'influence de 1'âge sur l'apparition des comportements agressifs est certaine. Dans une cagette peuplée de $I_{5}$ abeilles de 5 jours et de $I_{5}$ abeilles de ro jours, aucune abeille jeune ne semble intéressée par le leurre, alors que ces mêtmes abeilles séparées des ouvrières plus âgées sont capables d'attaquer le même leurre.

I $5^{\circ}$ Dans une population d'ouvrières homogène en ce qui concerne l'âge, les différences individuelles d'agressivité sont très réduites. Il reste néanmoins environ $20 \mathrm{p}$. I00 d'abeilles non agressives.

I $6^{\circ}$ Il ne semble pas y avoir de corrélation entre le développement ovarien et l'agressivité dans une ruche normale.

Par contre, dans une ruche orpheline, les ouvrières les plus agressives ont aussi les ovaires les plus gros.

- I $7^{\circ}$ Moins de 5 abeilles n'attaquent que très rarement un leurre à l'inté- 
rieur d'une cagette. Le nombre des attaques croît en fonction du nombre des abeilles présentes jusqu'à un palier qui est atteint vers 20 à 30.

I $8^{\circ}$ Le comportement agressif de l'abeille peut se laisser diviser en séquence. Ia première qui se manifeste par une agitation est l'agressivité diffuse. La deuxième constituée par l'approche est l'agressivité dirigée. La troisième est la reconnairsance. Enfin, j'ai réservé au combat proprement dit le terme d'agressivité effective.

I ${ }^{\circ}$ La règle de la pluralité des Stimuli significatifs est confirmée par l'étude quantitative des réactions des ouvrières en présence de différents leurres.

$20^{\circ}$ Eans le cas d'une stimulation continue, 1'intensité des réactions agressives diminue et devient même inexistante.

Dans le cas d'une stimulation discontinue, lorsque les intervalles de temps entre les présentations sont de dix minutes, il n'y a pas satiété mais abaissement considérable du seuil d'excitation. Lorsque les intervalles de temps entre les présentations sont réduits à trois minutes, il existe une balance entre les deux phénomènes précédents.

$2 \mathrm{I}^{\mathrm{O}}$ La reconnaissance d'une ouvrière par une autre s'effectue en deux temps : la reconnaissance en tant qu'étrangère et la reconnaissance en tant qu'indésirable. La reconnaissance en tant qu'étrangère se ferait grâce à des stimuli olfactifs, tandis que la reconnaissance en tant qu'indésirable serait due à des différences de comportement.

$22^{\circ}$ Lorsqu'on place des ouvrières en provenance de la même ruche dans deux cagettes, il se crée une différenciation qui varie proportionnellement avec le temps passé depuis la séparation et qui se répercute sur l'intensité des phénomènes agressifs lors de la réunion.

$23^{\circ}$ La différenciation se crée quand les ouvrières de deux groupes n'échangent pas de nourriture et seulement dans ce cas.

Deux groupes séparés seulement par une tôle perforée de trous, n'échangent pas de nourriture s'ils ont chacun leurs propres réserves et se différencient. Si l'un des groupes ne possède pas de nourriture, il en obtient de l'autre et il n'y a pas de différenciation.

$24^{\circ}$ Det1x groupes d'ouvrières capturées dans la même ruche et pourvues de la même qualité de nourriture ne se reconnaissent plus au bout de quelques jours.

Des nourritures très différentes ne modifient pas la vitesse de ce processus de différenciation. La reconnaissance serait donc sous la dépendance d'une substance distribuée en même temps que la nourriture.

$25^{\circ}$ L'interattraction, sous la dépendance de stimuli vibratoires, olfactifs et thermiques, joue également un rôle important dans le maintien de l'unité de la colonie.

$26^{\circ}$ Dans les conditions normales, la reconnaissance incombe aux abeilles gardiennes. Ces abeilles, dont le comportement agressif est effectif, doivent être distinguées des ouvrières, dont l'agressivité n'est que potentielle et qui ne deviennent fonctionnelles en ce sens qu'en fonction des besoins de la colonie.

\section{SUMMARY}

I. The experiments were conducted on small cages populated by 25 workers, on small hives containing I ooo to 2000 workers, and on normal hives.

2. Observation of the behaviour of the inhabitants of a cage in response to the introduction of foreign bees permits one to distinguish many different types of behaviout : agitation, approach, mauling, fighting.

3. In order to eliminate the influence of variations in the behaviour of foreign bees, the method of lures was employed. The behaviour of workers 
towards these lures closely resembles the behaviour induced by foreign bees,

4. Studies of the significant stimuli showed the outstanding role of movement. The role of "leucie " and to a lesser extent that of physical structure, of form and size, were equally visible.

5. A study of the olfactory components showed particularly the role of the odour of the venom.

This odour adds its effect that of the other factors and plays an important role in alerting the workers.

6. The significant stimuli outside the hive are similar,except for these concerning size. A lure of the size or smaller than a worker is not attacked.

7. The concept of "home " in bees is studied. Aggressive behaviour is very weak in new cages. A familiarisation substance, deposited by contact, is necessary for normal aggressive behaviour.

8. Aggressive behaviour may be found : inside the hive, within the limits of defensive perimeter of variable size, along the lines of flight of the foragers, near the feeders containing sugary substances or pollen situated at a short distance from the hive, in the foraging areas.

9. A study of the substances deposited by the foragers on the feeders permits one to suspect the existence of four substances. One general attractive substance produced by Nassanof's gland. One general repulsive substance released from the body of a worker when wounded. A substance attractive for the colony from which it is derived and repulsive for other colonies. A substance repulsive for foreign colonies.

Io. The influence of meteorological factors is certain especially wind and storm. The influence of temperature is less certain.

II. The level of aggressiveness is very low in periods of honey flow. On the other hand the appearance of robbery greatly increases the level of aggressiveness.

I2. There are great differences between the aggressive levels of two colonies. Racial differences are inconstant. In general the differences between the colonies in an apiary surpass racial differences except in the case of the well tempered Caucasian bee.

I3. In a population of workers taken at random from hive great differences in individual differences in aggressiveness is observed. About $50 \mathrm{p}$. Ioo of the individuals of these populations do not attack a lure moved about in the cage.

I4. The influence of age on aggressive behaviour is certain. In a cage populated by $\mathrm{I} 5$ bees 5 days old and by $\mathrm{I} 5$ bees ro days old no young bee appears to be interested by the lure, while these same bees seperated from the older workers are capable of attacking the same lure.

I5. In a population of workers, homogeneous with regard to age, individual differences in aggressiveness are much reduced. Nevertheless about 20 p. Ioo remain unaggressive.

I6. In a normal hive there does not appear to be any correlation between ovarian development and aggressiveness.

On the other hand in queenless hives the most aggressive workers have the largest ovaries.

I7. A lure is very rarely attacked when there are fewer than 5 bees in a cage. The number of attacks increases as a function of the number of bees present up to an upper limit which is attained towards 20 to 30 .

I8. The aggressive behaviour of a bee can be divided into a sequence. The first step, which is shown by agitation, is diffuse aggressiveness. The second which consists of approach is directed aggressiveness; the third recognition. Finally, I have reserved the term effective aggressiveness to actual fighting.

I9. The rule of the plurality of significant factors is confirmed by a quantitative study of the reactions of the workers in the presence of different lures. 
20. In the case of continuous stimulation the intensity of aggressive reactions diminishes and even disappears completly.

In the case of discontinuous stimulation, when the intervals of time between the presentations (of the stimuli) are each ten minutes long, there is no satiation but a considerable lowering of the level of excitation. When the intervals of time between the presentations are reduced to three minutes there is a balance between the two preceding phenomena.

2I. The recognition of one worker by another takes place in two stages: recognition as a foreigner and recognition as undesirable. Recognition as a foreigner takes place by olfactory stimuli, while recognition as undesirable is due to differences in behaviour.

22. When workers from the same hive are placed into 2 cages a differen1tiation is created which varies proportionally to the time elapsed since separation, and this differentiation is shown by the intensity of aggressive phenomena on reunion.

23. The differentiation is created when the workers of the two groups do not interchange food and only in this case.

Two groups separated only by a perforated partition do not interchange food when each has its own reserves, and so differentiation takes place. If one of the groups does not possess food, it obtains it from the other and there is no differentiation.

24. Two groups of workers taken from the same hive and provided with the same quantity of food do not recognise each other after a few days.

Very different types of food do not modify the speed of this process of differentiation. Recognition therefore depends on a substance distributed at the same time as the food.

25 . Interattraction depending on vibratory, olfactory and thermal stimuli also plays an important role in the maintenance of the unity of the colony.

26. Under normal conditions the duty of recognition falls on the guard bees. These bees, in which aggressive behaviour is effective ought to be distingutished from workers in which aggressiveness is reduced and only becomes functional when the colony requires it.

\section{RÉFÉRENCES BIBLIOGRAPHIQUES}

ADAM (Brother). - In search of the best strains of Bees. Bee world, vol. 32, 49-52, 57-62, I95I.

ADAM (Brother). - In search of the best strains of Bees, Second journey. Bee world, Vol. 35, I93-205, 235-245, I934.

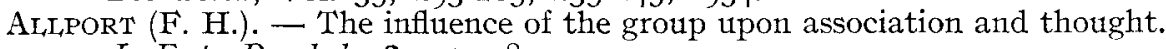
J. Exp. Psychol., 3, I59-I82, I920,

BAERENDS (G. P.). - Specializations in organs and movements with a releasing function. Symposia of the S. E. B., 4, 337-360, I950.

BEECKEN (W.). - Ueber die Putz und Sauberungshandlungen der Honigbiene (Apis mellifera). Arch. f. Bienenk., XV, 213-275, I934.

BETHE (A.). - Dürfen wir Ameisen und Bienen psychische Qualitäten zuschrieben? Pflüg. Arch. Ges. Physiol., \%0, I5-IO0, I898.

BETHE (A.). - Naturwiss., 20, I77, I932.

BEUTLER (R.). - Ueber den Blutzucker der Bienen. Z. vergl. Physiol., 24, 7I-II5, I950.

BUTLER (C. G.). - The method and importance of the recognition by a colony of Honeybees (Apis mellifera) of the presence of its queen. Trans. Roy. ent. soc. London, I05-III, I954.

Butr.ER (C. G.), FREE (J. B.). - The behaviour of worker honeybees at the hive entrance. Behaviour, vol. IV, 4, 262-29I, I952.

Butler (C. G.), JeFFreE (E. P.), Kalmus (H.). - The behaviour of a popu- 
lation of honeybees on an artificial and a natural crop. J.exp. Biol., 20, $65-75$, I 943.

BUTTLER-RREPEN (H. von). - Sind die Bienen teflexmaschinen. Biol. Z Zbl., 20, I-I 82 , I 900 .

CARMichaei, (L.). - In S. S. S'TEVENs, Handbook of experimental psychology. Wiley ed., 28I-303, I95I.

Chauvin (R.). - Aspects sociaux des grandes fonctions chez l'Abeille. La théorie du superorganisme. Insectes sociaux, I23-I29, I954.

Chauvin (R.). - L'animal en tant que constructeur. Son intérêt pour la psychologie générale. $J$. de Psycho. normale et pathol., 487-501, I956.

Courtors (G.), LECOMTE (J.). - Sur un procédé de marquage des Abeilles butineuses au moyen d'un radioisotope. $C$. $R$. Acad. Sc., 24\%, p. I47I 49 , I958.

Darchen (R.). - Les techniques de construction chez "Apis mellifica". Ann. des Sc. nat. Zool., I2 e série, II5-209, 1959.

Ducke (A.). - Enumeraçao dos Hymenopteros colligidos pela commisao e revisao dos abelhas do Brasil. Commisao de linhas telegraphicas estratigicas de Matto grosso ao Amazonas. Publ. $n^{0} 35$; Hist. Nat. Zool., I3-177, I9r6.

Ducke (A.). - Die stachellosen Bienen (Melipona) Brasiliens; nach morphologischen und ethologischen Merkmalen geordnet. Zool. Jahrb. Abt. Syst., vol. $49,335-448$, I925.

Durup (G.). - In PIEron H. - Vocabulaire de la psychologie, 356 p. Paris, I95I.

EIBL-EIBESFELT (I.). - Ueber das Vorkommen von Schrekstoffen bei Erdkrötenquappen. Experientia, 5, 236, I949.

FREE (J. B.). - The behaviour of robber honeybees. Behaviour, vol. VII, 233$240,1954$.

FREE (J. B.). - The defense of Bumblebee colonies. Behaviour, vol. XII, 232242 , I958.

FREE (J. B.), BUTLER (C. G.). - An analysis of the factors involved in the formation of a cluster of honeybees. Behaviour, vol. VII, I955.

FREE (J. B.), BUTLER (C. G.). - The size of apertures through which worker honeybees will feed one another. Bee world, 39, 304-3I6.

FrIsch (K. von). - Ueber einen Schrekstoff der Fischhaut und seine biologische Bedeutung. Z. f. Vergl. Physiol., 29, 46, I94I.

Frisch (K. von). - Eine eigenartige Rauberbande. Z. f. Bienentorschung, 2, $5 \mathrm{I}-52, \mathrm{I} 953$.

Friscri (K. von), Rosch (G. A.). - Neue Versuche über die Bedeutung von Duftorgan und Pollenduft für die Verständigung in Bienenvolk. $Z$. $f$. Vergl. Physiol., 4, I-2I, I923.

FRITSCH (R. H.). - Beobachtungen an einer neugebideten Brutkolonie der Silbermöve (Larus a. argentatus). Z. $t$. Tierpsych., 8, 252-273, I95I.

GLYNNES JONES (G. D.). - An observation on olfacting recognition by worker Honeybees. Bee World., II6-II7, I953.

GoETHE (F.). - $j$. f. Ornithologie, 25, I-I I9, I937.

Gorlıot (C.). - Action de la fumée sur Apis mellifica. Annales des Epiphyties $I I I, 259-27 \mathrm{I}, \mathrm{I} 954$.

Grassé (P. P.). - L'essaimage des Termites. Essai d'analyse causale d'un complexe instinctif. Bull. Biol. Fr. et B., LXXVI, 347-382, I942.

Grassé (P. P.). - Le fait social : ses critères biologiques, ses limites dans la structure et physiologie des sociétés animales, 11, 7-I7, C. N. R. S., Paris, I952.

Grassé (P. P.). - Ia reconstruction du nid et les coordinations interindividuelles chez Bellicositermes natalensis et Vubitermes sp. La théorie de la stigmergie : essai d'interprétation du comportement des termites constructeurs. Insectes sociaux, vol. VI, 4I-84, I959. 
Grassé (P. P.), NoIrot (Ch.). - La sociotomie. Behaviour, vol. 3, I46-I66, I95I. Grozdanie (S.). - " Hipnozo" medanasme pcele. Pcelarstvo 6 (3), 77-84, r95I. HaAs (A.). - Atypische Flugbahnen von Hummelmännchen. Z. Vergl. Physiol., 31, 28I-307, I949.

HAmly y-HARRIS (R.). - The stingless bees of North and South America considered in the light of domestication. Ent. Rec. Journ. Variation, vol. I5, 99-I00, I903.

Hamman (E.). - Wer hat die initiative bei den Ausflügen der Jungkönigin, die Königin oder die Arbeitsbienen? Insectes sociaux, vol. IV, 9I-I06, 1957.

HEDIGER (H.). - Säugetier-territorien und ihre markierung Bijdragen tot de dierkunde. Vol. 28 , I72-I84.

HEINTZ (E.). - Actions attractives et répulsives spécifiques de broyats et de substances extraites de broyats chez Apis mellifica et Tubifex tubifex. C. R. Soc. Biol., 149, 2224, I955.

Hertz (M.). - Beiträge zum Farbensinn und Formensinn der Biene. $Z . \quad f$. vergl. Physiol., 24, 4I3-2I, I937.

HERTZ (M.). - Zum Technik und Methode der Bienen mit Farbpapieren und Glassfiltren. Ibidem, 25, 239-50, I938.

HINDE (R. A.). - Changes in responsiveness to a constant stimulus. Brit. J. Of. Animal behaviour, 41-55, I954.

HRBACEK (J.). - - On the flight reaction of tadpoles of the common toad caused by chemical substances. Experientia, 6, I00-I02, I950.

Husing (J. O.), ULRICH (W.). - Untersuchungen uiber das Ovar von Arbeiterinen von Apis mellifica. Verh. des VVI Intern. Kongr. $t$. Entomol. Berlin, vol. III, I737-I904, I938.

JacoBs (W.). - Das Duftorgan von Apis mellifica und ähnliche Hautdrüseorgane sozialer und solitärer Apiden. $Z$. morph. Okol. Tiere, 3, I-8o.

JARVIS (R.). - - The effect of continuous vibrations on a colony of honeybees. Bee world, I950, vol. 3I, p. 57.

Kalmus (H.). - The defense of a source of food by honeybees. Nature, Lond. I48-228, I94I.

Karmus (H.). - The clustering of honeybees at a food source. B. journ. of Anim. Behaviour, vol. II, 63-72, I954.

Kalmus (H.), RibBands (C. R.). - The origin of the odours by which honeybees distinguish their companions. Proc. Roy. Soc., 140, 50-59, I952.

KALNITZKI (A.). - - Reines fécondées avec succès par des mâles ayant hiverné (en russe). Pchelovodstio, 370, I949.

Kaltofen (R. S.). - Das Problem des Volkesduftes bei der Honigbiene. Z. Vergl. Physiol., 33, 462-75, I952.

KARLSON (P.), LUSCHER (M.). - Pheromones : a new term for a class of biologically active substances; Nature, vol. I83, p. 55-56, I959.

Karstex (A.). - Psychysche Sattigung. Psych. Forsch., 10, 142-54.

KEMPENDORF (W.). - Arch. f. Molluskenkunde, 74, 1942.

KOHLER (F.). - Wache und Volksduft im Bienenstaat. Z. . Bienenk., 3, 57-63, I955.

KULLENBERG (B.). - Field experiments with chemical sexual attractants on aculeate hymenoptera males. Zoologiska Bidrag fr. Uppsala 31, 255-352, I956.

LAVIE (P.), Roth (M.). - Sur le thermopreferendum et la production de chaleur chez les Abeilles. Physiol. Comp. cecol., vol. 3, 57-62, I955.

LecomTe (J.). - L'interattraction chez l'Abeille. C. R. Acad. Sc., 229, 257-8, I949.

LECOMTE (J.). - - Sur le déterminisme de la formation de la grappe chez les Abeilles. $Z$. $f$. Vergl. Physiol., 32, 499-506, I950.

Lecomte (J.). - Les facteurs de l'agressivité chez l'Abeille. C. R. Acad. Sc., 232, $1376-78$, I95I. 
LECOMTE (J.). - Recherches sur le comportement agressif des ouvrières d'Apis mellifica. Behaviour, vol. III, 60-66, I95I.

LECOMTE (J.). - Hétérogénéité dans le comportement agressif des ouvrières d'Apis mellifica. C. R. Acad. Sc., 234, 890-9I, I952.

LECOMTE (J.). - Essai d'une analyse causale du comportement agressif des ouvrières d'Abeille. Insectes sociaux, $1, \mathrm{n}^{\circ} \mathrm{I}, 50-57$, I953.

L,ECOM'TE (J.). - Observations sur le comportement d'Abeilles vivant en serres chaudes durant l'hiver. L'A piculteur (section scientifique), 39-42, I955.

L,EсомTE (J.). - Sur le vol des Abeilles butineuses. Z. f. Tierpsychol., 13, I, 26-30, I956 a.

Lecomte (J.). - Nouvelles recherches sur l'interattraction chez Apis mellifica. Insectes sociaux, 3, n⿳⺈ I, Io6-Io8, I956 b.

LECOMTE $(J$.$) . - Formation de pistes par les butineuses d'une ruche ayant subi$ une rotation de $\mathrm{I} 80^{\circ} \mathrm{C}$. $Z$. $f$. Bienenfors., 3, 6, I-4, I956 c.

LECOMTE (J.). - Sur le marquage olfactif des sources de nourriture par les Abeilles butineuses. C. R. Acad. Sc., 245, 2385-2387, I957.

$I_{\text {EPPIK }}$ (O.). - Die durch Insektengifte hervorgrofenen Verwirrungsercheinungen bei Honigbienen. Z. Pflanzenkrkh., 5\%, I950.

LindaUter (M.). - Ein Beitrag zur Frage der Arbeitsteilung in Bienenstaat. Z. f. Vergl. Physiol. Bd., 34, 299-345, I952.

LINDZEY . - Handbook of social psychology. Cambridge Mass, I954.

Louveaux (J.). - Recherches sur la récolte du pollen par les Abeilles (Apis mellifica). Thèse, Paris, 206 p., I957.

LoREnz (K.). - Ueber den Begriff der Instinkhandlung. Folia biotherica, 2, I7-50, I937.

Madrizio (A.). - Pollenernährung und Lebensvorgänge bei der Honigbiene. Landwirtschaft $J$. d. Sch., 68, II5-I82, I954.

Mexerhoff (G.). - - Ueber die Demuthaltung bei der Honigbiene Apis mellifica. I. Mitt. Deutsch. Ent. Ges., I4 (3), 5-7, I955.

Michener (C .D.). - The evolution of social behavior in bees. Proc. of tenth Intern. Congress of Entom., vol. 2, 44I-47, I956.

MUI,LER (H.). - Versuche iiber die Farbenbienhaberei der Honigbiene. Kosmos, 12, 272-99, I882.

Mommers (J.). - De plaattsvastheid der Honingbijen. Med. Dir. Thuinb., 11, 529, I948.

Nixon (H. L.), RibBands (C. R.). - Food transmission within the honeybee community. Proceedings of the royal Society, B, 43-50, I952.

NogUeIRA-NETo (P.). - Notas bionomicas sobre Meloponineos ; sobre a pilhagem ; Papeis avulsos do depart de Zool., Sao-Paulo, vol. IX, no 2, I3-32, I949.

PAIN (J.). - La substance de fécondité dans le développement des ovaires des ouvrières d'Abeille. Critique des travaux de Müssbichler. Insectes sociaux, 1, 59-70, I954.

PAIN (J.). - Étude de l'apparition de l'attractivité chez les reines vierges d'Abeille; C.R. Acad. Sc., 248, 32I I-32I2.

PAIN (J.), Verge (J.). - Contribution à l'étude de l'ovaire des ouvrières d'Abeilles. L'Apiculteur, section scientifique, 45-55, I950.

Picard (F.). - L Les phénomènes sociaux chez les animaux. Paris ; A. Colinin, I933.

PREChtL (H. F. R.). - Zur Physiologie der angeborenen auslösenden Mechanismen I. Quantitative Untersuchungen über die Sperrbewegung junger Singvögel. Behaviour, 1, p. $32-50$, I953.

Rabaud (E.). - Phénomène social et sociétés animales. Bull. Biol. France et Bel., 63, rg29.

RaND (A.). - Résultats of Archbold expedition 34 and 44. Development and enemy recognition of curve billed Thrasker. Bull. Amer. Mus. N. H., 78, 2 I3-42, 79, 5I7-24, I94I. 
RENNER (M.). - Neue Untersuchungen über die physiologische Wirkung des Duftorganes der Honigbiene. Naturwissenschaften, 42, 589, I955.

RibBands (C. R.). - The foraging method of individual honeybees. J.anim. Ecol., I8, 47-66, I949.

Ribbands (C. R.). - Change in the behaviour of Honeybees following their recovery from anaesthesia. $J$. of exp. Biol., vol. 27, no 3-4, 302-310, I950.

Ribbands (C. R.). - Division of labour in the honeybee community. Proc. Roy. Soc., B, 140, 32, I952.

Ribbands (C. R.). - The defense of the honeybee community. Proc. of Royal Soc. $B, 142,5 \mathrm{I} 4-524$, I954.

RILLING (S.), MI'T'EISTAEDT (H.), RoEDER (K. D.). - Prey recognition in the praying Mantis. Behaviour, vol. XIV, I64-I84, I959.

Rösch (G. A.). - Untersuchungen uiber die Arbeitsteilung in Bienenstaat. I. Die Tätigkeiten in normalen Bienenstaate und ihre Beziehungen zum Alter der Arbeitsbienen. Z. Vergl. Physiol., 2, 57I-63I, I925.

Rösch (G. A.). - Ueber die Battätigkeit im Bienenvolk und das Alter der Baubienen? Weiterer Beitrag zum Frage nach der Arbeitsteilung im Bienenstaat. Z. vergl. Physiol., 6, 265-298, I927.

Rösch (G. A.). - Untersuchungen über die Arbeitsteilung in Bienenstaat. II. Die Tätigkeiten der Arbeitsbienen unter experimental verändenten Bedingungen. $Z$. vergl. Physiol., 12, I, 7 I, I93o.

SakAGami (S. F.). - Untersuchungen über die Arbeitsteilung in einem Zwergvolk der Honigbiene. Beiträge zur Biologie des Bienenvolkes, Apis mellifica I. Japanese J. of Zool., vol. II, II7-I85, I953.

Sakagami (S. F.). - Arbeitsteilung der Arbeiterinnen in einem Zwergvolk, bestehend aus gleichalterigen Volksgenossen. Beiträge zur Biologie des Bienenvolkes, Apis mellifera L. II. Jour. Fac. Sci. Hokkaido Univ., Ser. VI Zool. II, 343-400, I953.

SAKAGAMI (S. F.). - Occurrence of an aggressive behaviour in queenless hives, with considerations on the social organization of Honeybee. Insectes sociaux, 1, 33I-343, I954.

Schick (W.). - Ueber die Wirkung von Giftstaffen auf die Tänze der Bienen. Z. t. Vergl. Physiol., 33, I05-I28, 1953.

SchmedeKNECHT (O.). - Die Hymenopteren nord-und Mittleuropas, $1062 \mathrm{p}$. Iena, I930.

SchuA (L.). - Untersuchungen über den Einfluss meteorologischer Elemente auf das Verhalten der Honigbienen (Apis mellifica). Z. $t$. Vergl. Physiol. $B d ., 34,25^{8-277}$, I952.

Schwarz (H. F.). - Stingless Bees (Meliponidae) of the western Hemisphere. Bull. Amer. Mus. Bat. Hist., 90, I-XVIII, I-546.

SEGUY (E.). - Code universel des couleurs. Le Chevalier éd. Paris, I936.

SeItz (A.). - Die Paarbildung bei einiger Cichliden. Z. f. Tierpsychology, 4, 40-83, I940.

SENGUPTA (N. M.), Sinka (C. P. M.). - Mental work in isolation and group. Indian J. Psychol., 1, Io6-IIo, I926.

SrNGH (S.). - Behaviour studies of Honeybees in gathering nectar and pollen. Bull. Cornell A gricol. Exp. Sta. no 288, I-59, I950.

STEINHOFF (H.). - Untersuchungen über die Haftgahigkeit von Dufstoffen am Bienenkörper. $Z$. Vergl. Physiol., 31, 38-57, I948.

Stumper (R.). - Coefficient de température de la locomotion des fourmis. Le coefficient thermique de la combativité des fourmis. C. R. Soc. Biol., LXXX, 22 oct. Ig2I.

Stumper (R.). - Influence de la température sur l'activité des fourmis. Ann. Soc. Ent. Belg., I, XII, 63, I922.

Thorpe (W. H.). - The definition of some terms used in animal behaviour studies. Bull. of animal behaviour, IX, I95r.

ThorPe (W. H.). - Learning and instinct in animals ; 493 p. Methuen ; I956. 
TINBERGEN (N.). - Ueber die Orientierung des Bienenwolf (Philanthus triangulus Fabr.). $Z$. vergl. Physiol., I6; 305-334, I932.

TINBERGEN (N.). - Social releasers and the experimental method required for their study. Wilson Bull., 60, 6-52, I948.

TINBERGEN (N.). - The study of instinct. Oxford ; Claredon press., 228 p., I95I.

Tinbergen (N.), MeEuse (B. J.), Boerema (L. K.), Varossiead (L. K.). Die Balz des Samtfalters. Eumenis (Satyrus) Semele L. Z. Tierpsych., 5, 182-226, 1942

Z. Tierpsych. 5, 182-226, 1942,

VUILI,AUME (M.). - Contribution à la psychophysiologie de l'élevage des reines chez les Abeilles. Insectes sociaux, II3-I55, I957.

WEAVER (N.). - The foraging behaviour of Honeybees on hairywetch. II. The foraging area and foraging speed. Insectes sociaux, 44-57, I957.

WEIDE (W.). - Quelques remarques sur les réactions des abeilles mellifiques au courant électrique. $X V I I^{\mathrm{e}}$ Congrès International des apiculteurs; Bologne-Rome ; p. I39, $195^{8}$.

WEGNER (A. M. R.). - A remarquable observation on the indian Honeybee versus the yellow-throated Marten from Java. Treubia, 20 (I),3I-33, I949.

ZERRAHN (G.). - Formdressur und Formunterscheidung bei der Honigbiene. Z. Vergl. Physiol., 20, II7-I5o, I933. 